\title{
Molecular Testing Guideline for Selection of Lung Cancer Patients for EGFR and ALK Tyrosine Kinase Inhibitors:
}

\author{
Guideline from the College of American Pathologists, International Association for the \\ Study of Lung Cancer, and Association for Molecular Pathology
}

\begin{abstract}
Dr. Neal I. Lindeman, MD, Dr. Philip T. Cagle, MD, Dr. Mary Beth Beasley, MD, Dr. Dhananjay Arun Chitale, MD, Dr. Sanja Dacic, MD, PhD, Dr. Giuseppe Giaccone, MD, PhD, Dr. Robert Brian Jenkins, MD, PhD, Dr. David J. Kwiatkowski, MD, PhD, Dr. Juan-Sebastian Saldivar, MD, Dr. Jeremy Squire, PhD, Dr. Erik Thunnissen, MD, PhD, and Dr. Marc Ladanyi, MD

Departments of Pathology (Dr Lindeman) and Medicine (Dr Kwiatkowski), Brigham \& Women's Hospital, Boston, Massachusetts; the Department of Pathology and Genomic Medicine, The Methodist Hospital, Houston, Texas (Dr Cagle); the Department of Pathology, Mt Sinai Medical Center, New York, New York (Dr Beasley); the Department of Pathology, Henry Ford Hospital, Detroit, Michigan (Dr Chitale); the Department of Pathology, University of Pittsburgh Medical Center, Pittsburgh, Pennsylvania (Dr Dacic); the Medical Oncology Branch, National Institutes of Health, Bethesda, Maryland (Dr Giaccone); the Department of Laboratory Medicine and Pathology, Department of Laboratory Genetics, Mayo Clinic, Rochester, Minnesota (Dr Jenkins); the Department of Pathology, City of Hope National Medical Center, Duarte, California (Dr Saldivar); the Department of Pathology and Molecular Medicine, Kingston General Hospital, Queen's University, Kingston, Ontario, Canada (Dr Squire); the Department of Pathology, VU University Medical Center, Amsterdam, the Netherlands (Dr Thunnissen); and the Department of Pathology, Memorial Sloan-Kettering Cancer Center, New York, New York (Dr Ladanyi)
\end{abstract}

\section{Abstract}

\begin{abstract}
Objective-To establish evidence-based recommendations for the molecular analysis of lung cancers that are required to guide $E G F R$ - and $A L K$-directed therapies, addressing which patients and samples should be tested, and when and how testing should be performed.

Participants-Three cochairs without conflicts of interest were selected, one from each of the 3 sponsoring professional societies: College of American Pathologists, International Association for the Study of Lung Cancer, and Association for Molecular Pathology. Writing and advisory panels were constituted from additional experts from these societies.
\end{abstract}

\begin{abstract}
Evidence-Three unbiased literature searches of electronic databases were performed to capture articles published from January 2004 through February 2012, yielding 1533 articles whose
\end{abstract}

\footnotetext{
Copyright $@ 2013$ College of American Pathologists, American Society for Investigative Pathology, Association for Molecular Pathology, and the International Association for the Study of Lung Cancer.

Reprints: Neal I. Lindeman, MD, Brigham and Women's Hospital, Shapiro 5020, 75 Francis St, Boston, MA 02115-6110, nlindeman@partners.org.

For author conflict of interest disclosures, see the Appendix.
} 
abstracts were screened to identify 521 pertinent articles that were then reviewed in detail for their relevance to the recommendations. Evidence was formally graded for each recommendation.

Consensus Process-Initial recommendations were formulated by the cochairs and panel members at a public meeting. Each guideline section was assigned to at least 2 panelists. Drafts were circulated to the writing panel (version 1), advisory panel (version 2), and the public (version 3) before submission (version 4).

Conclusions-The 37 guideline items address 14 subjects, including 15 recommendations (evidence grade A/B). The major recommendations are to use testing for EGFR mutations and $A L K$ fusions to guide patient selection for therapy with an epidermal growth factor receptor (EGFR) or anaplastic lymphoma kinase (ALK) inhibitor, respectively, in all patients with advanced-stage adenocarcinoma, regardless of sex, race, smoking history, or other clinical risk factors, and to prioritize $E G F R$ and $A L K$ testing over other molecular predictive tests. As scientific discoveries and clinical practice outpace the completion of randomized clinical trials, evidencebased guidelines developed by expert practitioners are vital for communicating emerging clinical standards. Already, new treatments targeting genetic alterations in other, less common driver oncogenes are being evaluated in lung cancer, and testing for these may be addressed in future versions of these guidelines.

\section{BACKGROUND-EGFR MUTATIONS AND ALK FUSIONS}

Lung cancer is the leading cause of cancer-related mortality, accounting for approximately 1.4 million deaths per year worldwide and approximately 160000 deaths per year in the United States, which is approximately $25 \%$ to $30 \%$ of all US cancer deaths and more than the next 3 cancers (colon, prostate, breast) combined. ${ }^{1}$ Fortunately, the past decade has seen major advances in our understanding of the pathogenesis and management of lung cancers, adenocarcinoma in particular. Specifically, the discovery of the biologic and therapeutic importance of acquired genetic alterations in 2 genes that encode pharmacologically targetable tyrosine kinases involved in growth factor receptor signaling, epidermal growth factor receptor $(E G F R)$ and anaplastic lymphoma kinase $(A L K)$, has changed the way these cancers are diagnosed and treated.

As gefitinib and erlotinib, small-molecule competitive inhibitors of the EGFR tyrosine kinase, were being evaluated in clinical trials of advanced-stage lung cancer in the early part of the last decade, unusual prolonged responses to these medications were recognized in a subset of patients. ${ }^{2}$ This unusual clinical behavior, not seen previously with standard chemotherapy, led to investigations that identified a correlation between activating somatic mutation in the EGFR gene and clinical response to gefitinib and erlotinib. This initial exciting observation has led to sustained and continuing laboratory and clinical investigations into the mechanism and clinical consequences of EGFR mutations in lung cancer. In unselected advanced non-small cell lung cancer (NSCLC) patients, gefitinib and erlotinib produce response rates of $8 \%$ to $9 \%$, with a median time to progression of 2.2 months to 3.0 months. ${ }^{3}$ In contrast, advanced NSCLC patients selected on the basis of activating EGFR mutations in their tumors show response rates (RRs) of $68 \%$, with a mean progression-free survival (PFS) and time to progression of 12 months (Table 1). ${ }^{4-6}$ 
In 2009, the first randomized clinical trial (the Iressa Pan-Asia Study [IPASS]) showed that, for advanced NSCLC patients with an activating EGFR mutation, initial treatment with an EGFR tyrosine kinase inhibitor (TKI) was superior to standard platinum-based chemotherapy. ${ }^{7}$ In this study, which enrolled East Asian patients with stage IIIB/IV lung adenocarcinoma who never smoked tobacco (or only smoked lightly), the patients whose tumors contained an activating EGFR mutation and who received gefitinib had a significantly longer PFS than those receiving chemotherapy (hazard ratio [HR] for progression or death, $0.48 ; P<.001){ }^{7}$ Subsequently, 5 additional randomized controlled trials confirmed this association between activating EGFR mutations and objective response to gefitinib and/or erlotinib therapy (Table 2). However, in spite of these impressive differences in PFS, no study has shown an advantage in overall survival for EGFRmutation-bearing patients treated initially with an EGFR TKI in comparison to chemotherapy. This is likely to be at least partly due to the crossover design of these studies, in that a large fraction of the patients with EGFR-mutated tumors treated initially with chemotherapy crossed over to the EGFR TKI treatment arm, confounding the interpretation of overall survival data.

Three years after the initial discoveries of EGFR mutations in lung cancer, in 2007, Soda and coworkers ${ }^{8}$ reported that an inversion on chromosome arm $2 \mathrm{p}$ resulted in the creation of an EML4-ALK fusion gene in lung cancer. The fusion gene was identified in 5 of 75 (7\%) NSCLC patients examined. Subsequent studies have indicated that the prevalence of this gene fusion event is about $2 \%$ to $7 \%$ of all NSCLCs seen in the United States, with enrichment in adenocarcinomas in never smokers or light smokers. ${ }^{9-20}$ Testing for this $A L K$ gene fusion has been facilitated by the commercial availability of a dual-probe "break-apart" fluorescence in situ hybridization (FISH) assay for $A L K$ rearrangements that was already in clinical use to detect $A L K$ fusions in lymphomas and certain sarcomas. ${ }^{15} \mathrm{~A}$ recent report of a large clinical series indicated that $A L K$ rearrangements were seen in about $5 \%$ of 1500 NSCLC patients screened. ${ }^{13}$ Moreover, $A L K$ rearrangement-positive patients treated with a novel ALK inhibitor, crizotinib, showed an overall response rate of $57 \%$, with $72 \%$ having a PFS of 6 months or greater. ${ }^{13}$ The US Food and Drug Administration (FDA) has approved crizotinib for advanced-stage, $A L K$-positive lung cancer as is also recommended by recent guidelines from professional organizations, including the American Society of Clinical Oncology (ASCO), European Society for Medical Oncology, and National Comprehensive Cancer Network (NCCN).

Given the considerable published data on EGFR-mutated lung cancer and the rapid pace of work on $A L K$, representatives of 3 professional organizations with interest in the diagnosis and management of lung cancer-the College of American Pathologists (CAP), the International Association for the Study of Lung Cancer (IASLC), and the Association for Molecular Pathology (AMP)—convened to systematically review the published data and develop evidence-based recommendations for the molecular testing of lung cancers for these 2 critical predictive biomarkers in a clinical practice guideline (CPG).

CPGs are systematically developed statements intended to assist practitioners and patients in making decisions about appropriate health care options for specific clinical circumstances. Attributes of good CPGs include validity, reliability, reproducibility, clinical applicability, 
clinical flexibility, clarity, multidisciplinary process, review of evidence, and documentation. Specifically, utilization of CPG recommendations may provide improvements in outcomes and in medical practice; minimize inappropriate practice variation; provide decision support tools for practitioners, a reference for medical education, criteria for self-evaluation, and indicators and criteria for external quality review; and assist with reimbursement and coverage decisions. Finally, the process of CPG development can also identify areas where further research is needed.

\section{Clinical Practice Guideline Questions}

This CPG addresses 5 principal and 14 corollary questions regarding molecular testing in NSCLC:

I. When should molecular testing for NSCLC be performed?

$1 \quad$ Which patients should be tested for EGFR mutations and ALK rearrangements?

$2 \quad$ When should a patient specimen be tested for EGFR mutations or ALK rearrangements?

3 How rapidly should test results be available?

II. How should EGFR testing be performed?

$4 \quad$ How should specimens be processed for EGFR mutation testing?

$5 \quad$ What are the specimen requirements for EGFR testing?

$6 \quad$ How should EGFR testing be performed?

$7 \quad$ What is the role of KRAS analysis in selecting patients for targeted therapy with EGFR TKIs?

8 What additional testing considerations are important in the setting of secondary or acquired EGFR TKI resistance?

III. How should $A L K$ testing be performed?

$9 \quad$ What methods should be used for ALK testing?

IV. Should other genes be routinely tested in lung adenocarcinoma?

10 Are other molecular markers suitable for testing in lung cancer?

V. How should molecular testing of lung adenocarcinomas be implemented and operationalized?

11 Must all adenocarcinomas be tested for both EGFR and ALK?

12 How should EGFR and ALK results be reported?

13 How should EGFR and ALK testing be validated?

14 How should quality assurance be maintained? 


\section{Disclaimer}

Clinical practice guidelines and consensus statements reflect the best available evidence and expert consensus supported in practice. They are intended to assist physicians and patients in clinical decision making and to identify questions and settings for further research. With the rapid flow of scientific information, new evidence may emerge between the time a practice guideline or consensus statement is developed and when it is published or read. Guidelines and statements are not continually updated and may not reflect the most recent evidence. Guidelines and statements address only the topics specifically identified therein and are not applicable to other interventions, diseases, or stages of diseases. Furthermore, guidelines and statements cannot account for individual variation among patients and cannot be considered inclusive of all proper methods of care or exclusive of other treatments. It is the responsibility of the treating physician, relying on independent experience and knowledge, to determine the best course of treatment for the patient. Accordingly, adherence to any practice guideline or consensus statement is voluntary, with the ultimate determination regarding its application to be made by the physician in light of each patient's individual circumstances and preferences. CAP, IASLC, and AMP make no warranty, express or implied, regarding guidelines and statements and specifically exclude any warranties of merchantability and fitness for a particular use or purpose. CAP, IASLC, and AMP assume no responsibility for any injury or damage to persons or property arising out of or related to any use of this statement or for any errors or omissions.

In formulating recommendations for molecular testing in lung cancer, CAP, IASLC, and AMP considered these tenets of guideline development, emphasizing review of data from appropriately conducted and analyzed clinical trials. Practice guidelines are not intended to supplant physician judgment with respect to particular patients or special clinical situations. The literature and expert review process was directed toward evaluating and selecting the best science for the best possible patient care; a cost analysis was not performed for this guideline.

\section{METHODS}

A detailed account of the methods used to create this guideline can be found in the supplemental digital content at www.archivesofpathology.org in the June 2013 table of contents.

\section{Panel Composition}

The CAP Pathology and Laboratory Quality Center, and representatives from the IASLC and AMP, jointly convened an expert author panel and scientific advisory panel consisting of experts in clinical pathology and oncology, and research and development relevant to molecular testing in NSCLC. A conference with the expert author and advisory panels was held in December 2010, at which representatives from industry, public health policy and regulatory affairs, patient advocacy, and commercial drug and/or diagnostic device manufacturers were invited to participate. Representatives from the FDA, the National Cancer Institute, ASCO, and the NCCN attended the conference. The opinions of panel members associated with official government agencies represent their individual views and 
not necessarily those of the agency with which they are affiliated. All members of the expert (author) panel were required to disclose financial and personal conflicts of interest (see below).

\section{Systematic Literature Review and Analysis}

The literature search strategy involved searching the following electronic databases from January 2004 through February 2012: Ovid MEDLINE, Ovid MEDLINE In-Process \& Other Non-indexed Citations, and the Wiley Cochrane Library. The following keywords and MeSH terms were used in the search: lung neoplasms; lung cancer; carcinoma, non-small cell lung; EGFR; Epidermal growth factor receptor; ALK; KRAS; BRAF; mutation; amplification; gene copy number; rearrangement; fusion; translocation; inversion; immunohistochemistry; IHC; and FISH. All searches were limited to the English language.

\section{Eligible Study Designs}

Systematic reviews with or without meta-analyses, randomized controlled trials, cohort studies, case-control studies, case series, and method comparisons were eligible for this study. Also included were testing guidelines and proficiency testing strategies of various US and international organizations.

\section{Inclusion Criteria}

Articles were eligible for inclusion if they met the following criteria:

1. The study compared, prospectively or retrospectively, the sensitivity, specificity, negative predictive value, or positive predictive value of $E G F R$ or $A L K$ tests for detection of an EGFR mutation, $A L K$ rearrangement, or response to a targeted EGFR or ALK TKI; the study described technical comparisons across various assay platforms; the study examined potential testing algorithms for NSCLC molecular testing; or the study examined the correlation of EGFR or $A L K$ status in primary versus metastatic tumors from the same patients.

2. The study population consisted of patients with a diagnosis of NSCLC.

3. The primary outcomes included the sensitivity, specificity, positive predictive value, and negative predictive value of tests to determine EGFR or $A L K$ status or treatment response, alone and in combination; concordance across platforms; and accuracy in determining EGFR or $A L K$ status and benefit from EGFR or ALK TKI therapy.

\section{Exclusion Criteria}

Letters, commentaries, editorials, reviews, and case reports were excluded.

\section{Tests Examined}

Additional test methods considered included EGFR copy number by FISH or bright-field chromogenic in situ hybridization, immunohistochemistry for expression of ALK (kinase domain or carboxy-terminal) or mutated EGFR protein, and reverse transcription- 
polymerase chain reaction (RT-PCR) detection of EML4-ALK fusion transcript. Alterations in other genes, including $K R A S, B R A F$, and $M E T$, were also considered.

\section{Outcomes of Interest}

The primary outcomes of interest were the correlations between $E G F R$ mutation or $A L K$ rearrangement and benefit from EGFR or ALK TKI therapies, respectively. Other outcomes of interest included accuracy in determining EGFR or $A L K$ status, concordance across technical platforms, sensitivity, and specificity of different tests. After careful consideration of each of these, the expert panel and advisory panel agreed that the primary recommendations of this guideline should focus on EGFR mutation assays and ALK FISH assays.

The panel reviewed the results of randomized controlled trials in lung cancer, evaluating therapies targeting EGFR or ALK, such as gefitinib, erlotinib, and crizotinib. The panel also reviewed unblinded trials comparing various testing methods, describing test characteristics, and defining strategies for quality assurance of testing in the literature.

\section{Environmental Scan}

At the December 2010 conference, individuals representing regulatory agencies (FDA) also provided information about the regulatory framework. Individuals involved with quality assurance in the United States (CAP), the Netherlands, and Canada (Province of Ontario) also provided information about programs to measure and improve EGFR and $A L K$ testing. This information was used to help the panel specify testing requirements and exclusions, and the necessary quality assurance monitoring that will make the testing less variable and more accurate.

\section{Quality Assessment and Grading of the Included Evidence}

Grading of recommendations was based on overall ratings of individual components of the evidence, such as strength of evidence, its consistency, clinical impact, generalizability, and applicability to the international health care system. ${ }^{20-22}$ For strength of the evidence, we considered the level of evidence based on its hierarchy, number of studies and number of patients, magnitude of effect from the weighted mean difference or risk ratio, statistical precision measured as a point estimate or confidence interval, and methodologic quality of included studies. ${ }^{22}$ The quality of systematic reviews, randomized control trials, and cohort studies was assessed by using the AMSTAR (Assessment of Multiple Systematic Reviews) instrument and SIGN (Scottish Intercollegiate Guidelines Network) 50 checklists, respectively. ${ }^{23,24}$

The overall grade of the recommendation was obtained by rating all components of the evidence. The overall grade indicates the strength of the body of evidence to assist the users of clinical practice guidelines in making appropriate and informed clinical judgments. ${ }^{23}$ Grade A or B evidence supports "recommendations," which are generally based on a body of evidence that can be trusted to guide clinical practice in all or in most situations. Grade C evidence is insufficient for a "recommendation" and provides support for "suggestions," for which care should be taken in application. Grade D evidence is weak and does not provide 
support for "recommendations" or "suggestions." Expert consensus opinion was used where grade $\mathrm{C}$ or above evidence was lacking.

\section{Revision Dates}

This guideline will be reviewed regularly, as mandated by publication of substantive and high-quality medical evidence that could potentially alter the original guideline recommendations. If necessary, the entire panel will reconvene to discuss potential changes. When appropriate, panel members will recommend revision of the guideline to their respective organizations for review and approval.

\section{Conflict of Interest Policy}

Before acceptance on the expert panel, potential member authors from all guideline partnering organizations completed the CAP conflict of interest process, whose policy and form requires disclosure of material financial interest in, or potential for benefit of significant value from, the guideline's development or its recommendations beginning 12 months prior and ending when the guideline was submitted for publication (see "Appendix"). The potential members completed the conflict of interest disclosure form conservatively, listing any relationship that could be interpreted as constituting an actual, potential, or apparent conflict. Regarding members declaring potentially perceived or real conflict, guideline cochairs agreed that these individuals would best serve as advisory panel members for the guideline, but not authors on the expert panel. CAP, IASLC, and AMP provided funding for this project; no industry funds were used in the development of the guideline.

\section{OUTCOMES}

\section{CAP/IASLC/AMP Expert Panel Literature Review and Analysis}

The expert author panel cochairs (N.I.L., P.T.C., M.L.) reviewed 1533 potentially relevant abstracts identified in the original literature searches to select studies pertinent to the guideline: 2 cochairs independently reviewed each abstract, and disagreements were resolved by the third cochair. Full-text articles (521) were then reviewed for all selected abstracts by 2 members of the expert author panel; discrepancies were resolved by a cochair. Evidence tables were developed from selected studies that met the criteria for inclusion. A third literature review was performed by the authors of each section of the guideline, to verify that the highest levels of evidence supported each of their recommendations and, if not, to reevaluate the recommendation and modify or defend it.

\section{Consensus Development Based on Evidence}

The entire panel met in December 2010 (Chicago, Illinois); additional work on the guideline was completed through electronic mail and monthly teleconferences of the cochairs and/or expert panel. The purposes of the panel meeting were to refine the questions addressed by the guideline, solicit input and testimony from the nonwriting advisory panel, and make writing assignments for the respective sections. All members of the expert panel participated in the preparation of the draft guideline, which was then disseminated for review by the entire panel. Feedback from external reviewers was also solicited. The content of the 
guideline and the manuscript were reviewed by an independent review panel and approved by the CAP Transformation Program Office Steering Committee, by the IASLC Board of Directors, and by the AMP Clinical Practice Committee and Executive Council. The recommendations are summarized in Table 3.

\section{SECTION I: WHEN SHOULD MOLECULAR TESTING FOR NSCLC BE PERFORMED?}

\section{Question 1: Which Patients Should Be Tested for EGFR Mutations and ALK Rearrangements?}

1.1a: Recommendation-EGFR molecular testing should be used to select patients for EGFR-targeted TKI therapy, and patients with lung adenocarcinoma should not be excluded from testing on the basis of clinical characteristics.

1.1b: Recommendation- $A L K$ molecular testing should be used to select patients for ALK-targeted TKI therapy, and patients with lung adenocarcinoma should not be excluded from testing on the basis of clinical characteristics.

Evidence Grade: EGFR: A; ALK: B: Clinical characteristics (eg, age, sex, ethnicity, smoking history) are not sufficiently sensitive or specific to be used to select or exclude patients for treatment or testing. Ethnicity, smoking history, and sex have all been associated with the presence of EGFR mutations in NSCLC. Multiple studies have established that $E G F R$ mutations are more common in women than men, in patients who have never smoked tobacco than in patients who have smoked tobacco, and in East Asians than in other ethnic groups. ${ }^{7,25-29}$ In contrast to $E G F R$-mutated lung cancer, $A L K$ gene fusions do not show sharp differences in prevalence according to sex and ethnic origin, but do show a similar strong association with patients who have never smoked tobacco and younger age. ${ }^{11,18,30,31}$ However, while these clinical characteristics may have value for population studies, they are insufficiently specific to be used to select individual patients for treatment with a targeted inhibitor. Similarly, these characteristics are insufficiently sensitive to be used as prerequisites for testing an individual patient for EGFR mutation or $A L K$ fusion, as significant numbers of patients who might benefit from EGFR- or ALK-targeted therapy might be inappropriately excluded (Tables 4 through 7). Prediction models combining several of these variables to define patients who have a very low probability of $E G F R$ mutations (eg, <1\%) have been developed but will require further evaluation. ${ }^{32,33}$

1.2: Recommendation-In the setting of lung cancer resection specimens, $E G F R$ and $A L K$ testing is recommended for adenocarcinomas and mixed lung cancers with an adenocarcinoma component, regardless of histologic grade. In the setting of fully excised lung cancer specimens, EGFR and $A L K$ testing is not recommended in lung cancers that lack any adenocarcinoma component, such as "pure" squamous cell carcinomas, "pure" small cell carcinomas, or large cell carcinomas lacking any immunohistochemistry (IHC) evidence of adenocarcinoma differentiation. 
Evidence Grade: EGFR and ALK: A: As a preamble to the discussion of this recommendation, we note that "non-small cell" lung carcinoma is no longer considered appropriate as a pathologic diagnosis for resection specimens or as an operational category for clinical management. This evolution is also reflected in the version 3.2012 NCCN guidelines that recommend avoiding use of the generic term non-small cell lung carcinoma (NSCLC) as a single diagnostic term for complete resection specimens. ${ }^{34}$ The distinction between squamous carcinoma, small cell carcinoma, neuroendocrine carcinoma, and adenocarcinomas has become critical for determining subsequent molecular characterization of tumors and patient management.

EGFR mutations have been detected in several histologic lung cancer types, but most tumors with $E G F R$ mutations are adenocarcinomas or mixed carcinomas with an adenocarcinoma component, including adenosquamous carcinomas. While there is some evidence that $E G F R$ mutations are more likely in low-grade adenocarcinomas with lepidic, papillary, or acinar histology than in poorly differentiated, mucinous, or solid adenocarcinomas, EGFR mutations are found at significant frequencies in adenocarcinomas of all grades. Therefore, adenocarcinoma subtype should not be used as a determinant of which samples should, or should not, be tested. ${ }^{35-38}$

$A L K$ rearrangements are also associated with adenocarcinoma histology, without any single subtype being strongly predictive. Studies in Western populations have shown that $A L K$ rearrangements are more frequent in adenocarcinomas with largely solid histology and/or signet ring cells, but this has not been observed in East Asian populations. ${ }^{17,39,40} A L K$ fusions appear very infrequent in squamous cell carcinomas lacking any adenocarcinoma component (Table 8) but have been reported in adenosquamous carcinomas. ${ }^{41}$

Likewise, EGFR mutations are very infrequent in well-characterized fully excised specimens of squamous cell carcinoma lacking any adenocarcinoma component. ${ }^{35,38,42-51}$ A few studies ${ }^{52-60}$ have reported EGFR mutations in squamous cell carcinoma at a low frequency (Table 9). Most of these latter studies have focused on molecular or clinical data from patients with advanced disease diagnosed by small biopsies, raising concerns that many, if not most, of these EGFR-mutated "squamous" cancers may have been small biopsies in which the diagnosis of adenosquamous or poorly differentiated adenocarcinomas can be challenging. ${ }^{35,40}$ As this histologic distinction is becoming critical in the selection of cases for mutation analysis, in cases where the distinction between poorly differentiated squamous cell carcinoma and poorly differentiated adenocarcinoma is especially difficult, appropriate IHC should be performed for TTF-1, p63, or p40, and other relevant markers. ${ }^{61-63}$ Likewise, undifferentiated or large cell carcinomas with histochemical or immunohistochemical evidence of adenocarcinoma lineage (eg, TTF-1 or mucin positive) or lacking IHC evidence of squamous carcinoma lineage (eg, p63 or p40 negative) are also appropriate for EGFR and $A L K$ testing. The use of IHC and other specialized histochemical techniques to establish lineage in lung adenocarcinoma is an evolving field (and the selection of stains/antibodies and their associated interpretive criteria) and is outside the scope of this guideline. The interested reader is referred to published IASLC guidelines for an introduction to this topic. ${ }^{63}$ 
EGFR mutations have not been detected in small cell lung cancer (SCLC), except in rare cases of combined SCLC with an adenocarcinoma component; in some of these cases a response to EGFR TKI was reported. ${ }^{64-69}$ In addition, adenocarcinomas with EGFR mutations that were initially treated successfully with an EGFR TKI may show transformation to small cell histology at relapse, as a mechanism of resistance in these patients, the recurrence of the lung cancer as a small cell carcinoma retains the $E G F R$ mutation from the antecedent adenocarcinoma. ${ }^{69-71}$

Among other subtypes of lung cancer, rare EGFR mutations have been reported in pulmonary salivary gland-type tumors, large cell carcinomas, sarcomatoid carcinomas, and large cell neuroendocrine carcinoma. ${ }^{34,72-77}$ This guideline does not make specific recommendations for these less common tumors, although testing of large cell carcinomas showing IHC evidence of adenocarcinoma differentiation should be considered. ${ }^{77}$ EGFR mutations have not been found in carcinoids. ${ }^{78}$

1.3: Recommendation-In the setting of more limited lung cancer specimens (biopsies, cytology) where an adenocarcinoma component cannot be completely excluded, EGFR and $A L K$ testing may be performed in cases showing squamous or small cell histology but clinical criteria (eg, young age, lack of smoking history) may be useful in selecting a subset of these samples for testing.

Evidence Grade: EGFR and ALK: A: Lung cancers with mixed histology (eg, adenosquamous, mixed adeno/small cell) can have mutations in EGFR or rearrangements in $A L K$ and, if so, respond to treatment. ${ }^{79}$ Therefore, in tissues with incomplete sampling in which the possibility of an adenocarcinoma component cannot be excluded, testing may be indicated. In this context, clinical criteria, such as young age, lack of smoking history, or a documented preceding adenocarcinoma, may be used to select patients for testing.

1.4: Recommendation-To determine EGFR and $A L K$ status for initial treatment selection, primary tumors or metastatic lesions are equally suitable for testing.

Evidence Grade: EGFR and ALK: B: Discordances in EGFR mutation status between primary tumors and corresponding metastases appear rare ${ }^{80}$ (Table 10). The clinical significance of these relatively uncommon discrepancies remains uncertain but it should be noted that some discrepancies may reflect the higher risk of false negatives when analyzing lung cancer metastatic to lymph nodes due to the admixture of lymphoid cells. Accordingly, the choice of which sample to test should be based primarily on the specimen qualities themselves (tumor content and preservation), rather than whether they are primary or metastatic lesions. All things being equal, the most recent available tissue is preferred, but no evidence supports subjecting a patient to a procedure to procure tissue specifically to obtain testing of a metastasis before initiation of TKI therapy when an earlier primary lesion is available and suitable for analysis, unless there is a strong clinical suspicion of its origin from a separate primary tumor.

This is in contrast to patients with metastasis or relapse after initially successful response to TKI treatment (ie, acquired resistance), in which case repeated biopsies are performed to 
confirm a clonal relationship to the treated primary tumor, permit analysis of the mechanism of resistance and, potentially, direct the patient to targeted, protocol-based experimental therapies that may differ according to the mechanism of acquired resistance.

1.5: Expert Consensus Opinion-For patients with multiple, apparently separate, primary lung adenocarcinomas, each tumor may be tested but testing of multiple different areas within a single tumor is not necessary.

Separate primary tumors that harbor different mutations are not uncommon.$^{81}$ If an $E G F R$ mutation is discovered in any tumor, the patient may benefit from an EGFR TKI. Therefore, if a patient presents with apparently separate primary tumors (based on location and nonoverlapping histologic features), each primary tumor may be tested. However, the decision whether or not to test each of a patient's multiple tumors depends on each patient's clinical context and requires communication between the laboratory and the clinical care team.

Adequate evidence has not been published to support mutation analysis of different regions of a tumor, neither with respect to mutation sensitivity in otherwise sufficiently cellular regions, nor with respect to clinical outcomes. Although some data suggest that variation in EGFR copy number within a tumor may impact mutation detection rate in samples from different zones of the tumor, performing FISH to select an area for mutation testing is impractical, and any area with sufficient tumor content to enable detection of a mutation may be selected for analysis. ${ }^{80,82-84}$ Recent detailed genomic studies in other cancers have provided further support for the concept that key driver mutations are well preserved but secondary mutations are not. ${ }^{85}$ As key driver mutations, EGFR mutations and $A L K$ fusions appear to follow this pattern and this is further supported by the extreme rarity of the $E G F R$ wild-type recurrent tumors in patients with $E G F R$-mutated lung adenocarcinomas treated with EGFR TKIs. ${ }^{70}$

\section{Question 2: When Should a Patient Specimen Be Tested for EGFR Mutation or ALK Rearrangement?}

2.1a: Recommendation-EGFR mutation testing should be ordered at the time of diagnosis for patients presenting with advanced-stage disease (stage IV according to the 7th edition tumor node metastasis [TNM] staging system) who are suitable for therapy, or at time of recurrence or progression in patients who originally presented with lower-stage disease but were not previously tested.

2.1b: Suggestion- $A L K$ rearrangement testing should be ordered at the time of diagnosis for patients presenting with advanced-stage disease (stage IV according to the 7th edition TNM staging system) who are suitable for therapy, or at time of recurrence or progression in patients who originally presented with lower-stage disease but were not previously tested.

Evidence Grade: EGFR: A; ALK: C: Patients with advanced-stage disease have short life expectancies, on the order of 4 to 5 months in the absence of treatment. Although patients may derive some benefit from first-line chemotherapy with use of targeted TKIs as secondline agents, patients with $E G F R$ mutations/ALK rearrangements show superior outcomes 
when the targeted TKI therapies are administered as first-line agents. ${ }^{34,86}$ For these patients, timely diagnosis is critical and molecular testing should be initiated as soon as a diagnosis of adenocarcinoma is established.

Reflex testing, a testing policy that does not require a separate clinician order for each case, is appropriate if agreed upon by the lung cancer care team and may help to ensure expedited and consistent routing of specimens for molecular testing. However, some patients may not be candidates for targeted TKI therapy for clinical reasons, and good communication between the clinical care team and the testing laboratory is needed to ensure testing is performed for patients whose management will be impacted by the test result. Specifically, testing is not necessary for patients with stage IV disease who are being considered for palliative or hospice care only. Similarly, in settings in which reflex testing is the practice, a mechanism should be provided for the clinical care team to communicate to the pathologist examining a small biopsy or cytology sample when a more suitable diagnostic specimen (eg, a resection) is expected to be obtained, and the molecular testing should be deferred to the subsequent, more generous sample.

2.2a: Expert Consensus Opinion-EGFR testing of tumors at diagnosis from patients presenting with stage I, II, or III disease is encouraged but the decision to do so should be made locally by each laboratory, in collaboration with its oncology team.

2.2b: Expert Consensus Opinion- $A L K$ testing of tumors at diagnosis from patients presenting with stage I, II, or III disease is encouraged, but the decision to do so should be made locally by each laboratory, in collaboration with its oncology team.

Patients with localized disease have a potential for surgical cure and may never need targeted therapies. Testing the initial surgical specimen at the time of resection affords the benefits of having recent tissue to test as well as, in many instances, larger resection specimens with ample material. By contrast, excluding patients with early-stage disease from testing and waiting until progression may necessitate testing of a smaller biopsy sample of borderline quality or quantity and/or subjecting patients to invasive procedures in order to obtain adequate samples, or trying to retrieve the earlier resection specimen from long-term storage or from another institution, which can be challenging and timeconsuming. Furthermore, EGFR testing may have use as a favorable prognostic factor, beyond its use as a predictor of response to targeted inhibitors. ${ }^{86,87}$

These benefits of testing all early-stage disease patients must be balanced against the cost of performing testing that may not be used to select therapy for the patients who never relapse. The portability of the initial testing results should also be considered, in the case of a patient with a delayed relapse who may present for targeted therapy years later at another institution.

Currently, the question of whether or not to test a diagnostic specimen in early-stage disease is a local decision that must be made in conjunction with each institution's oncology care team, as insufficient published evidence supports a universal recommendation. However, evidence to support this treatment practice may be forthcoming. Traditionally, most novel 
therapeutic agents are studied initially in patients with advanced disease that is refractory to standard therapy. If activity is noted in this setting, the agents are typically next studied in the first-line setting for advanced-stage disease. If activity is noted in this setting, then the agent may be studied in earlier-stage disease. This is where EGFR inhibitors are todaygiven the success in first-line treatment of patients with advanced-stage disease and EGFR mutations, a next wave of clinical trials will test whether these agents may be beneficial as adjuvant therapy in early-stage disease, a notion already supported by retrospective analyses. ${ }^{88}$ ALK therapy is one step removed, as trials testing its value as first-line therapy in advanced disease are ongoing.

2.3: Recommendation-Tissue should be prioritized for $E G F R$ and $A L K$ testing.

Evidence Grade: EGFR: A; ALK: B: $E G F R$ and $A L K$ testing are the most important uses of the diagnostic sample after a diagnosis of adenocarcinoma is established. If specimens are insufficient for molecular testing, patients may need to undergo another invasive diagnostic procedure before they can be treated. Therefore, it is critical to retain sufficient material for molecular analysis and to be judicious in the use of sections for IHC studies, histochemical stains, or deeper levels that may not be essential to establish a histopathologic diagnosis. This is particularly critical for specimens that have a limited amount of cancer cells. This concept has also now been incorporated into the new IASLC classification. ${ }^{63} \mathrm{In}$ instances where there is not enough tissue for $E G F R$ and $A L K$ testing, pathologists should alert the oncologist and include a note in the surgical pathology report to this effect. Because substantial tissue can be lost when blocks are refaced in histology laboratories while cutting unstained slides after initial sectioning, consideration should be given to cutting multiple additional unstained sections "up front" when the sample is first processed in histology. These unstained sections could then be used for deeper levels or additional histochemical/ immunohistochemical stains as needed to establish the diagnosis, and for ensuing molecular testing, without having to reface and recut the blocks. The benefit of such a sample-sparing protocol must be balanced against the cost of cutting additional sections, some of which might not be used.

\section{Question 3: How Rapidly Should Test Results Be Available?}

3.1: Expert Consensus Opinion-EGFR and $A L K$ results should be available within 2 weeks (10 working days) of receiving the specimen in the testing laboratory.

Clinical response to EGFR TKI in EGFR-mutated tumors is typically seen rapidly, and the drugs themselves have relatively modest side effects when compared to platinum-based chemotherapy ${ }^{89}$ For these reasons, some oncologists are willing to initiate EGFR TKI therapy before the $E G F R$ test result is available. However, randomized controlled trials have demonstrated that $E G F R$ wild-type tumors respond better to conventional chemotherapy than to EGFR TKIs. ${ }^{7,26,90,91}$ Thus, in most clinical circumstances, EGFR TKI therapy should not be administered as first-line therapy without evidence of a sensitizing EGFR mutation. Therefore, the turnaround time (TAT) for EGFR testing has become increasingly important, especially for patients with advanced-stage disease. 
To that end, and in the absence of published data establishing an evidence-based recommendation, it is our expert consensus opinion that a TAT goal of 1 week (5 working days) should be established for $E G F R$ and $A L K$ testing, up to a maximum TAT of 2 weeks (10 working days). This TAT refers to the period from the receipt of suitable material by the molecular pathology laboratory where the testing is performed to the reporting of the final results to the clinical care team, and is not related to the period of time between when a patient undergoes a diagnostic procedure and when a specimen is submitted to the laboratory for testing. We consider achieving this TAT goal to be most critical for patients with advanced-stage disease, although we believe it is a reasonable goal for all testing.

3.2: Expert Consensus Opinion—Laboratories with average TATs beyond 2 weeks need to make available a more rapid test—either in-house or through a reference laboratory -in instances of clinical urgency.

Patients with stage IV lung cancer have median untreated life expectancy of approximately 16 weeks; $20 \%$ of this time should not be spent waiting for test results. If laboratories cannot provide results for the sickest of patients within 2 weeks, then they need to make available a method or another laboratory that can. This is particularly germane for large-scale multiplexed assays that afford the capability of testing many genes at once but may take several weeks to complete and analyze. While this technology has great scientific promise and platform consolidation is logistically appealing, the ability to generate large amounts of data of unproven significance should not take precedence over the timely generation of clinically useful data. This recommendation is based upon expert consensus, given the lack of published experimental data addressing this topic.

3.3: Expert Consensus Opinion-Laboratory departments should establish processes to ensure that specimens that have a final histopathologic diagnosis are sent to outside molecular pathology laboratories within 3 working days of receiving requests and to intramural molecular pathology laboratories within 24 hours.

Another critical component of the overall testing time is the delivery of tissues necessary to perform these tests, both between institutions and within pathology departments. It is our expert consensus opinion that pathology departments should have established processes in place to retrieve and send out materials (blocks or unstained sections) within 3 working days of receiving such requests, once a final histopathologic diagnosis has been established. In local cases, where tumor material must be transferred from surgical pathology or cytology to the molecular diagnostic laboratory, intradepartmental delivery of materials should occur within 1 working day for finalized current or recent (eg, not in long-term storage) cases. As stated above, reflex testing and/or preparation of unstained recut sections at the time the sample is first processed in the histology laboratory may help to ensure expedited and consistent intradepartmental routing of specimens for molecular testing.

Molecular pathology laboratories with high demand for these tests in otherwise busy pathology departments may benefit from having a specialized histologic service dedicated to expeditious processing of samples for molecular testing within the pathology department or 
having a dedicated histology technician and equipment within the molecular pathology laboratory.

\section{SECTION II: HOW SHOULD EGFR TESTING BE PERFORMED?}

\section{Question 4: How Should Specimens Be Processed for EGFR Mutation Testing?}

4.1: Expert Consensus Opinion-Pathologists should use formalin-fixed, paraffinembedded (FFPE) specimens or fresh, frozen, or alcohol-fixed specimens for polymerase chain reaction (PCR)-based EGFR mutation tests. Other tissue treatments (eg, acidic or heavy metal fixatives, or decalcifying solutions) should be avoided in specimens destined for EGFR testing.

The effects of fixation and preanalytic specimen processing are no different for $E G F R$ mutation analysis than for other molecular diagnostics applications that rely upon PCR amplification, and EGFR testing can be performed on fresh, frozen, FFPE, or alcohol-fixed specimens. Accordingly, molecular tests should be validated for each of the specimen types likely to be encountered (ie, FFPE, fresh, frozen, alcohol fixed), and testing should be performed and reported only on validated specimen types. Other specimen types should be rejected as inadequate or tested at the discretion of the laboratory director, with clear communication that the test was performed on a nonvalidated specimen type.

Fresh or frozen specimens are optimal for analysis of long (ie, >1000 bp) DNA segments. ${ }^{92-94}$ However, this is not typically necessary for EGFR testing. One drawback to testing fresh or frozen tissues is the need for correlative histologic examination, which may require cutting and staining frozen sections flanking the portion of the specimen submitted for testing. In contrast, the use of FFPE material for DNA extraction allows a more convenient and accurate assessment of tumor content.

Different tissue fixatives, processing protocols, and storage conditions, with associated variations in chemical and physical conditions, including time to fixation, mechanism of fixation, processing temperature, pressure, and $\mathrm{pH}$, storage time and conditions, all can affect the quality and quantity of DNA, RNA, and proteins in the specimens, and their analyses. Selection of a proper section for analysis, and correct interpretation of negative results, requires that the molecular pathology laboratory have access to this information.

Ten percent neutral-buffered formalin is the fixative that is most widely used, and most molecular assays have been optimized and validated on such tissues. Formalin fixation leads to chemical cross-links to proteins, RNA, and other DNA molecules, with concomitant fragmentation of DNA, which inhibits molecular analysis in a length-dependent fashion. In general, molecular analyses of formalin-fixed DNA that require DNA segments shorter than $300 \mathrm{bp}$ are usually successful, while those requiring a length between 300 and $1000 \mathrm{bp}$ succeed inconsistently, and those requiring a length of greater than $1000 \mathrm{bp}$ are often unsuccessful. ${ }^{92}$ Formalin fixation also causes random nucleotide base changes, which can lead to false-positive results, typically in samples with low DNA concentration or with ultrasensitive assays..$^{95-97}$ 
Alcohol (70\% ethanol) has been shown to be comparable to, if not better than, $10 \%$ neutralbuffered formalin for molecular assays requiring nucleic acid extraction, but alcohol is not a favored fixative in routine histology laboratories for a variety of reasons, including tradition, safety, cost, and compatibility with some other FDA-approved procedures (eg, ERBB2 [HER2/neu] FISH, estrogen receptor IHC). ${ }^{93,98}$ Most cytology fixatives are alcohol based and, therefore, cytology specimens are typically suitable for DNA-based molecular assays. ${ }^{99-101}$

Most molecular analyses are inhibited by heavy metal fixatives (eg, Zenker, B5, B plus, acid zinc formalin) owing to competition between the metals in the fixative and the magnesium needed as a cofactor for most DNA polymerases and other enzymes involved in molecular methods. ${ }^{93,102,103}$ Specimens processed with heavy metal fixatives should not be used for EGFR testing.

Acidic solutions (eg, Bouin solution, bone-decalcifying solutions) fragment DNA extensively. ${ }^{104,105}$ Tissues treated with acidic solutions should not be used for EGFR testing. This is particularly problematic for analysis of bone metastases, which are usually decalcified in acidic solutions. The use of nonacidic chelating decalcifying solutions may better preserve DNA for molecular testing. ${ }^{105}$ Moreover, unbuffered formalin spontaneously oxidizes to formic acid over time. ${ }^{106}$

The relatively broad time range of specimen fixation found in pathology practice usually has no effect on morphologic details, but longer durations of fixation adversely affect the quality of nucleic acid. ${ }^{92}$ Fixation times of 6 to 12 hours for small biopsy samples and 8 to 18 hours for larger surgical specimens generally give best results, although our expert consensus opinion is that fixation times of 6 to 48 hours should give acceptable results, in accordance with CAP Laboratory Accreditation Program Checklist MOL.39358 for HER2/neu in situ hybridization..$^{98,107}$ This is a generalization, however, and the effect of extreme fixation times should be assessed by each laboratory during validation. This knowledge should be incorporated into the interpretation and reporting of molecular pathology results when fixation times are extreme.

4.2: Expert Consensus Opinion-Cytologic samples are also suitable for EGFR and $A L K$ testing, with cell blocks being preferred over smear preparations.

Although it has been shown that smears can be used effectively for DNA extraction for $E G F R$ mutation assays, it is our expert consensus opinion that, for cytology specimens such as malignant pleural effusions, use of a cell block is recommended over smear preparations because of the ability to correlate with malignant cell content, the preservation of the original diagnostic specimen, and the possible retention of more material for additional diagnostic studies. ${ }^{62,101,108,109}$ In addition, analysis of FISH requires nonoverlapping tumor cells, which can be a challenge to identify on 4',6-diamidino-2-phenyl-indole (DAPI)stained smears. As with surgical pathology specimens, the cell pellet should be fixed in $10 \%$ neutral-buffered formalin for 6 to 48 hours before processing. Fixation in $70 \%$ ethanol is also acceptable; in which case validation of the molecular assays on DNA extracted from alcohol-fixed tissues should be done. 


\section{Question 5: What Are the Specimen Requirements for EGFR Testing?}

5.1: Expert Consensus Opinion-Pathologists should determine the adequacy of specimens for EGFR testing by assessing cancer cell content and DNA quantity and quality.

$E G F R$ mutation testing can be performed on specimens procured by almost any procedure: surgical resection, open biopsy, endoscopy, transthoracic needle biopsy, fine-needle aspiration, or thoracentesis. In general, larger tumor specimens (eg, resections) are generally preferred for mutation assays because of greater amount of material and greater capacity to enrich the malignant content by dissection. However, most advanced-stage lung tumor specimens are small biopsy or cytology specimens such as pleural fluids or fine-needle aspirates. EGFR mutation assays have been shown to be able to detect mutations from cytologic specimens, particularly if cell blocks are available. ${ }^{109-114}$ Ultimately, any specimen that meets the laboratory's requirements for tumor content, fixation, and quality, as established during validation, may be chosen for analysis. Specimens that fail to meet these requirements may be analyzed at the laboratory director's discretion, but these specimens present some additional challenges that might necessitate additional testing procedures or communication in the report.

One of the issues with small specimens is the possibility of false-negative results. ${ }^{45,115-117}$ The number of tumor cells in comparison with normal tissue, such as inflammatory and stromal cells, is an important factor that influences the reliability of mutational analysis. ${ }^{115}$ This is particularly important for less sensitive methods, such as unmodified direct DNA sequencing. In such cases, it may be appropriate to add to the report of a negative result a recommendation for repeated testing on additional material if it becomes available.

Although PCR-based methods can in principle detect mutations from a single cell, a low copy number DNA template can generate sequence artifacts, mainly guanine to adenine transitions, due to stochastic occurrence of polymerase errors early in the PCR in the setting of low template. ${ }^{96}$ In addition, the DNA damage caused by formalin fixation can also lead to sequence artifacts. ${ }^{95}$ As much as 1 artificial mutation per 500 bases may be observed in the analysis of formalin-fixed tissue with low DNA content. ${ }^{97}$ The frequency of errors reflects both Taq DNA polymerase's normal error frequency and the degree of damage and crosslinking of DNA by formalin. For this reason, some laboratories perform duplicate amplifications of FFPE samples to ensure accurate results. For direct DNA sequencing, mutational artifacts should be distinguished from true mutations by bidirectional sequencing and by confirmatory sequencing of independent PCR products. ${ }^{107}$ Whole genome amplification is a method to increase the amount of template DNA in insufficient specimens. It is prone to the same types of artifacts as PCR amplification of low templates and it is therefore prudent to analyze specimens in duplicate, beginning with a duplicate wholegenome-amplification step. ${ }^{118}$

Laboratories offering EGFR testing should determine the requirements for each type of specimen they may encounter (eg, fluids, fresh tissues, fixed tissues). All specimens from a patient should be considered for testing, and the choice of which specimen to test should be made by a pathologist familiar with the molecular testing to be performed, based primarily 
upon tumor content and likely DNA quality as influenced by fixatives and other solutions used in histology.

If no adequate specimen is available and a new specimen needs to be procured, then the decision regarding which specimen to obtain is a complex one. Factors in this decision include the patient's overall health, accessibility of lesions, radiographic appearance of lesions, and ability to schedule procedures promptly. The pathology factors that contribute to this decision include the minimum specimen requirements for each sample type, as well as the relative likelihood of each sample type meeting these requirements. As such, it is important for the molecular pathologist to monitor the percentage of specimens that are being rejected as inadequate for each specimen type and to provide consultation to the oncology care team to assist in obtaining the specimen type that is most likely to yield a diagnostic result. Although not a guideline recommendation, some pathology departments may send a cytopathologist or cytotechnologist to provide immediate consultation in the clinic or interventional radiology suite regarding adequacy of specimens obtained by needle biopsy procedures.

5.2: Expert Consensus Opinion-Each laboratory should establish the minimum proportion and number of cancer cells needed for mutation detection during validation.

The minimum percentage tumor cellularity requirements will depend on the methodology being used for analysis. In general, a minimum mutated allele frequency of 25\% (50\% cancer cell frequency, assuming heterozygosity and disomy) is required for unmodified Sanger sequencing, although this is a generalization and each laboratory must determine its sensitivity cutoff for each assay. ${ }^{119}$ Several more sensitive mutation detection techniques have sensitivities in the range of $10 \%$ down to $1 \%$ or even lower. ${ }^{119-122}$ These are general approximations, however, and each laboratory must determine the minimum amount of tumor cells needed for analysis (analytic sensitivity) during validation, for each specimen type that will be accepted by the laboratory (fixed tissue, fresh/frozen tissue, fluid) and for each analyte measured. Ideally, these studies are performed with patient specimens, although cell lines may be necessary if appropriate patient specimens are not available. The use of plasmids is not recommended owing to an increased risk for intralaboratory contamination similar to that of PCR products.

Importantly, the association between mutated allele content and cancer cell content is significantly affected by genomic copy number changes. EGFR-mutated alleles are often amplified. ${ }^{123,124}$ While it might be ideal to determine the EGFR copy numbers for the validation specimens (ie, by FISH) and use disomic tumors for sensitivity assessment, this may not be practical for most laboratories, in which case the sensitivity studies should be performed with more than 1 specimen, to control for the variation in EGFR copies between tumors or cell lines.

In addition to establishing the analytic sensitivity of the EGFR testing method during validation, the performance of the assay also needs to be monitored in an ongoing fashion once clinical testing is initiated. Accordingly, a low-positive control specimen (near the 
lower limit of tumor content of specimens accepted by the laboratory) should be tested in each clinical assay run.

5.3: Expert Consensus Opinion-A pathologist should assess the tumor content of each specimen and either perform, or guide a trained technologist to perform, microdissection for tumor cell enrichment as needed.

Appropriate assessment of the specimen is critical for accurate results and preventing falsenegative results and assay failures. A representative stained slide must be reviewed by a pathologist to determine and document the cellular content and tumor purity in the focus of tissue to be tested. An ideal specimen would have not only a very high proportion of malignant cells relative to the admixed nonneoplastic cells, but also a minimal amount of substances that may inhibit amplification, such as mucin and necrotic tissue. In general, assessment of tumor content and purity is more accurate in fixed sections than in frozen sections, and this has prompted some laboratories to designate FFPE tumor material as the preferred specimen type.

Estimates of tumor content from hematoxylin-eosin-stained sections vary considerably between pathologists. ${ }^{125}$ Establishing gold standard calibration specimens through formal cell counting of selected areas can be used to train pathologists and assess their accuracy and precision. In the absence of a true standard, consensus opinion can be used to assess tumor content in a specimen near the threshold for acceptability.

Often, the entire tissue section may have a suboptimal proportion of tumor for analysis, but a subregion within the section may be more suitable, and an enrichment strategy must be used to isolate cells from the more concentrated area only. In this event, the tumor enrichment can be performed directly by the pathologist or by a trained technologist under guidance by the pathologist, in which case, the ideal region should be demarcated on the slide by a pathologist during their hematoxylin-eosin review of the case, with documentation of tumor content, and used as a reference for the tumor enrichment procedure. Tumor enrichment procedures should also be assessed during test validation.

Dissection of areas rich in tumor cells from surrounding normal tissue is the typical method for enriching a specimen for malignant DNA content. The main benefit of dissection is the production of relatively pure specimens of a morphologically confirmed cell population. Dissection methods include gross macrodissection or coring of an area out of tissue or a paraffin block, microdissection from glass slides, with or without visualization under a microscope, and flow cytometric sorting or laser capture microdissection (LCM) techniques to enrich the specimen cell by cell. Manual dissection is quick, relatively simple and requires inexpensive equipment such as a standard or inverted microscope. As different laboratories will have different resources available for this step, any method can be adopted for tumor enrichment, as long as the cellularity requirements for the assay are established accordingly.

Laser capture microdissection is a time-consuming and labor-intensive method that requires expensive equipment. Although the actual microdissection is relatively simple, personnel 
must be specially trained to use the equipment. Another disadvantage of LCM is that DNA yield is often low. The main advantage of this technique is that a pure cell population with minimal normal tissue contaminants can be acquired. Small specimens, such as endobronchial or needle biopsies requiring LCM to isolate tumor cells, showed a high failure rate (53\%-66\%) by DNA direct sequencing in contrast to larger resection or excisional biopsy specimens (24\%). ${ }^{126}$ In addition, LCM specimens typically have low DNA content, which can lead to assay imprecision and PCR artifacts that can be misinterpreted as unusual or novel mutations ${ }^{96,127}$ (see "Question 6" discussion below).

\section{Question 6: How Should EGFR Testing Be Performed?}

6.1: Recommendation-Laboratories may use any validated EGFR testing method with sufficient performance characteristics.

Evidence Grade: B: Multiple test platforms are acceptable for EGFR mutation testing, and this guideline does not recommend any individual method(s) to the exclusion of others. Rather, we recommend that tests offered for clinical care meet specified minimal performance characteristics, and require that laboratories establish acceptable performance during validation and maintain acceptable quality during production. The performance characteristics that are most relevant for this discussion are sensitivity and specificity. Other test characteristics of particular importance are TAT and spectrum of mutations detected.

A variety of methods are used to detect $E G F R$ mutations, including Sanger sequencing with and without mutated allele enrichment, the amplification refractory mutation system, length analysis, restriction fragment length polymorphism, real-time PCR, high-resolution melting curve analysis, single-base extension genotyping (including mass spectrometry-based genotyping), and denaturing high-performance liquid chromatography, each having different advantages and disadvantages $27,36,57,115,120,121,128-156$ (Table 11). At the time of writing, published data on the application of massively parallel sequencing to the detection of EGFR mutations were still quite limited but this technology is expected to soon become more widespread. ${ }^{157-159}$

6.2: Expert Consensus Opinion-Laboratories should use EGFR test methods that are able to detect mutations in specimens with at least $50 \%$ cancer cell content, although laboratories are strongly encouraged to use (or have available at an external reference laboratory) more sensitive tests that are able to detect mutations in specimens with as little as $10 \%$ cancer cells.

The historical reference method, bidirectional sequence determination by the Sanger method with fluorescence-tagged dideoxy terminators, is usually able to precisely detect mutated sequences when they constitute approximately $25 \%$ of the total DNA (potentially even lower for specific nucleotide changes), which corresponds to a minimum tumor content of approximately $50 \%$ for a heterozygous mutation with no polysomy or amplification. ${ }^{160}$ Although this method, with this level of performance, was the initial method used to establish the value of the test for predicting response of tumors to erlotinib and gefitinib, many specimens fall short of this tumor content. ${ }^{47,161,162}$ As a consequence, laboratories 
exclusively using this method would have to reject a significant proportion of specimens as inadequate for testing.

All laboratories must establish the lower sensitivity of their methodology during test validation. Any tumor enrichment procedures, such as manual microdissection, must be included as part of the validation. The sensitivity limit (also called analytic sensitivity) should be defined as the lowest concentration of tumor cells in which a mutation is detected with $100 \%$ precision in replicates repeated both within run and between run. ${ }^{107}$ As stated earlier, because of possible variation in the genomic copy number of mutated EGFR alleles between tumors, this cutoff should be validated on more than 1 tumor specimen. Wild-type results above this limit can be reported confidently as negative.

Although the published evidence supports a recommendation that any method must be at least as sensitive as the Sanger sequencing technique that first established the clinical value of mutation detection, our expert consensus opinion is that more sensitive methods should be available, because of the many patients who only have had samples with low tumor content. ${ }^{115,163}$ In our opinion, an ideal test should be able to detect mutations in specimens with as little as $10 \%$ cancer cells. In particular, laboratories that use Sanger sequencing are strongly encouraged to use a mutated allele-enriching strategy, such as locked nucleic acid or peptide nucleic acid clamps, coamplification at lower denaturation temperature PCR, or enzymatic digestion of wild-type sequences, to enhance the sensitivity for the common critical mutations in exon 19 (747_750 LREA deletions), 20 (T790M), and 21 (L858R). ${ }^{70,156,164}$ If a laboratory cannot offer a more sensitive method than unmodified Sanger sequencing, then that laboratory must communicate its limitation clearly to its clinicians and make available referral to another laboratory for more sensitive testing for specimens with lower tumor content.

Although analytic sensitivity is very important for expanding testing to patient specimens with low tumor content or purity, ultrasensitive molecular assays (defined here as an analytic sensitivity of below 1\%) can be problematic. In specimens with high tumor content, if an ultrasensitive molecular assay finding is positive while an assay finding of conventional sensitivity is negative, the result is either interpreted as a possible false positive due to mispriming or low cross-contamination, or as a true positive reflecting a very small mutated subclone. Thus, there is a risk of losing specificity with regard to predicting response to targeted therapy. Some studies using such methods have found novel, possibly artifactual mutations, or failed to show a relationship between classic EGFR mutations and treatment response. ${ }^{165}$ Finally, technical artifacts may be seen with ultrasensitive methods that require experience and caution in interpretation.

Accordingly, specificity of ultrasensitive methods must receive additional attention during validation. Multiple negative lung cancer specimens should be tested, as should no-template controls. Given the huge collective testing experience accumulated and reflected in online databases such as the Catalogue of Somatic Mutations in Cancer (COSMIC), novel EGFR mutations are rare today, and the discovery of novel mutations is cause for careful scrutiny and reevaluation of methodology. Artifacts should be presented in the laboratory's standard 
test operating procedure manual to assist in interpretation, and laboratories should clearly communicate with clinicians when results are unclear or uncertain.

Although not a guideline recommendation, a suggested approach is to offer a 2-tiered testing strategy, in which both standard-sensitivity and high-sensitivity testing is performed and reported. An example would be Sanger sequencing with, and without, mutated enrichment by locked nucleic acid/peptide nucleic acid. The report would then indicate whether a mutation was detected only with the ultrasensitive method or also by the less sensitive method, which could then be correlated with the morphologic estimate of tumor content.

Each laboratory should have a dialogue with its clinicians to understand the TAT needs within its health care setting. If results are needed within a few days, then multistep testing such as Sanger sequencing may be less desirable than a 1-step procedure such as allelespecific PCR. Similarly, if a sample has borderline tumor content for the method in question and TAT is critical, it may be better to go directly to a more sensitive method or have the patient undergo another sampling procedure, rather than attempt an analysis that may end up with an inconclusive interpretation.

6.3: Expert Consensus Opinion-Clinical EGFR mutation testing should be able to detect all individual mutations that have been reported with a frequency of at least $1 \%$ of EGFR-mutated lung adenocarcinomas.

Another critical issue in method selection is the spectrum of mutations tested. This is not a concern for Sanger sequencing, which provides information on mutations throughout the exons sequenced (usually exons 18 to 21 ), but it is an important consideration in the selection or design of mutation-specific assays. The 2 most common mutations in $E G F R$, the short in-frame deletions in exon 19 and the L858R point mutation in exon 21, account for about $90 \%$ of all EGFR mutations, and these are the mutations with by far the most extensive data on EGFR TKI response rates (Table 12). Nonetheless, response data are accumulating for other less common mutations and therefore, our consensus opinion is that limiting testing to the 2 major mutations is no longer considered acceptable.

Routine EGFR assays for EGFR exon 19 deletions should be designed to detect not just the common 15-bp and 18-bp deletions, but also the less common 9-, 12-, 24-, and 27-bp deletions, as well as the uncommon 15-bp and 18-bp insertions. ${ }^{166}$ EGFR exon 18 should be analyzed for E709 and G719 mutations; exon 20 for S768, T790M, and insertions; and exon 21 for L858R, T854, and L861Q mutations. Pretreatment T790M mutations and most exon 20 insertions are associated with lack of response to first-generation EGFR TKIs, and this should be communicated in the report. ${ }^{137,167-169}$

Given the accumulated experience with EGFR mutations, the detection of "novel" mutations or mutations only reported very rarely should be viewed with great caution and should prompt replicate assays on new DNA extracts to rule out artifactual mutations due to formalin fixation, PCR errors, or whole-genome-amplification errors (if used). Nevertheless, rare variants and rare mutations will occur, and such findings should not be automatically discarded as errors. 
The recommendation for broad mutation detection may conflict with the recommendation for TAT. In these instances, laboratories may consider offering 2 assays: a rapid assay for the most common mutations, which can be reported within a few days in cases of clinical urgency, and a more comprehensive follow-up assay to detect the remaining mutations, which may take longer to report.

6.4: Recommendation-Immunohistochemistry for total EGFR is not recommended for selection of EGFR TKI therapy.

Evidence Grade: A: Interest in IHC-based testing is driven by the fact that it is a technology available to essentially all pathology departments, and it can be performed for specimens where the number or proportion of tumor cells poses challenges for molecular tests based on bulk DNA extraction from tissue. There are 3 main types of EGFR IHC: IHC for total EGFR, IHC for phosphorylated EGFR, and IHC for mutated forms of EGFR.

Immunohistochemistry for total EGFR is not an acceptable test for EGFR TKI treatment selection because it has been shown to correlate poorly or not at all with the presence of EGFR mutations. ${ }^{123,170,171}$ However, in other settings, the role of IHC for total EGFR may need to be reassessed in the future if the anti-EGFR monoclonal antibody cetuximab becomes a therapeutic option in mutation-negative, EGFR-overexpressing patients. ${ }^{172}$

Experience with IHC for phosphorylated EGFR is still limited and concerns remain regarding the stability of phosphorylation status in routinely handled pathology material. Use of such IHC assays for EGFR TKI treatment selection would be premature at this point.

The third type of IHC assay that has been evaluated uses commercially available mutationspecific rabbit monoclonal antibodies directed against the most common mutated forms of EGFR: the 15-bp/5-amino-acid deletion (E746_A750del) in exon 19 and the L858R point mutation in exon 21. ${ }^{173}$ In several independent studies, ${ }^{173-175}$ IHC with the EGFR L858R mutated antibody has confirmed excellent sensitivity and specificity relative to mutation testing. The EGFR exon 19 mutated-specific antibody showed excellent sensitivity and specificity for cases with the 15-bp deletion in exon 19 but reduced sensitivity for exon 19 deletions of other sizes. ${ }^{174,176-178}$ If scoring cutoffs are set stringently to ensure a high positive predictive value, IHC with EGFR mutation-specific antibodies could be used as an initial screen to identify most patients who are candidates for EGFR inhibitors; however, for all specimens negative with these 2 mutation-specific monoclonal antibodies, that is, most samples overall, molecular testing is still needed. In the absence of an algorithm that includes molecular testing of negative cases, mutated EGFR allele-specific IHC is currently too insensitive to be used as a stand-alone assay for EGFR TKI treatment selection. However, for patients with only a low cellularity specimen deemed inadequate for DNA analysis, this IHC may be the best option available, but there is still no prospective clinical experience with this special situation. ${ }^{179}$ Overall, the body of published data is insufficient to make an evidence-based recommendation regarding the use of EGFR mutation-specific IHC at this time. Laboratories that plan to use these antibodies clinically should validate their use against a valid molecular assay, communicate their clinical performance characteristics (eg, sensitivity, specificity) to their clinicians, and make available referral to 
another molecular laboratory for molecular testing to exclude mutations in IHC-negative tumors (if not available in-house).

6.5: Recommendation-EGFR copy number analysis (ie, FISH or chromogenic in situ hybridization) is not recommended for selection of EGFR TKI therapy.

Evidence Grade: B: Increased EGFR gene copy number (polysomy or amplification) is observed in about $40 \%$ of cases, with a range of $8 \%$ to $66 \% .{ }^{54,129,180-182}$ Across multiple studies, the EGFR TKI response rates for patients with EGFR polysomy/amplification is $30 \%$ (Table 13), consistently well below the mean response rate seen for patients with EGFR mutations (68\%) (Table 1). Amplification of the mutated EGFR allele is common and drives a strong statistical association of EGFR polysomy/amplification with EGFR mutation. ${ }^{170,171}$ The correlation of EGFR polysomy/amplification with EGFR TKI response is secondary to this strong association with EGFR mutation, and in the cases where EGFR mutation and copy number are discrepant, the mutation status is better associated with EGFR TKI response. ${ }^{170,171}$ In studies with data on both, EGFR TKI response rates for cases with $E G F R$ polysomy/amplification and wild-type $E G F R$ sequence are very low, essentially in the range of $E G F R$-nonmutated cases without increased $E G F R$ copy number. ${ }^{170,171}$ In contrast, $E G F R$-mutated cases lacking amplification show response rates comparable to EGFR-mutated cases overall. ${ }^{170,171}$ Finally, comparisons of EGFR amplification and EGFR mutation as predictors of response and clinical outcome in earlier clinical trials of TKI versus placebo in the second-line (or greater) setting were hampered by the small size of the subsets of patients with available molecular data, in particular mutation data. ${ }^{4,6,163}$ The IPASS study, a large phase III randomized clinical trial with data on both EGFR mutation and amplification, showed that EGFR TKI treatment selection based on mutation status leads to better clinical outcomes in the first-line setting than selection based on EGFR gene copy number, and subsequently published large phase III randomized controlled trials of TKI treatment response in the first-line setting used mutation analysis. ${ }^{7,26,90,91,183-185}$ Thus, EGFR copy number testing, whether by FISH or chromogenic in situ hybridization, is less predictive than mutation testing and should not be used as a method for EGFR TKI treatment selection. ${ }^{170,171}$ More study is needed to determine if mutated allele copy number is a modifier of benefit in the setting of EGFR mutation.

\section{Question 7: What Is the Role of KRAS Analysis in Selecting Patients for Targeted Therapy With EGFR TKIs?}

7.1: Recommendation-KRAS mutation testing is not recommended as a sole determinant of EGFR TKI therapy.

Evidence Grade: B: The most common ( $30 \%)$ oncogene mutated in lung adenocarcinomas is $K R A S$. The frequency of $K R A S$ mutations varies between ethnic groups; they are less frequent in Asians (5\%-10\%) when compared with individuals of white European or white American ancestry (25\%-35\%) and African ancestry (15\%$25 \%) .{ }^{25,186-188}$ Approximately $90 \%$ to $95 \%$ of patients with KRAS-mutated lung adenocarcinomas have a history of tobacco use and therefore, regional differences in the proportions of $K R A S$-mutated lung adenocarcinomas may also reflect variations in smoking 
prevalence, but KRAS mutations can also be observed in approximately 5\% of lung cancer patients who never smoked tobacco. ${ }^{189,190}$ The substantial cumulative clinical experience and published data have shown that $E G F R$ and KRAS mutations are mutually exclusive.

Several studies compared response rates, PFS, and overall survival in patients with KRASmutated lung cancer treated with EGFR TKI, and 2 meta-analyses addressing these questions have been reported. ${ }^{28,180,191-201}$ The association between KRAS mutations and a lack of response to EGFR TKI was based on retrospective reviews of EGFR TKI in the second- and third-line setting. ${ }^{28,180,191-193,195-202}$ Objective response to EGFR TKI can be seen in $0 \%$ to $3 \%$ of patients with KRAS mutations and $26 \%$ of patients with KRAS wild type. ${ }^{28,180,191-193,195-202}$

In part because of the ease of testing for KRAS codon 12 and 13 mutations and its widespread availability owing to indications in metastatic colorectal cancer, testing for $K R A S$ mutations as a negative predictor of response to EGFR TKI has become part of molecular diagnostic algorithms for lung adenocarcinoma in many centers. However, with more recent data showing that $E G F R$ wild-type tumors have less favorable outcomes if they are treated with EGFR TKI than if they are treated with conventional platinum-based chemotherapy, the decision to treat with an EGFR TKI can no longer be made without an $E G F R$ result, and the role of KRAS testing in this context has diminished. ${ }^{26,90,91}$ The significance of $K R A S$ mutational analysis may become increasingly important with the further development of new therapies targeting downstream RAS pathways such as $\mathrm{PI} 3 \mathrm{~K} / \mathrm{AKT} / \mathrm{mTOR}$ and RAS/RAF/MEK, but at this time, the absence of a KRAS mutation does not add clinically useful information to the EGFR mutation result and should not be used as a determinant of EGFR TKI therapy. However, because KRAS and EGFR mutations are mutually exclusive, a rapid and inexpensive $K R A S$ assay may be performed initially to exclude $K R A S$-mutated tumors from EGFR mutation testing as part of an algorithm designed to maximize testing efficiency, provided that the sample is sufficient to perform the KRAS test without sacrificing $E G F R$ and $A L K$ testing, and that the totality of clinically relevant molecular results can be obtained within the target TAT.

There are other clinical settings in which $K R A S$ mutation has been examined as a biomarker that are not directly related to the present guidelines. In patients without $E G F R$ mutations for whom chemotherapy fails, erlotinib may be administered as a second-line agent. In these patients, KRAS mutation may presage a poorer outcome, although the evidence for this from the BR21 trial is limited by small sample size and lack of statistical significance. ${ }^{170} \mathrm{KRAS}$ mutation is also not predictive of benefit (or lack of benefit) from cetuximab therapy in lung cancer patients. ${ }^{172,203}$

\section{Question 8: What Additional Testing Considerations Are Important in the Setting of Secondary or Acquired EGFR TKI Resistance?}

8.1: Recommendation-If a laboratory performs testing on specimens from patients with acquired resistance (AR) to EGFR kinase inhibitors, such tests should be able to detect the secondary EGFR T790M mutation in as few as 5\% of cells. 
Evidence Grade: B: Although clinical and radiographic responses to EGFR TKIs in patients with "sensitizing" EGFR mutations are significant in approximately $70 \%$ of cases, these patients almost invariably experience recurrence or progression while on treatment after a median of 8 to 16 months, a clinical phenomenon termed acquired resistance. ${ }^{137,204-206}$ Clinical management implications of AR mechanisms are still evolving without established treatment guidelines; additional tumor material may be procured in this clinical setting in the course of diagnostic or therapeutic procedures, such as biopsies, to confirm recurrence or metastasis, or management of malignant effusions. In the event that tumor specimens from AR patients are tested, the following suggestions are included in this guideline.

The most common mechanism of AR involves the emergence of an additional EGFR tyrosine kinase domain mutation, T790M, caused by a single base substitution, $\mathrm{C}$ to $\mathrm{T}$, at nucleotide 2369; this mutation is found as a second mutation on the EGFR allele harboring the initial "sensitizing" EGFR mutation. ${ }^{137,168,207}$ Because AR is, within the tumor cell population, a subclonal process, that is, it is driven by the selection and outgrowth of a subclone of tumor cells that harbor T790M that confers a survival advantage in the presence of EGFR TKI, the technical sensitivity of the detection method is even more critical than in the testing for baseline, sensitizing EGFR mutations that are present in every tumor cell. Initial reports found this mutation in approximately $50 \%$ of tumors at the time of treatment failure. ${ }^{137,168}$ However, because T790M is often not present in every tumor cell, conventional Sanger sequencing, even with microdissection, is considered insufficient for this testing. ${ }^{207}$ More recent studies based on higher sensitivity approaches place the prevalence of $\mathrm{T} 790 \mathrm{M}$ in AR samples in the $60 \%$ to $70 \%$ range. ${ }^{208}$ In vitro studies have shown that cell population-level EGFR TKI resistance becomes detectable in the presence of as little as 5\% T790M-bearing cells and, in the absence of further clinical data, our consensus opinion is that assays for T790M should have sensitivity to detect mutations in $5 \%$ of cells. ${ }^{209}$ This means that unmodified Sanger sequencing alone is insufficient, and laboratories using Sanger sequencing should consider a mutation-enriching strategy such as peptide nucleic acid/locked nucleic acid clamps, or have a more sensitive assay (eg, allelespecific PCR) that targets the T790M mutation in the setting of AR.

Most studies have only rarely detected T790M in pretreatment samples. ${ }^{210}$ When it is detected in the pretreatment setting, it should be confirmed as either somatic or germline by testing of normal DNA from the patient. Germline T790M mutation has been associated with familial lung cancer, and therefore its detection should trigger evaluation of the family history and genetic counseling, keeping in mind that risk estimates and screening recommendations for unaffected T790M carriers remain to be determined. ${ }^{210,211}$

Other rare second-site mutations in the EGFR tyrosine kinase domain have been described in AR specimens, including L747S, D761Y, and T854A, but owing to their relatively low prevalence, there is not much clinical experience with these and insufficient data have been published to formulate an evidence-based recommendation. ${ }^{212}$

A less common mechanism of EGFR TKI resistance is amplification of another receptor tyrosine kinase, most often $M E T$ or $E R B B 2$. In initial reports, $M E T$ amplification was 
reported in up to $20 \%$ of AR cases, with a portion of these also harboring the EGFR T790M mutation, but more recent studies suggest this number is closer to $10 \% .^{71,204,213,214}$ However, there is currently a lack of a precise definition of clinically significant $M E T$ amplification in this setting and more research is needed before guidelines can be formulated. More recently, ERBB2 amplification has been reported in another subset of AR cases. ${ }^{318}$

Several clinical trials aimed at overcoming these distinct mechanisms of AR are underway and it is therefore likely that the further management of these patients will soon require determining T790M status and amplification of other receptor tyrosine kinases. T790M status may also become important in determining whether first-line EGFR TKIs should be continued in patients with AR. Recent data suggest that AR patients with the T790M mutation can derive continued clinical benefit from the first-line EGFR TKI. ${ }^{209,213}$

Interestingly, SCLC histology and associated "SCLC-type" radiosensitivity and chemosensitivity have been observed in some AR cases, further supporting the notion that biopsy of recurrent tumor can be clinically valuable in AR. ${ }^{213}$

\section{SECTION III: HOW SHOULD ALK TESTING BE PERFORMED? Question 9: What methods should be used for ALK testing?}

9.1: Recommendation-Laboratories should use an $A L K$ FISH assay using dual-labeled break-apart probes for selecting patients for ALK TKI therapy; ALK immunohistochemistry, if carefully validated, may be considered as a screening methodology to select specimens for $A L K$ FISH testing.

Evidence Grade: B: The genetic alteration of $A L K$ in lung adenocarcinoma is due to chromosomal rearrangement. The most common of these rearrangements involves a pericentric inversion on the short arm of chromosome $2, \operatorname{inv}(2)(\mathrm{p} 21 \mathrm{p} 23)$, which creates a fusion gene encoding the aminoterminal portion of EML4 (2p21) and the intracellular region of $A L K$ (2p23), genes that are normally approximately $13 \mathrm{Mb}$ apart. ${ }^{8,215}$ Although the $E M L 4-A L K$ fusion is the most common, other less common variant fusions have been reported, including translocations with other chromosomes (KIF5B-ALK, TFG-ALK). ${ }^{215,216}$ The NPM-ALK translocation that has been well characterized in anaplastic large cell lymphoma (for which the gene was named) has not been reported in lung cancer.

FISH was the methodology used in the initial studies that demonstrated improved clinical response of patients with $A L K$-rearranged tumors to treatment with crizotinib, a targeted ALK TKI. ${ }^{15,17,217}$ Although FISH assays have been developed by using both break-apart and fusion strategies, the break-apart assay design has shown the best association with clinical outcome. ${ }^{12,218}$ A commercial assay (Abbott Molecular Probes, Abbott Park, Illinois) is available that contains a SpectrumOrange-labeled $300-\mathrm{kb}$ probe on the telomeric $3^{\prime}$ side of $A L K$ and a SpectrumGreen-labeled $442-\mathrm{kb}$ probe on the centromeric $5^{\prime}$ side. With this probe set, the wild-type configuration appears as a fused yellow signal, while $A L K$ rearrangement is seen as distinct and separated orange and green signals (Figures 1 through 4). In the USA, FDA has approved this commercial assay as a "companion diagnostic" to select patients to 
receive an FDA-approved ALK TKI. The published evidence indicates that this FISH assay is an acceptable means of selecting patients for treatment with an ALK TKI.

Whether or not the FDA-approved commercial assay is used, for accurate and precise results, the probe set used for clinical testing should be characterized in detail and the signal configurations and cutoff values for detecting $A L K$ rearrangement should show reproducible performance with normal controls and known abnormal patient specimens and cell lines. If another set of probes or assay design is used, validation studies should demonstrate comparable or superior performance when compared to the commercial probes with regard to signal intensity, magnitude of signal splitting in positive cases, analytic precision, clinical sensitivity, and clinical specificity in accordance with published standards. ${ }^{219,220}$ For laboratories that elect to use laboratory-developed probes for $A L K$ FISH testing, attention should also be given to batch variability of clones, DNA-labeling enzymes, and other reagents. Moreover, any laboratory-developed tests should retain the ability to detect variant fusions of $A L K$ with partners other than $E M L 4$.

IHC-mediated identification of lung adenocarcinomas with overexpression of ALK has been investigated as a simpler, quicker, and cheaper alternative to FISH-based identification of $A L K$ rearrangements. However, IHC studies using the anti-ALK1 antibody typically used for anaplastic large cell lymphoma (mouse monoclonal anti-human CD246, clone ALK1) have been disappointing, likely due to the low expression level of the fusion protein in $A L K$ rearranged lung adenocarcinomas in comparison to anaplastic large cell lymphoma. ${ }^{11,79,216,221-223}$ A substantial proportion of $A L K$-rearranged lung adenocarcinomas are not identified by the ALK1 antibody, using standard techniques, and thus it is not reliable for $A L K$ rearrangement screening in this setting.

To improve the sensitivity of detection of the $A L K$ rearrangement by IHC with the commercially available ALK1 antibody, some groups have developed alternative methods, including an intercalated antibody-enhanced polymer method, tyramide amplification, and an enhanced polymer-based detection system, with subsequent triaging of equivocal cases for ALK FISH. ${ }^{15,216}$ The current data are still limited and more studies need to be published to recommend this approach with this antibody.

A different antibody to ALK (mouse monoclonal, clone 5A4) has been reported to have excellent sensitivity and specificity relative to $A L K$ FISH results, at least for strong IHC staining and for negative or weak IHC staining, while intermediate IHC staining results were poorly predictive of $A L K$ rearrangement status. ${ }^{221}$ High sensitivity, specificity, and reproducibility, as compared to FISH, have been shown with 2 rabbit monoclonal antihuman ALK antibodies (clones D5F3 and D9E4), and the former, ALK antibody D5F3, has just recently become commercially available. ${ }^{221}$

Based on promising recent results with these newer monoclonal antibodies, IHC assays hold the potential to facilitate the routine identification of $A L K$-rearranged lung adenocarcinoma. Where sensitive IHC assays are available, our consensus opinion is that a properly validated IHC method may be used as a screening modality, and that tumors that fail to demonstrate ALK immunoreactivity with a sensitive IHC method need not be tested for $A L K$ 
rearrangement by FISH. The use of sensitive ALK IHC assays as screening tests has been adopted in some countries. Our opinion is that tumors that are positive for ALK IHC, either weakly or strongly, should still be referred to FISH for confirmation of a rearrangement. At this time, there are insufficient data available to develop a specific recommendation on the use of ALK IHC as a sole determinant of ALK TKI therapy.

9.2: Recommendation-RT-PCR is not recommended as an alternative to FISH for selecting patients for ALK inhibitor therapy.

Evidence Grade: B: RT-PCR is not currently recommended as a first-line diagnostic method for determining $A L K$ fusion status because of concerns for a higher failure rate of an RNA-based assay in routine FFPE pathology material, and the risk of false negatives, owing to variability in the EML4-ALK fusion structure and the existence of other $A L K$ fusion partners. To date, there have been at least 13 molecular variants of $E M L 4-A L K$ reported, representing chimeric transcripts fusing $E M L 4$ exons 2, 6, 13, 14, 15, 17, 18, or 20 to $A L K$ exon 20 or immediately upstream within intron 19 of $A L K .^{222}$ Fusion of $A L K$ to $T F G$ and $K I F 5 B$ has been reported in 1 case each, raising the likelihood that additional variant fusions may exist. ${ }^{215,216,224}$ It is possible to design multiplexed RT-PCR assays or to use multiple pairs of primers in separate or sequential reactions to detect the different EML4-ALK variants but multiplexed assays can be difficult to optimize and multiple separate assays may require more RNA than can be regularly extracted from small FFPE samples.

9.3: Expert Consensus Opinion-A pathologist should be involved in the selection of sections for $A L K$ FISH testing, by assessing tumor architecture, cytology, and specimen quality.

Because cells are analyzed individually for evidence of $A L K$ rearrangement using a fluorescent microscope, tumor percentage is not as critical for $A L K$ FISH testing as it is for $E G F R$ mutation testing. For $A L K$ FISH, it is important to choose slides or regions of slides in which the tumor cells can be readily distinguished from admixed normal cells under fluorescence, typically through a combination of cytologic and architectural features that can be appreciated without stains or visualization of cytoplasm. In addition, areas should be chosen in which tumor cells are not overlapping one another.

Specimen requirements for $A L K$ FISH are generally similar to those for $E G F R$ mutation testing: formalin fixation is acceptable, specimens should have enough cancer cells to analyze clearly, and DNA-damaging fixatives or acidic decalcifying agents should be avoided, as should specimens with abundant necrosis. Unlike EGFR mutation testing, however, FISH testing can be problematic when performed on alcohol-fixed samples. Another important distinction between ALK FISH and EGFR mutation analysis is that FISH testing should ideally be performed on recently cut sections, although protocols can be adapted to older slides.

Laboratories may follow the standard operating procedures that have proven to be successful for FISH on formalin-fixed, paraffin-embedded tissue sections in their setting. Attention 
must be paid to particular steps in the protocol that may affect probe penetration and hybridization to target DNA in order to optimize signal intensities.

Particular attention should be paid during validation to the choice of glass slides used for FISH. Several types of slides are manufactured for specialized applications at the expense of suitability for FISH. For example, some slides designed for tissue microarrays have a heavy coating that generates a fluorescent matrix where tumor cells get embedded and cannot be properly treated for FISH-probe penetration. Other slides are designed for microdissection and do not hold the tissue adequately during pretreatment for FISH.

Modifications in the protease digestion protocol may be required, depending on the size of the tissue, duration and type of fixation, nuclear structure and tissue preservation, and time between sectioning and digestion. This may be particularly valuable with difficult sections, including cytology specimens and samples from bone biopsies. Tissue digestion should be standardized to maintain nuclear morphology. Overdigested chromatin may display artifactual "split signals" that may lead to false-positive findings.

Hybridization and washing steps should be standardized by using established protocols. Use of automated tissue processors and standardized commercial tissue digestion kits can improve consistency and should be considered.

9.4: Expert Consensus Opinion-A pathologist should participate in the interpretation of $A L K$ FISH slides, either by performing the analysis directly or by reviewing the interpretations of cytogeneticists or technologists with specialized training in solid tumor FISH analysis.

The selection of nuclei to analyze is a step that is distinct from the scoring of probe signals. When evaluating the results of FISH, several factors should be kept in mind: the architecture of the tissue, including local variations in neoplastic cell content, fixation, and tumor cellularity within the section; the frequent presence of truncated nuclei; and the complex nature of cytogenetic arrangements such as heterogeneous increases in ploidy and aneusomy often seen in lung cancer. The FISH technologist should work closely with a pathologist who can identify tumor-rich areas. Typically, areas selected for FISH evaluation will be marked on a hematoxylin-eosin-stained slide that is directly parallel to the section used for FISH. Areas of the FFPE section selected for signal scoring should pass rigorous quality criteria as being suitable for FISH analysis. Inclusion of macrophages or other nontumor cells in the analysis will dilute positive break-apart scores and can lead to false-negative results. Experienced scorers who have undergone specific training in FISH in solid tumors should analyze the slides. The scorers should also have had training on the morphologic appearance of lung cancer, and should have easy access to assistance from a pathologist with training in FISH. Laboratories with experienced reviewers may use 1 scorer in cases with clearly negative or positive ( $>50 \%$ of cells) cases and a second scorer for less clear cases; otherwise 2 independent reviewers are recommended.

Interpretation should be performed in areas of the slide with good signal, in which at least $50 \%$ of all nuclei are easily analyzable, with minimal background or nuclear fluorescent 
"noise." The FISH signal intensity should be consistently greater than background intensity in the regions of the slide chosen for analysis. Areas where the borders of individual nuclei are not clearly identifiable and/ or high cell density causes excessive nuclear overlap are easy to misinterpret, and should be avoided. At the same time that the quality of the tissue section is reviewed, the FISH signals should be assessed, looking for areas with bright, distinct signals and low background in which individual nuclei are clearly distinguishable. Signals in a nucleus should in general have the same intensity and the DAPI staining should be uniform.

Importantly, the interpretive criteria of FISH assays for $A L K$ rearrangement in lung carcinoma are not necessarily identical to those applied in other neoplastic diseases (eg, anaplastic large cell lymphoma, inflammatory myofibroblastic tumor), even if the identical FISH probe set is used. The most common positive result of a break-apart dual-labeled FISH assay in lung cancer will result in 1 separate orange/red and 1 separate green signal (Figure 4). The native unaltered $A L K$ region will remain as a yellow fusion signal but also commonly appears as 2 narrowly split orange/red and green signals. The second most common positive result in lung cancer is loss of the green $5^{\prime}$ probe with a remaining unpaired $3^{\prime}$ orange/red probe, indicating an unbalanced rearrangement. Importantly, proper interpretation of the FDA-approved commercial break-apart assay considers only nuclei with loss of a green signal, or orange/red and green signals that are separated by a gap larger than 2 signal diameters, to be indicative of an $A L K$ gene rearrangement. Split signals of lesser magnitude separation are seen in the absence of $A L K$ rearrangement and should not be interpreted as positive. ${ }^{15}$ The identification of a 2-diameter gap by readers requires experience, and inclusion of well-characterized negative and positive control sections is an essential part of validating the assay.

Other observations likely to be encountered when scoring signals include extra isolated $3^{\prime}$ $A L K$ signals as well as extra signals (split and/or fusion) arising from polysomies, ploidy changes, and more complex $A L K$ rearrangements. ${ }^{15}$ Currently, these findings are of uncertain significance. All results should be entered onto score sheets and should be coded.

In the trials demonstrating ability of $A L K$ FISH to predict treatment response, a case was considered positive if $15 \%$ or more of 50 nuclei assessed in a tumor-rich portion of the section showed the classic split-signal pattern. ${ }^{15,217}$ Therefore, this cutoff is suggested and is part of the labeling of the FDA-approved commercial assay. Laboratories should still validate clinically sensitive and specific cutoffs in their own hands and different cutoffs must be reconciled with those from the commercial reference method. In certain situations with low tumor cell content, cutoffs as low as $5 \%$ may be considered, especially if IHC or RT-PCR results are available to support it, but this area requires more study.

Limited data exist to recommend cutoff values for the other "nonclassic" patterns of $A L K$ rearrangement, such as loss of $5^{\prime}$ signal, and all testing laboratories should establish their own cutoff values for these other patterns.

9.5: Expert Consensus Opinion-Testing for secondary mutations in $A L K$ associated with acquired resistance to ALK inhibitors is not currently required for clinical management. 
Several groups have reported a diverse set of secondary mutations in $A L K$ that confer acquired resistance to crizotinib, including L1152R, C1156Y, F1174L, L1196M, L1198P, D1203N, and G1269A. ${ }^{225-230}$ To date, however, the numbers of such cases are too small to recommend testing for these mutations for routine clinical management, although we anticipate this indication to grow in the near future as effective second-line therapies become available.

\section{SECTION IV: SHOULD OTHER GENES BE ROUTINELY TESTED IN LUNG ADENOCARCINOMA?}

\section{Question 10: Are Other Molecular Markers Suitable for Testing in Lung Cancer?}

10.1a: Recommendation-Testing for EGFR should be prioritized over other molecular markers in lung adenocarcinoma.

10.1b: Suggestion-After $E G F R$ testing, testing for $A L K$ should be prioritized over other proposed molecular markers in lung adenocarcinoma, for which published evidence is insufficient to support testing guideline development at the present time.

Evidence Grade: EGFR: A; ALK: C: Many additional molecular markers have been proposed as having value in management of lung cancer, in a variety of settings, including exposure to other molecularly targeted therapies, traditional chemotherapy, radiation, or surgery, as well as in other stages of disease and other histologic types of lung cancer. For each of these molecular markers, insufficient data have been published to establish definitive recommendations as to where, when, and how they should be used. However, as discussed in the sections above, clear and compelling published evidence supports the need for $E G F R$ and $A L K$ testing of advanced-stage lung adenocarcinomas as prerequisites to treatment with targeted TKIs. Precious tumor tissue must be reserved for these analyses, before any other molecular analysis is considered. Other tests may be performed in clinical trials or in clinical-pathologic contexts deemed appropriate by agreement between pathologists and clinicians at each individual treatment center, provided sufficient material remains after the essential EGFR and $A L K$ tests are completed.

\section{SECTION V: HOW SHOULD MOLECULAR TESTING OF LUNG ADENOCARCINOMAS BE IMPLEMENTED AND OPERATIONALIZED?}

\section{Question 11: Must All Adenocarcinomas Be Tested for Both EGFR and ALK?}

11.1: Expert Consensus Opinion-Laboratories may implement testing algorithms to enhance the efficiency of molecular testing of lung adenocarcinomas, provided the overall TAT requirements are met.

Currently, the higher costs and labor of simultaneous testing make it difficult to implement, in spite of its obvious advantage in TAT. Stepwise-testing algorithms make more efficient use of resources, but pose a challenge for timely delivery of final results. Given this time constraint, we recommend that stepwise-testing algorithms, if used, should nonetheless be completed within 10 working days. These algorithms are based on the observation that 
$E G F R, A L K$, and $K R A S$ alterations are mutually exclusive, with very rare reported exceptions. ${ }^{217,231,232}$

The simplest algorithm would be to test for EGFR mutations first and proceed to ALK FISH if the EGFR results are wild type.

An alternative algorithm would involve an initial sensitive and rapid EGFR mutation screening test by a method such as denaturing high-performance liquid chromatography, high-resolution melting analysis, or single-stranded conformational polymorphism. Depending on assay design, these rapid screening methods could detect a mutation but fail to characterize it completely (ie, fail to define the size of an exon 19 deletion or distinguish between L858R and L861Q point mutations) or may be affected by single nucleotide polymorphisms (SNPs). For samples in which a mutation is detected but not adequately characterized by a screening method, a more specific method, such as sequencing, would be performed to establish a definitive diagnosis. If the EGFR mutation screening test result is negative, then testing for $A L K$ FISH should be performed. This involves an additional step, but would reduce the amount of definitive EGFR and ALK FISH testing considerably.

A third algorithm, slower still but potentially more cost-effective, would begin with a simple $K R A S$ analysis. KRAS-mutated tumors, which represent $25 \%$ to $30 \%$ of lung adenocarcinomas and which do not have either $E G F R$ mutations or $A L K$ rearrangements, would not proceed to either EGFR or $A L K$ testing. The tumors without KRAS mutations would then enter into one of the algorithms above. If used, such an approach should still meet the above TAT recommendations and should not be undertaken if the KRAS testing will exhaust the sample and thereby preclude EGFR and $A L K$ testing.

Whether or not to use any of these, or other testing algorithms, is a decision that each testing laboratory must make, in conjunction with its clinical care team, to balance its available resources and clinical needs within its individual health care setting.

\section{Question 12: How Should EGFR and ALK Results Be Reported?}

12.1: Expert Consensus Opinion-EGFR mutation testing reports and $A L K$ FISH reports should include a results and interpretation section readily understandable by oncologists and by nonspecialist pathologists.

Oncologists should be able to readily glean the information needed to select appropriate therapy, and to explain the result to their patients. Pathologists should be able to learn sufficient details from the reports to help determine whether repeated testing is appropriate, or to help resolve discrepancies between clinical and laboratory results or between tests performed at different laboratories.

The preclinical section of reports should include the standard identifiers of the patient and specimen, as well as an assessment of the specimen's morphologic characteristics: diagnosis and tumor content (percentage of total nuclei that are malignant). In addition, histopathologic characteristics that may affect the interpretation should be mentioned, such 
as extensive necrosis, atypical specimen processing or fixation, or low total number of tumor cells.

The results section of reports should include, prominently, the names of any clinically significant mutations identified, in formal Human Genome Variation Society (HGVS) nomenclature. Additional, more commonly used terminology may be included, as requested by each institution's clinical care teams. Incidental findings, variants of uncertain significance, and benign polymorphic variants should be clearly presented as such, to leave the reader no doubt as to the lack of evidence supporting their role in clinical management. For multiplexed assays, ideally, results could be presented in a table listing each clinically significant variant that is assessed by the test, with an adjacent result for each. Inconclusive results should be clearly reported as such.

Reports should include a histopathologic assessment of tumor content for the tumor section tested and the reported result should include an overall statement of the cancer's likelihood to respond or resist EGFR TKI therapy. If the result is inconclusive, whether due to assay failure or an insufficient specimen, or another reason, the interpretation should state why (as best as is known) and suggest requirements for testing a different specimen that would be more likely to yield a successful result.

The technical section of the report should include enough information for another laboratorian to understand what was done, in the event of a discrepancy between laboratories, or when requested to retest in another laboratory. The basic methodology should be reported, along with the assay sensitivity. For sequencing assays, each exon sequenced should be listed; for targeted mutation assays, each mutation targeted should be listed. Standard language regarding FDA oversight of laboratory-developed tests should be used, as appropriate.

The same overall principles apply to $A L K$ reports, with a few distinctions. The results section should also include the number of cells analyzed, and the number and percentage of cells with each finding. Proper International System for Human Cytogenetic Nomenclature (ISCN) nomenclature may be used but, perhaps even more so than for HGVS nomenclature and molecular test results, ISCN nomenclature is difficult for the nonspecialist to understand, and colloquial nomenclature is essential for clear communication of results.

\section{Question 13: How Should EGFR and ALK Testing Be Validated?}

13.1: Expert Consensus Opinion-EGFR and $A L K$ testing validation should follow the same guidelines as for other molecular diagnostics and FISH tests.

Technical validation, the set of experiments performed in the clinical laboratory to assure that an assay is safe and reliable for use in patient care, is required in the United States under the Clinical Laboratory Improvement Amendments of 1988 (CLIA '88). Although the required procedures differ between laboratory-developed tests and FDA-approved commercial assays, all tests must be properly validated before introduction into clinical use. $^{233}$ The CAP has published recommendations and examples on validation for a variety 
of assays. ${ }^{234-239}$ This section will focus on specific points in the validation that the panel believes are of particular emphasis for $E G F R$ and $A L K$ validation.

Validation samples should be of all types that will be subjected to testing-frozen, fresh, and fixed specimens (including each fixative to be used), as appropriate. However, it is not necessary to separately validate identically processed tissues of different origins (ie, not necessary to validate separately FFPE lung, FFPE lymph node, and FFPE brain).

All relevant mutations or rearrangements that are to be reported should be included in the validation set, to whatever extent is possible. While some rare EGFR mutations may not be obtainable, the common exon 19 deletions, L858R, T790M, G719, and exon 20 insertions are required. Similarly, $A L K$-positive cases with split signals and with loss of $5^{\prime}$ signals should both be included in validation sets. It is not necessary to separately validate each individual mutation in each specimen-processing type, although it is recommended that each type of mutation (ie, point mutation, deletion, insertion, split signal, loss of signal) be assessed in each specimen-processing type, if possible. Cell lines may be used, but not to the exclusion of clinical specimens except for rare mutations.

Precision studies should assess the reproducibility of the entire analytic process, beginning with the pathologist's tumor assessment and enrichment strategies (eg, dissection). Operationally, therefore, when validation specimens undergo repeated testing on different assay runs, those samples should be reexamined by a pathologist and redissected.

Accuracy of results is best assessed by comparison with another laboratory performing a properly validated assay. Similarly, a new method within a laboratory may be validated against a previously validated method in the same laboratory. Comparison with clinical history of treatment response is suboptimal, but may be used as evidence of true positive mutated specimens, in the absence of another accredited laboratory for comparison. This should not be an issue in the United States, where many CLIA-certified laboratories offer these tests.

Analytic sensitivity of EGFR testing should be assessed in DNA from mutated specimens with low tumor content, diluted both in water/buffer and in normal DNA, to determine tumor cell content, in terms of both absolute cell count and tumor percentage, at which accuracy and precision (reproducibility) deteriorate. The need for replicate measurements to improve accuracy as tumor content decreases should be determined thus. Because of variation in EGFR copy number, sensitivity studies should be done with more than 1 specimen, and the least sensitive result should be stated as the overall test sensitivity. Cell lines are not ideal substitutes for clinical specimens, although FFPE cell pellets may be helpful, especially for mutations that are difficult to obtain. The sensitivity for FFPE specimens may differ from that for specimens fixed in alcohol or frozen.

Analytic specificity studies should establish criteria for distinguishing between true-positive and false-positive results. Specificity of $E G F R$ and $A L K$ results should be confirmed by clinically validated Sanger sequencing and Abbott Vysis ALK Break Apart FISH Probe Kit, respectively, or by methods traceable to those methods. 
No template controls and very-low-concentration wild-type specimens are essential to establish specificity of ultrasensitive EGFR mutation detection methods. Artifacts associated with ultrasensitive methods should be recorded in the standard operating procedure manual.

$A L K$ FISH should be performed on clearly benign tissue as well as $A L K$ wild-type tumors, to help establish the minimum frequency of split signals that can be reported as true positive, as well as to confirm the 2-probe-diameter minimum distance of signal splitting that can be interpreted as true positive.

\section{Question 14: How Should Quality Assurance Be Maintained?}

14.1: Expert Consensus Opinion-Laboratories should follow similar quality control and quality assurance policies and procedures for $E G F R$ and $A L K$ testing in lung cancers as for other clinical laboratory assays. In particular, laboratories performing EGFR and $A L K$ testing for TKI therapy should enroll in proficiency testing, if available.

While specific requirements and approaches may vary somewhat from one country to another, or even between different accrediting organizations within one country (eg., Joint Commission versus CAP in the United States), the fundamental principles are conserved and retained; tests must be be properly validated, undergo regular quality control and instrument maintenance, with monitoring of the laboratory environment and reagent integrity, be performed by competent personnel following clear and informative standard operating procedures, with participation in external proficiency testing procedures and subject to regular inspections by accrediting agencies.

Outside the United States, there are local initiatives for EGFR mutation testing in, among others, Germany, Austria, France, Italy, Greece, the Netherlands, Spain, and Japan. 1,125,240-242 In some countries the national pathology society has rules stating that participation in ring trials for external quality assurance in molecular diagnostics is obligatory. The frequency of these assessments varies from once a year (the Netherlands, Greece, Italy) to twice a year (Germany).

In some countries, proficiency testing is performed by sending a similar sample (set) simultaneously to the participating laboratories, which report the results to the organizing body. Subsequently, the results are compared and a concordant result is a sign of adequate performance. Currently, there are no US regulatory requirements for reporting proficiency testing for $E G F R$ and $A L K$ assays, although proficiency testing must be performed and documented, as with all laboratory tests. The CAP offers an external proficiency testing program for $E G F R$ and KRAS mutation testing, and is developing a program for $A L K$ FISH. CLIA regulations require alternative assessment schemes as substitutes for mandated successful performance on external proficiency testing. When an external proficiency testing program is not available, then laboratories may organize their own proficiency testing program by exchanging specimens with 1 or more other laboratories at least twice per year.

In Europe, an initiative for EGFR testing has been started in collaboration with the European Molecular Genetics Quality Network, European Society of Pathology, European Society for Medical Oncology, and European Thoracic Oncology Platform, in which 10 specimens (cell 
lines, neutral buffered formalin fixed for 24 hours and embedded in paraffin) are validated by 4 laboratories (Greece, United Kingdom, Germany, Italy) and now run in a pilot scheme of 24 laboratories. ${ }^{125}$

In regions of the world where sample exchange is not available, laboratories may confirm accuracy of their results by semiannual clinical chart review of tested patient specimens, with the understanding that accurate determination of EGFR and $A L K$ status may not be determined exclusively by benefit from EGFR TKI therapy, as erlotinib/gefitinib response rates for $E G F R$-mutated lung cancers can be in the $75 \%$ to $90 \%$ range, and the crizotinib response rates are comparable for $A L K$-rearranged lung cancers. ${ }^{243}$ This may be due to upstream or downstream factors that render the EGFR TKI ineffective.

\section{CONCLUSIONS: GUIDELINE DEVELOPMENT IN THE ERA OF GENOMIC MEDICINE}

During the past decade, scientific and technologic progress in cancer genomics research has accelerated the pace of discoveries that can be potentially translated into significant clinical advances for patients with major common cancers. The clinical translation of these discoveries drives an ever-increasing need for tumor genotyping, based on these newly established relationships between type of targetable gene mutation and response to targeted agents. In the case of the present molecular testing guideline for selection of lung cancer patients for EGFR and ALK TKIs, the pressing need to establish standards and provide recommendations had to be addressed in the context of the limitations of the literature. For many recommendations, especially more technical ones, articles reporting controlled studies were few or absent. For recommendations shaped by survival data, the recent and rapid clinical development of these indications, especially that of crizotinib in $A L K$-rearranged lung cancers, meant that relatively limited published data were available as compared to previous molecular testing guidelines such as the ASCO/CAP Guideline Recommendations for Human Epidermal Growth Factor Receptor 2 Testing in Breast Cancer. ${ }^{98}$ In such a rapidly evolving area (and era) of medical practice, we expect that testing guidelines will increasingly have to be developed on more limited published data, integrating expert consensus opinion, with an expectation that such guidelines will be updated regularly as more rigorous meta-analyses of controlled studies become possible over time. Indeed, the present guideline does not encompass less prominent but nonetheless important testing areas, for instance, for selection of patients for MET-targeted therapies (MET amplification or overexpression $)^{244,245}$ and ERBB2-targeted therapies (ERBB2 mutations), ${ }^{246,247}$ and moreover, even as the present guideline was under development, new testing indications in lung cancer emerged, notably for rearrangements of the ROS and RET genes. ${ }^{*}$ Moreover, recent technical innovations, such as "next generation" or massively parallel sequencing, afford the potential to detect all of these alterations, plus many others, in 1 assay. ${ }^{157,248,249}$ Although these technologies are very promising, at the present, there are still insufficient published data on the accuracy, precision, sensitivity, specificity, TAT, and clinical validity of these methods in a clinical laboratory setting. Whereas these next-generation sequencing-

$*_{248,260,319,320,321,322}$ 
based methods are currently not ready for routine widespread clinical implementation, their application to clinical medicine is growing rapidly, and they may form the core technology of the next version of these guidelines. Nonetheless, many aspects of the current guideline are "platform-independent" or "platform-agnostic" and, therefore, they should inform the evaluation and implementation of emerging diagnostic tests for EGFR and $A L K$ status based on massively parallel sequencing.

Thus, the challenges for guideline development are mounting and include the variety of types of genetic alterations to be tested, the rapidly increasing number of clinically relevant cancer genes, the limited published literature and testing experience associated with the accelerated regulatory approval of targeted drugs, and the special issues created by the coapproval of commercial companion diagnostic tests. Even as models for guideline development evolve to adapt to these new factors and pressures, there remains an ongoing clinical need for such testing guidelines to establish and widely disseminate best practices based on systematic and critical literature review and broad consensus opinion from highly experienced stakeholders.

\section{Supplementary Material}

Refer to Web version on PubMed Central for supplementary material.

\section{Acknowledgments}

We would like to thank the following:

Steering Committee: Paul A. Bunn Jr, MD, Neal I. Lindeman, MD, and Jan A. Nowak, MD, PhD.

Advisory Panel: Timothy C. Allen, MD, JD, Alain Charles Borczuk, MD, Lucian R. Chirieac, MD, Fred Hirsch, MD, Anthony John Iafrate, MD, PhD, Kirk D. Jones, MD, Loren J. Joseph, MD, Keith Minto Kerr, MBChB, Rajyalakshmi Luthra, PhD, Mahesh M. Mansukhani, MD, Alberto M. Marchevsky, MD, Tetsuya Mitsudomi, MD, Marina N. Nikiforova, MD, Kim Norris, Christopher N. Otis, MD, Helmut H. Popper, MD, Jay F. Schamberg, MD, Iris Schrijver, MD, Saul Suster, MD, William D. Travis, MD, Gail H. Vance, MD, Marileila Varella-Garcia, PhD, Regina Vidaver, PhD, Cindy L. Vnencak-Jones, PhD, and Maureen F. Zakowski, MD.

Speakers from 2010 December conference: D. Ross Camidge, MD, Barbara Conley, MD, Bruce Johnson, MD, Shakun Malik, MD, Vincent Miller, MD, Tony Mok, MD, Rolf Stahel, MD, and Gail H. Vance, MD.

Staff: Megan T. Wick, MT(ASCP), for staffing the expert panel and data verification; Carol Colasacco, MLIS, SCT(ASCP), for data verification; Tony Smith, MLS, ECM ${ }^{S}$ (AIIM), for his contributions to the literature review process and article referencing work; Sandi Larsen, MBA, MT(ASCP), John Olsen, MD, and Lisa Fatheree, SCT(ASCP), for their oversight of the December 2010 conference and conflict of interest process; and Avtar Lal, $\mathrm{MD}, \mathrm{PhD}$, and R. Bryan Rumble, MSc, for contributing to the statistical evaluation of the literature.

We also thank the editors from the 3 societies (Leslie Litzky, MD, Timothy J. O'Leary, MD, PhD, and Alex A. Adjei, $\mathrm{MD}, \mathrm{PhD}$ ) for their supervision of the journal peer review process subsequent to the approval of this manuscript by the 3 societies.

\section{References}

1. World Health Organization. [Accessed October 26, 2012] Cancer fact sheet No. 297. http:// www.who.int/mediacentre/factsheets/fs297/en/. Published 2012

2. Miller VA, Kris MG, Shah N, et al. Bronchioloalveolar pathologic subtype and smoking history predict sensitivity to gefitinib in advanced non-small-cell lung cancer. J Clin Oncol. 2004; 22(6): 1103-1109. [PubMed: 15020612] 
3. Garassino MC, Borgonovo K, Rossi A, et al. Biological and clinical features in predicting efficacy of epidermal growth factor receptor tyrosine kinase inhibitors: a systematic review and metaanalysis. Anticancer Res. 2009; 29(7):2691-2701. [PubMed: 19596948]

4. Shepherd FA, Rodrigues Pereira J, Ciuleanu T, et al. Erlotinib in previously treated non-small-cell lung cancer. N Engl J Med. 2005; 353(2):123-132. [PubMed: 16014882]

5. Stinchcombe TE, Socinski MA. Gefitinib in advanced non-small cell lung cancer: does it deserve a second chance? Oncologist. 2008; 13(9):933-944. [PubMed: 18784157]

6. Thatcher N, Chang A, Parikh P, et al. Gefitinib plus best supportive care in previously treated patients with refractory advanced non-small-cell lung cancer: results from a randomised, placebocontrolled, multicentre study (Iressa Survival Evaluation in Lung Cancer). Lancet. 2005; 366(9496): 1527-1537. [PubMed: 16257339]

7. Mok TS, Wu YL, Thongprasert S, et al. Gefitinib or carboplatin-paclitaxel in pulmonary adenocarcinoma. N Engl J Med. 2009; 361(10):947-957. [PubMed: 19692680]

8. Soda M, Choi YL, Enomoto M, et al. Identification of the transforming EML4-ALK fusion gene in non-small-cell lung cancer. Nature. 2007; 448(7153):561-566. [PubMed: 17625570]

9. Boland JM, Erdogan S, Vasmatzis G, et al. Anaplastic lymphoma kinase immunoreactivity correlates with ALK gene rearrangement and transcriptional up-regulation in non-small cell lung carcinomas. Hum Pathol. 2009; 40(8):1152-1158. [PubMed: 19386350]

10. Inamura K, Takeuchi K, Togashi Y, et al. EML4-ALK fusion is linked to histological characteristics in a subset of lung cancers. J Thorac Oncol. 2008; 3(1):13-17. [PubMed: 18166835]

11. Inamura K, Takeuchi K, Togashi Y, et al. EML4-ALK lung cancers are characterized by rare other mutations, a TTF-1 cell lineage, an acinar histology, and young onset. Mod Pathol. 2009; 22(4): 508-515. [PubMed: 19234440]

12. Koivunen JP, Mermel C, Zejnullahu K, et al. EML4-ALK fusion gene and efficacy of an ALK kinase inhibitor in lung cancer. Clin Cancer Res. 2008; 14(13):4275-4283. [PubMed: 18594010]

13. Kwak EL, Bang YJ, Camidge DR, et al. Anaplastic lymphoma kinase inhibition in non-small-cell lung cancer. N Engl J Med. 2010; 363(18):1693-1703. [PubMed: 20979469]

14. Paik JH, Choe G, Kim H, et al. Screening of anaplastic lymphoma kinase rearrangement by immunohistochemistry in non-small cell lung cancer: correlation with fluorescence in situ hybridization. J Thorac Oncol. 2011; 6(3):466-472. [PubMed: 21258247]

15. Rodig SJ, Mino-Kenudson M, Dacic S, et al. Unique clinicopathologic features characterize ALKrearranged lung adenocarcinoma in the western population. Clin Cancer Res. 2009; 15(16):52165223. [PubMed: 19671850]

16. Salido M, Pijuan L, Martinez-Aviles L, et al. Increased ALK gene copy number and amplification are frequent in non-small cell lung cancer. J Thorac Oncol. 2011; 6(1):21-27. [PubMed: 21107285]

17. Shaw AT, Yeap BY, Mino-Kenudson M, et al. Clinical features and outcome of patients with nonsmall-cell lung cancer who harbor EML4-ALK. J Clin Oncol. 2009; 27(26):4247-4253. [PubMed: 19667264]

18. Shaw AT, Yeap BY, Solomon BJ, et al. Effect of crizotinib on overall survival in patients with advanced non-small-cell lung cancer harbouring ALK gene rearrangement: a retrospective analysis. Lancet Oncol. 2011; 12(11):1004-1012. [PubMed: 21933749]

19. Shinmura K, Kageyama S, Tao H, et al. EML4-ALK fusion transcripts, but no NPM-, TPM3-, CLTC-, ATIC-, or TFG-ALK fusion transcripts, in non-small cell lung carcinomas. Lung Cancer. 2008; 61(2):163-169. [PubMed: 18242762]

20. Kim H, Yoo S-B, Choe J-Y, et al. Detection of ALK gene rearrangement in non-small cell lung cancer: a comparison of fluorescence in situ hybridization and chromogenic in situ hybridization with correlation of ALK protein expression. J Thorac Oncol. 2011; 6(8):1359-1366. [PubMed: 21587085]

21. Hillier S, Grimmer-Somers K, Merlin T, et al. FORM: an Australian method for formulating and grading recommendations in evidence-based clinical guidelines. BMC Med Res Methodol. 2011; 11:23. [PubMed: 21356039] 
22. Merlin T, Weston A, Tooher R. Extending an evidence hierarchy to include topics other than treatment: revising the Australian 'levels of evidence'. BMC Med Res Methodol. 2009; 9:34. [PubMed: 19519887]

23. Shea BJ, Grimshaw JM, Wells GA, et al. Development of AMSTAR: a measurement tool to assess the methodological quality of systematic reviews. BMC Med Res Methodol. 2007; 7:10. [PubMed: 17302989]

24. Scottish Intercollegiate Guidelines Network. SIGN 50: A Guideline Developers' HandbookMethodology Checklist 2: Randomized Controlled Trials. Edinburgh, Scotland: Scottish Intercollegiate Guidelines Network; 2008.

25. Shigematsu H, Lin L, Takahashi T, et al. Clinical and biological features associated with epidermal growth factor receptor gene mutations in lung cancers. J Natl Cancer Inst. 2005; 97(5):339-346. [PubMed: 15741570]

26. Mitsudomi T, Morita S, Yatabe Y, et al. Gefitinib versus cisplatin plus docetaxel in patients with non-small-cell lung cancer harbouring mutations of the epidermal growth factor receptor (WJTOG3405): an open label, randomised phase 3 trial. Lancet Oncol. 2010; 11(2):121-128. [PubMed: 20022809]

27. Rosell R, Moran T, Queralt C, et al. Screening for epidermal growth factor receptor mutations in lung cancer. N Engl J Med. 2009; 361(10):958-967. [PubMed: 19692684]

28. Douillard JY, Shepherd FA, Hirsh V, et al. Molecular predictors of outcome with gefitinib and docetaxel in previously treated non-small-cell lung cancer: data from the randomized phase III INTEREST trial. J Clin Oncol. 2010; 28(5):744-752. [PubMed: 20038723]

29. Morinaga R, Okamoto I, Fujita Y, et al. Association of epidermal growth factor receptor (EGFR) gene mutations with EGFR amplification in advanced non-small cell lung cancer. Cancer Sci. 2008; 99(12):2455-2460. [PubMed: 18957054]

30. Sun Y, Ren Y, Fang Z, et al. Lung adenocarcinoma from East Asian never-smokers is a disease largely defined by targetable oncogenic mutant kinases. J Clin Oncol. 2010; 28(30):4616-4620. [PubMed: 20855837]

31. Zhang X, Zhang S, Yang X, et al. Fusion of EML4 and ALK is associated with development of lung adenocarcinomas lacking EGFR and KRAS mutations and is correlated with ALK expression. Mol Cancer. 2010; 9:188. [PubMed: 20624322]

32. Girard N, Sima CS, Jackman DM, et al. Nomogram to predict the presence of EGFR activating mutation in lung adenocarcinoma. Eur Respir J. 2012; 39(2):366-372. [PubMed: 21778168]

33. Dogan S, Shen R, Ang DC, et al. Molecular epidemiology of EGFR and KRAS mutations in 3,026 lung adenocarcinomas: higher susceptibility of women to smoking-related KRAS-mutant cancers. Clin Cancer Res. 2012; 18(22):6169-6177. [PubMed: 23014527]

34. National Comprehensive Cancer Network. [accessed October 16, 2012] The NCCN clinical practice guidelines in oncology (NCCN guidelines) for non-small cell lung cancer. Version 3.2012. Published 2012. www.ncen.org

35. Liu Y, Xu ML, Zhong HH, Heng WJ, Wu BQ. EGFR mutations are more frequent in welldifferentiated than in poor-differentiated lung adenocarcinomas. Pathol Oncol Res. 2008; 14(4): 373-379. [PubMed: 18985444]

36. Rekhtman N, Paik PK, Arcila ME, et al. Clarifying the spectrum of driver oncogene mutations in biomarker-verified squamous carcinoma of lung: lack of EGFR/KRAS and presence of PIK3CA/ AKT1 mutations. Clin Cancer Res. 2012; 18(4):1167-1176. [PubMed: 22228640]

37. Ohtsuka K, Ohnishi H, Furuyashiki G, et al. Clinicopathological and biological significance of tyrosine kinase domain gene mutations and overex-pression of epidermal growth factor receptor for lung adenocarcinoma. J Thorac Oncol. 2006; 1(8):787-795. [PubMed: 17409961]

38. Kosaka T, Yatabe Y, Endoh H, Kuwano H, Takahashi T, Mitsudomi T. Mutations of the epidermal growth factor receptor gene in lung cancer: biological and clinical implications. Cancer Res. 2004; 64(24):8919-8923. [PubMed: 15604253]

39. Takahashi T, Sonobe M, Kobayashi M, et al. Clinicopathologic features of non-small-cell lung cancer with EML4-ALK fusion gene. Ann Surg Oncol. 2010; 17(3):889-897. [PubMed: 20183914] 
40. Yoshida A, Tsuta K, Watanabe S, et al. Frequent ALK rearrangement and TTF-1/p63 coexpression in lung adenocarcinoma with signet-ring cell component. Lung Cancer. 2011; 72(3): 309-315. [PubMed: 21036415]

41. Chaft JE, Rekhtman N, Ladanyi M, Riely GJ. ALK-rearranged lung cancer: adenosquamous lung cancer masquerading as pure squamous carcinoma. J Thorac Oncol. 2012; 7(4):768-769. [PubMed: 22425930]

42. Sartori G, Cavazza A, Sgambato A, et al. EGFR and K-ras mutations along the spectrum of pulmonary epithelial tumors of the lung and elaboration of a combined clinicopathologic and molecular scoring system to predict clinical responsiveness to EGFR inhibitors. Am J Clin Pathol. 2009; 131(4):478-489. [PubMed: 19289583]

43. Sugio K, Uramoto H, Ono K, et al. Mutations within the tyrosine kinase domain of EGFR gene specifically occur in lung adenocarcinoma patients with a low exposure of tobacco smoking. Br J Cancer. 2006; 94(6):896-903. [PubMed: 16552419]

44. Tsao AS, Tang XM, Sabloff B, et al. Clinicopathologic characteristics of the EGFR gene mutation in non-small cell lung cancer. J Thorac Oncol. 2006; 1(3):231-239. [PubMed: 17409862]

45. Marchetti A, Martella C, Felicioni L, et al. EGFR mutations in non-small-cell lung cancer: analysis of a large series of cases and development of a rapid and sensitive method for diagnostic screening with potential implications on pharmacologic treatment. J Clin Oncol. 2005; 23(4):857-865. [PubMed: 15681531]

46. Tam IY, Chung LP, Suen WS, et al. Distinct epidermal growth factor receptor and KRAS mutation patterns in non-small cell lung cancer patients with different tobacco exposure and clinicopathologic features. Clin Cancer Res. 2006; 12(5):1647-1653. [PubMed: 16533793]

47. Pao W, Miller V, Zakowski M, et al. EGF receptor gene mutations are common in lung cancers from "never smokers" and are associated with sensitivity of tumors to gefitinib and erlotinib. Proc Natl Acad Sci U S A. 2004; 101(36):13306-13311. [PubMed: 15329413]

48. Huang SF, Liu HP, Li LH, et al. High frequency of epidermal growth factor receptor mutations with complex patterns in non-small cell lung cancers related to gefitinib responsiveness in Taiwan. Clin Cancer Res. 2004; 10(24):8195-8203. [PubMed: 15623594]

49. Sonobe M, Manabe T, Wada H, Tanaka F. Mutations in the epidermal growth factor receptor gene are linked to smoking-independent, lung adenocarcinoma. Br J Cancer. 2005; 93(3):355-363. [PubMed: 16052218]

50. Tokumo M, Toyooka S, Kiura K, et al. The relationship between epidermal growth factor receptor mutations and clinicopathologic features in non-small cell lung cancers. Clin Cancer Res. 2005; 11(3):1167-1173. [PubMed: 15709185]

51. Tomizawa Y, Iijima H, Sunaga N, et al. Clinicopathologic significance of the mutations of the epidermal growth factor receptor gene in patients with non-small cell lung cancer. Clin Cancer Res. 2005; 11(19 pt 1):6816-6822. [PubMed: 16203769]

52. Qin BM, Chen X, Zhu JD, Pei DQ. Identification of EGFR kinase domain mutations among lung cancer patients in China: implication for targeted cancer therapy. Cell Res. 2005; 15(3):212-217. [PubMed: 15780185]

53. Han SW, Kim TY, Hwang PG, et al. Predictive and prognostic impact of epidermal growth factor receptor mutation in non-small-cell lung cancer patients treated with gefitinib. J Clin Oncol. 2005; 23(11):2493-2501. [PubMed: 15710947]

54. Cappuzzo F, Hirsch FR, Rossi E, et al. Epidermal growth factor receptor gene and protein and gefitinib sensitivity in non-small-cell lung cancer. J Natl Cancer Inst. 2005; 97(9):643-655. [PubMed: 15870435]

55. Wu CC, Hsu HY, Liu HP, et al. Reversed mutation rates of KRAS and EGFR genes in adenocarcinoma of the lung in Taiwan and their implications. Cancer. 2008; 113(11):3199-3208. [PubMed: 18932251]

56. Chou TY, Chiu CH, Li LH, et al. Mutation in the tyrosine kinase domain of epidermal growth factor receptor is a predictive and prognostic factor for gefitinib treatment in patients with nonsmall cell lung cancer. Clin Cancer Res. 2005; 11(10):3750-3757. [PubMed: 15897572] 
57. Park S, Holmes-Tisch AJ, Cho EY, et al. Discordance of molecular biomarkers associated with epidermal growth factor receptor pathway between primary tumors and lymph node metastasis in non-small cell lung cancer. J Thorac Oncol. 2009; 4(7):809-815. [PubMed: 19487967]

58. Park SH, Ha SY, Lee JI, et al. Epidermal growth factor receptor mutations and the clinical outcome in male smokers with squamous cell carcinoma of lung. J Korean Med Sci. 2009; 24(3):448-452. [PubMed: 19543508]

59. Gandara DR, Grimminger P, Mack PC, et al. Association of epidermal growth factor receptor activating mutations with low ERCC1 gene expression in non-small cell lung cancer. $\mathrm{J}$ Thorac Oncol. 2010; 5(12):1933-1938. [PubMed: 20975603]

60. Tsao MS, Sakurada A, Ding K, et al. Prognostic and predictive value of epidermal growth factor receptor tyrosine kinase domain mutation status and gene copy number for adjuvant chemotherapy in non-small cell lung cancer. J Thorac Oncol. 2011; 6(1):139-147. [PubMed: 21107284]

61. Rekhtman N, Ang DC, Sima CS, Travis WD, Moreira AL. Immunohistochemical algorithm for differentiation of lung adenocarcinoma and squamous cell carcinoma based on large series of whole-tissue sections with validation in small specimens. Mod Pathol. 2011; 24(10):1348-1359. [PubMed: 21623384]

62. Rekhtman N, Brandt SM, Sigel CS, et al. Suitability of thoracic cytology for new therapeutic paradigms in non-small cell lung carcinoma: high accuracy of tumor subtyping and feasibility of EGFR and KRAS molecular testing. J Thorac Oncol. 2011; 6(3):451-458. [PubMed: 21266922]

63. Travis WD, Brambilla E, Noguchi M, et al. International Association for the Study of Lung Cancer/American Thoracic Society/European Respiratory Society international multidisciplinary classification of lung adenocarcinoma. J Thorac Oncol. 2011; 6(2):244-285. [PubMed: 21252716]

64. Fukui T, Tsuta K, Furuta K, et al. Epidermal growth factor receptor mutation status and clinicopathological features of combined small cell carcinoma with adenocarcinoma of the lung. Cancer Sci. 2007; 98(11):1714-1719. [PubMed: 17784875]

65. Morinaga R, Okamoto I, Furuta K, et al. Sequential occurrence of non-small cell and small cell lung cancer with the same EGFR mutation. Lung Cancer. 2007; 58(3):411-413. [PubMed: 17601631]

66. Tatematsu A, Shimizu J, Murakami Y, et al. Epidermal growth factor receptor mutations in small cell lung cancer. Clin Cancer Res. 2008; 14(19):6092-6096. [PubMed: 18829487]

67. Araki J, Okamoto I, Suto R, Ichikawa Y, Sasaki J. Efficacy of the tyrosine kinase inhibitor gefitinib in a patient with metastatic small cell lung cancer. Lung Cancer. 2005; 48(1):141-144. [PubMed: 15777982]

68. Okamoto I, Araki J, Suto R, Shimada M, Nakagawa K, Fukuoka M. EGFR mutation in gefitinibresponsive small-cell lung cancer. Ann Oncol. 2006; 17(6):1028-1029. [PubMed: 16357019]

69. Zakowski MF, Ladanyi M, Kris MG. EGFR mutations in small-cell lung cancers in patients who have never smoked. N Engl J Med. 2006; 355(2):213-215. [PubMed: 16837691]

70. Arcila ME, Oxnard GR, Nafa K, et al. Rebiopsy of lung cancer patients with acquired resistance to EGFR inhibitors and enhanced detection of the T790M mutation using a locked nucleic acid-based assay. Clin Cancer Res. 2011; 17(5):1169-1180. [PubMed: 21248300]

71. Balak MN, Gong Y, Riely GJ, et al. Novel D761Y and common secondary T790M mutations in epidermal growth factor receptor-mutant lung adenocarcinomas with acquired resistance to kinase inhibitors. Clin Cancer Res. 2006; 12(21):6494-6501. [PubMed: 17085664]

72. Dahse R, Berndt A, Kosmehl H. PCR-based testing for therapy-related EGFR mutations in patients with non-small cell lung cancer. Anticancer Res. 2008; 28(4B):2265-2270. [PubMed: 18751405]

73. Macarenco RS, Uphoff TS, Gilmer HF, et al. Salivary gland-type lung carcinomas: an EGFR immunohistochemical, molecular genetic, and mutational analysis study. Mod Pathol. 2008; 21(9): 1168-1175. [PubMed: 18587327]

74. Dahse R, Driemel O, Schwarz S, et al. Epidermal growth factor receptor kinase domain mutations are rare in salivary gland carcinomas. Br J Cancer. 2009; 100(4):623-625. [PubMed: 19174819]

75. Han SW, Kim HP, Jeon YK, et al. Mucoepidermoid carcinoma of lung: potential target of EGFRdirected treatment. Lung Cancer. 2008; 61(1):30-34. [PubMed: 18192072]

76. Rossi A, Galetta D, Gridelli C. Biological prognostic and predictive factors in lung cancer. Oncology. 2009; 77(suppl 1):90-96. [PubMed: 20130436] 
77. Rekhtman N, Tafe LJ, Chaft JE, et al. Distinct profile of driver mutations and clinical features in immunomarker-defined subsets of pulmonary large-cell carcinoma [published online ahead of print November 30, 2012]. Mod Pathol. 10.1038/modpathol.2012.195

78. Rickman OB, Vohra PK, Sanyal B, et al. Analysis of ErbB receptors in pulmonary carcinoid tumors. Clin Cancer Res. 2009; 15(10):3315-3324. [PubMed: 19447869]

79. Paik JH, Choi CM, Kim H, et al. Clinicopathologic implication of ALK rearrangement in surgically resected lung cancer: a proposal of diagnostic algorithm for ALK-rearranged adenocarcinoma. Lung Cancer. 2012; 76(3):403-409. [PubMed: 22129856]

80. Yatabe Y, Matsuo K, Mitsudomi T. Heterogeneous distribution of EGFR mutations is extremely rare in lung adenocarcinoma. J Clin Oncol. 2011; 29(22):2972-2977. [PubMed: 21730270]

81. Girard N, Deshpande C, Azzoli CG, et al. Use of epidermal growth factor receptor/Kirsten rat sarcoma 2 viral oncogene homolog mutation testing to define clonal relationships among multiple lung adenocarcinomas: comparison with clinical guidelines. Chest. 2010; 137(1):46-52. [PubMed: 19376842]

82. Casorzo L, Corigliano M, Ferrero P, Venesio T, Risio M. Evaluation of 7q31 region improves the accuracy of EGFR FISH assay in non small cell lung cancer. Diagn Pathol. 2009; 4:36. [PubMed: 19889201]

83. Sholl LM, Yeap BY, Iafrate AJ, et al. Lung adenocarcinoma with EGFR amplification has distinct clinicopathologic and molecular features in never-smokers. Cancer Res. 2009; 69(21):8341-8348. [PubMed: 19826035]

84. Liang Z, Zhang J, Zeng X, Gao J, Wu S, Liu T. Relationship between EGFR expression, copy number and mutation in lung adenocarcinomas. BMC Cancer. 2010; 10:376. [PubMed: 20637128]

85. Gerlinger M, Rowan AJ, Horswell S, et al. Intratumor heterogeneity and branched evolution revealed by multiregion sequencing. N Engl J Med. 2012; 366(10):883-892. [PubMed: 22397650]

86. Keedy VL, Temin S, Somerfield MR, et al. American Society of Clinical Oncology provisional clinical opinion: epidermal growth factor receptor (EGFR) mutation testing for patients with advanced non-small-cell lung cancer considering first-line EGFR tyrosine kinase inhibitor therapy. J Clin Oncol. 2011; 29(15):2121-2127. [PubMed: 21482992]

87. Marks JL, Broderick S, Zhou Q, et al. Prognostic and therapeutic implications of EGFR and KRAS mutations in resected lung adenocarcinoma. J Thorac Oncol. 2008; 3(2):111-116. [PubMed: 18303429]

88. D’Angelo SP, Janjigian YY, Ahye N, et al. Distinct clinical course of EGFR-mutant resected lung cancers: results of testing of 1118 surgical specimens and effects of adjuvant gefitinib and erlotinib. J Thorac Oncol. 2012; 7(12):1815-1822. [PubMed: 23154553]

89. Mitsudomi T. Erlotinib, gefitinib, or chemotherapy for EGFR mutation-positive lung cancer? Lancet Oncol. 2011; 12(8):710-711. [PubMed: 21783418]

90. Fukuoka M, Wu YL, Thongprasert S, et al. Biomarker analyses and final overall survival results from a phase III, randomized, open-label, first-line study of gefitinib versus carboplatin/paclitaxel in clinically selected patients with advanced non-small-cell lung cancer in Asia (IPASS). J Clin Oncol. 2011; 29(21):2866-2874. [PubMed: 21670455]

91. Maemondo M, Inoue A, Kobayashi K, et al. Gefitinib or chemotherapy for non-small-cell lung cancer with mutated EGFR. N Engl J Med. 2010; 362(25):2380-2388. [PubMed: 20573926]

92. Srinivasan M, Sedmak D, Jewell S. Effect of fixatives and tissue processing on the content and integrity of nucleic acids. Am J Pathol. 2002; 161(6):1961-1971. [PubMed: 12466110]

93. Gillespie JW, Best CJ, Bichsel VE, et al. Evaluation of non-formalin tissue fixation for molecular profiling studies. Am J Pathol. 2002; 160(2):449-457. [PubMed: 11839565]

94. Pirker R, Herth FJ, Kerr KM, et al. Consensus for EGFR mutation testing in non-small cell lung cancer: results from a European workshop. J Thorac Oncol. 2010; 5(10):1706-1713. [PubMed: 20871269]

95. Wong C, DiCioccio RA, Allen HJ, Werness BA, Piver MS. Mutations in BRCA1 from fixed, paraffin-embedded tissue can be artifacts of preservation. Cancer Genet Cytogenet. 1998; 107(1): 21-27. [PubMed: 9809029] 
96. Akbari M, Hansen MD, Halgunset J, Skorpen F, Krokan HE. Low copy number DNA template can render polymerase chain reaction error prone in a sequence-dependent manner. J Mol Diagn. 2005; 7(1):36-39. [PubMed: 15681472]

97. Williams C, Ponten F, Moberg C, et al. A high frequency of sequence alterations is due to formalin fixation of archival specimens. Am J Pathol. 1999; 155(5):1467-1471. [PubMed: 10550302]

98. Wolff AC, Hammond ME, Schwartz JN, et al. American Society of Clinical Oncology/College of American Pathologists guideline recommendations for human epidermal growth factor receptor 2 testing in breast cancer. Arch Pathol Lab Med. 2007; 131(1):18-43. [PubMed: 19548375]

99. Aisner DL, Deshpande C, Baloch Z, et al. Evaluation of EGFR mutation status in cytology specimens: an institutional experience [published online ahead of print November 18, 2011]. Diagn Cytopathol. 10.1002/dc.21851

100. Malapelle U, Bellevicine C, Zeppa P, Palombini L, Troncone G. Cytology-based gene mutation tests to predict response to anti-epidermal growth factor receptor therapy: a review. Diagn Cytopathol. 2011; 39(9):703-710. [PubMed: 21837660]

101. da Cunha Santos G, Saieg MA, Geddie W, Leighl N. EGFR gene status in cytological samples of nonsmall cell lung carcinoma: controversies and opportunities. Cancer Cytopathol. 2011; 119(2): 80-91. [PubMed: 21400669]

102. Fiallo P, Williams DL, Chan GP, Gillis TP. Effects of fixation on polymerase chain reaction detection of Mycobacterium leprae. J Clin Microbiol. 1992; 30(12):3095-3098. [PubMed: 1452690]

103. Wilson IG. Inhibition and facilitation of nucleic acid amplification. Appl Environ Microbiol. 1997; 63(10):3741-3751. [PubMed: 9327537]

104. Baloglu G, Haholu A, Kucukodaci Z, Yilmaz I, Yildirim S, Baloglu H. The effects of tissue fixation alternatives on DNA content: a study on normal colon tissue. Appl Immunohistochem Mol Morphol. 2008; 16(5):485-492. [PubMed: 18594471]

105. Moore JL, Aros M, Steudel KG, Cheng KC. Fixation and decalcification of adult zebrafish for histological, immunocytochemical, and genotypic analysis. Biotechniques. 2002; 32(2):296-298. [PubMed: 11848405]

106. Fox CH, Johnson FB, Whiting J, Roller PP. Formaldehyde fixation. J Histochem Cytochem. 1985; 33(8):845-853. [PubMed: 3894502]

107. College of American Pathologists. [Accessed April 11, 2012] CAP Laboratory accreditation checklists. http://www.cap.org/apps/cap.portal

108. Betz BL, Roh MH, Weigelin HC, et al. The application of molecular diagnostic studies interrogating EGFR and KRAS mutations to stained cytologic smears of lung carcinoma. Am J Clin Pathol. 2011; 136(4):564-571. [PubMed: 21917678]

109. Billah S, Stewart J, Staerkel G, Chen S, Gong Y, Guo M. EGFR and KRAS mutations in lung carcinoma. Cancer Cytopathol. 2011; 119(2):111-117. [PubMed: 21400670]

110. Chen CM, Chang JW, Cheung YC, et al. Computed tomography-guided core-needle biopsy specimens demonstrate epidermal growth factor receptor mutations in patients with non-smallcell lung cancer. Acta Radiol. 2008; 49(9):991-994. [PubMed: 18651255]

111. Boldrini L, Gisfredi S, Ursino S, et al. Mutational analysis in cytological specimens of advanced lung adenocarcinoma: a sensitive method for molecular diagnosis. J Thorac Oncol. 2007; 2(12): 1086-1090. [PubMed: 18090579]

112. Fassina A, Gazziero A, Zardo D, Corradin M, Aldighieri E, Rossi GP. Detection of EGFR and KRAS mutations on transthoracic needle aspiration of lung nodules by high resolution melting analysis. J Clin Pathol. 2009; 62(12):1096-1102. [PubMed: 19640859]

113. Smouse JH, Cibas ES, Janne PA, Joshi VA, Zou KH, Lindeman NI. EGFR mutations are detected comparably in cytologic and surgical pathology specimens of nonsmall cell lung cancer. Cancer Cytopathol. 2009; 117(1):67-72.

114. Lozano MD, Zulueta JJ, Echeveste JI, et al. Assessment of epidermal growth factor receptor and K-ras mutation status in cytological stained smears of non-small cell lung cancer patients: correlation with clinical outcomes. Oncologist. 2011; 16(6):877-885. [PubMed: 21572125] 
115. Janne PA, Borras AM, Kuang Y, et al. A rapid and sensitive enzymatic method for epidermal growth factor receptor mutation screening. Clin Cancer Res. 2006; 12(3 pt 1):751-758. [PubMed: 16467085]

116. Pan QL, Pao W, Ladanyi M. Rapid polymerase chain reaction-based detection of epidermal growth factor receptor gene mutations in lung adenocarcinomas. J Mol Diagn. 2005; 7(3):396403. [PubMed: 16049312]

117. Sasaki H, Endo K, Konishi A, et al. EGFR mutation status in Japanese lung cancer patients: genotyping analysis using LightCycler. Clin Cancer Res. 2005; 11(8):2924-2929. [PubMed: 15837743]

118. Croft DT Jr, Jordan RM, Patney HL, et al. Performance of whole-genome amplified DNA isolated from serum and plasma on high-density single nucleotide polymorphism arrays. J Mol Diagn. 2008; 10(3):249-257. [PubMed: 18403606]

119. Endo K, Konishi A, Sasaki H, et al. Epidermal growth factor receptor gene mutation in non-small cell lung cancer using highly sensitive and fast TaqMan PCR assay. Lung Cancer. 2005; 50(3): 375-384. [PubMed: 16199108]

120. Hoshi K, Takakura H, Mitani Y, et al. Rapid detection of epidermal growth factor receptor mutations in lung cancer by the SMart-Amplification Process. Clin Cancer Res. 2007; 13(17): 4974-4983. [PubMed: 17785547]

121. Heideman DAM, Thunnissen FB, Doeleman M, et al. A panel of high resolution melting (HRM) technology-based assays with direct sequencing possibility for effective mutation screening of EGFR and K-ras genes. Cell Oncol. 2009; 31(5):329-333. [PubMed: 19759413]

122. Miyazawa H, Tanaka T, Nagai Y, et al. Peptide nucleic acid-locked nucleic acid polymerase chain reaction clamp-based detection test for gefitinib-refractory $\mathrm{T} 790 \mathrm{M}$ epidermal growth factor receptor mutation. Cancer Sci. 2008; 99(3):595-600. [PubMed: 18271876]

123. Li AR, Chitale D, Riely GJ, et al. EGFR mutations in lung adenocarcinomas: clinical testing experience and relationship to EGFR gene copy number and immunohistochemical expression. $\mathbf{J}$ Mol Diagn. 2008; 10(3):242-248. [PubMed: 18403609]

124. Soh J, Okumura N, Lockwood WW, et al. Oncogene mutations, copy number gains and mutant allele specific imbalance (MASI) frequently occur together in tumor cells. PLoS ONE. 2009; 4(10):e7464. [PubMed: 19826477]

125. Thunnissen E, Bovee JV, Bruinsma H, et al. EGFR and KRAS quality assurance schemes in pathology: generating normative data for molecular predictive marker analysis in targeted therapy. J Clin Pathol. 2011; 64(10):884-892. [PubMed: 21947301]

126. Eberhard DA, Giaccone G, Johnson BE. Biomarkers of response to epidermal growth factor receptor inhibitors in Non-Small-Cell Lung Cancer Working Group: standardization for use in the clinical trial setting. J Clin Oncol. 2008; 26(6):983-994. [PubMed: 18281673]

127. Sieben NL, ter Haar NT, Cornelisse CJ, Fleuren GJ, Cleton-Jansen AM. PCR artifacts in LOH and MSI analysis of microdissected tumor cells. Hum Pathol. 2000; 31(11):1414-1419. [PubMed: 11112218]

128. Molina-Vila MA, Bertran-Alamillo J, Reguart N, et al. A sensitive method for detecting EGFR mutations in non-small cell lung cancer samples with few tumor cells. J Thorac Oncol. 2008; 3(11):1224-1235. [PubMed: 18978556]

129. Takano T, Ohe Y, Sakamoto H, et al. Epidermal growth factor receptor gene mutations and increased copy numbers predict gefitinib sensitivity in patients with recurrent non-small-cell lung cancer. J Clin Oncol. 2005; 23(28):6829-6837. [PubMed: 15998907]

130. Horiike A, Kimura H, Nishio K, et al. Detection of epidermal growth factor receptor mutation in transbronchial needle aspirates of non-small cell lung cancer. Chest. 2007; 131(6):1628-1634. [PubMed: 17565015]

131. Yatabe Y, Hida T, Horio Y, Kosaka T, Takahashi T, Mitsudomi T. A rapid, sensitive assay to detect EGFR mutation in small biopsy specimens from lung cancer. J Mol Diagn. 2006; 8(3): 335-341. [PubMed: 16825506]

132. Miyamae Y, Shimizu K, Mitani Y, et al. Mutation detection of epidermal growth factor receptor and KRAS genes using the smart amplification process version 2 from formalin-fixed, paraffinembedded lung cancer tissue. J Mol Diagn. 2010; 12(2):257-264. [PubMed: 20093389] 
133. Kawada I, Soejima K, Watanabe H, et al. An alternative method for screening EGFR mutation using RFLP in non-small cell lung cancer patients. J Thorac Oncol. 2008; 3(10):1096-1103. [PubMed: 18827604]

134. van Eijk R, Licht J, Schrumpf M, et al. Rapid KRAS, EGFR, BRAF and PIK3CA mutation analysis of fine needle aspirates from non-small-cell lung cancer using allele-specific qPCR. PLoS ONE. 2011; 6(3):e17791. [PubMed: 21408138]

135. Do H, Krypuy M, Mitchell PL, Fox SB, Dobrovic A. High resolution melting analysis for rapid and sensitive EGFR and KRAS mutation detection in formalin fixed paraffin embedded biopsies. BMC Cancer. 2008; 8:142. [PubMed: 18495026]

136. Willmore-Payne C, Holden JA, Layfied LJ. Detection of epidermal growth factor receptor and human epidermal growth factor receptor 2 activating mutations in lung adenocarcinoma by highresolution melting amplicon analysis: correlation with gene copy number, protein expression, and hormone receptor expression. Hum Pathol. 2006; 37(6):755-763. [PubMed: 16733218]

137. Pao W, Miller VA, Politi KA, et al. Acquired resistance of lung adenocarcinomas to gefitinib or erlotinib is associated with a second mutation in the EGFR kinase domain. PLoS Med. 2005; 2(3):e73. [PubMed: 15737014]

138. Santis G, Angell R, Nickless G, et al. Screening for EGFR and KRAS mutations in endobronchial ultrasound derived transbronchial needle aspirates in non-small cell lung cancer using COLDPCR. PLoS ONE. 2011; 6(9):e25191. [PubMed: 21949883]

139. Sueoka N, Sato A, Eguchi H, et al. Mutation profile of EGFR gene detected by denaturing highperformance liquid chromatography in Japanese lung cancer patients. J Cancer Res Clin Oncol. 2007; 133(2):93-102. [PubMed: 16947044]

140. Engelman JA, Cantley LC. The role of the ErbB family members in non-small cell lung cancers sensitive to epidermal growth factor receptor kinase inhibitors. Clin Cancer Res. 2006; $12(14 \mathrm{pt}$ 2):4372s-4376s. [PubMed: 16857813]

141. Jiang SX, Yamashita K, Yamamoto M, et al. EGFR genetic heterogeneity of nonsmall cell lung cancers contributing to acquired gefitinib resistance. Int J Cancer. 2008; 123(11):2480-2486. [PubMed: 18785203]

142. Krypuy M, Newnham GM, Thomas DM, Conron M, Dobrovic A. High resolution melting analysis for the rapid and sensitive detection of mutations in clinical samples: KRAS codon 12 and 13 mutations in non-small cell lung cancer. BMC Cancer. 2006; 6:295. [PubMed: 17184525]

143. Kuang Y, Rogers A, Yeap BY, et al. Noninvasive detection of EGFR T790M in gefitinib or erlotinib resistant non-small cell lung cancer. Clin Cancer Res. 2009; 15(8):2630-2636. [PubMed: 19351754]

144. Ogino S, Meyerhardt JA, Cantor M, et al. Molecular alterations in tumors and response to combination chemotherapy with gefitinib for advanced colorectal cancer. Clin Cancer Res. 2005; 11(18):6650-6656. [PubMed: 16166444]

145. Ohnishi H, Ohtsuka K, Ooide A, Matsushima S, Goya T, Watanabe T. A simple and sensitive method for detecting major mutations within the tyrosine kinase domain of the epidermal growth factor receptor gene in non-small-cell lung carcinoma. Diagn Mol Pathol. 2006; 15(2):101-108. [PubMed: 16778591]

146. Pham D, Kris MG, Riely GJ, et al. Use of cigarette-smoking history to estimate the likelihood of mutations in epidermal growth factor receptor gene exons 19 and 21 in lung adenocarcinomas. $\mathbf{J}$ Clin Oncol. 2006; 24(11):1700-1704. [PubMed: 16505411]

147. Su Z, Dias-Santagata D, Duke M, et al. A platform for rapid detection of multiple oncogenic mutations with relevance to targeted therapy in non-small-cell lung cancer. J Mol Diagn. 2011; 13(1):74-84. [PubMed: 21227397]

148. Azzoli CG, Baker S Jr, Temin S, et al. American Society of Clinical Oncology Clinical Practice Guideline update on chemotherapy for stage IV non-small-cell lung cancer. J Clin Oncol. 2009; 27(36):6251-6266. [PubMed: 19917871]

149. Bosari S, Marchetti A, Buttitta F, et al. Detection of p53 mutations by single-strand conformation polymorphisms (SSCP) gel electrophoresis: a comparative study of radioactive and nonradioactive silver-stained SSCP analysis. Diagn Mol Pathol. 1995; 4(4):249-255. [PubMed: 8634780] 
150. Fan X, Furnari FB, Cavenee WK, Castresana JS. Non-isotopic silver-stained SSCP is more sensitive than automated direct sequencing for the detection of PTEN mutations in a mixture of DNA extracted from normal and tumor cells. Int J Oncol. 2001; 18(5):1023-1026. [PubMed: 11295051]

151. Fukui T, Ohe Y, Tsuta K, et al. Prospective study of the accuracy of EGFR mutational analysis by high-resolution melting analysis in small samples obtained from patients with non-small cell lung cancer. Clin Cancer Res. 2008; 14(15):4751-4757. [PubMed: 18676744]

152. Kimura H, Kasahara K, Kawaishi M, et al. Detection of epidermal growth factor receptor mutations in serum as a predictor of the response to gefitinib in patients with non-small-cell lung cancer. Clin Cancer Res. 2006; 12(13):3915-3921. [PubMed: 16818687]

153. Newton CR, Graham A, Heptinstall LE, et al. Analysis of any point mutation in DNA: the amplification refractory mutation system (ARMS). Nucleic Acids Res. 1989; 17(7):2503-2516. [PubMed: 2785681]

154. Takano T, Ohe Y, Tsuta K, et al. Epidermal growth factor receptor mutation detection using highresolution melting analysis predicts outcomes in patients with advanced non small cell lung cancer treated with gefitinib. Clin Cancer Res. 2007; 13(18 pt 1):5385-5390. [PubMed: 17875767]

155. Whitcombe D, Theaker J, Guy SP, Brown T, Little S. Detection of PCR products using selfprobing amplicons and fluorescence. Nat Biotechnol. 1999; 17(8):804-807. [PubMed: 10429248]

156. Li J, Wang L, Janne PA, Makrigiorgos GM. Coamplification at lower denaturation temperaturePCR increases mutation-detection selectivity of Taq-Man-based real-time PCR. Clin Chem. 2009; 55(4):748-756. [PubMed: 19233916]

157. Beadling C, Neff TL, Heinrich MC, et al. Combining highly multiplexed PCR with semiconductor-based sequencing for rapid cancer genotyping. J Mol Diagn. 2012 pii:S1525S1578(12)00305-4.

158. Buttitta F, Felicioni L, Del Grammastro M, et al. Effective assessment of EGFR mutation status in bronchoalveolar lavage and pleural fluids by next-generation sequencing. Clin Cancer Res. 2013; 19(3):691-698. [PubMed: 23243218]

159. Querings S, Altmuller J, Ansen S, et al. Benchmarking of mutation diagnostics in clinical lung cancer specimens. PLoS ONE. 2011; 6(5):e19601. [PubMed: 21573178]

160. Tsiatis AC, Norris-Kirby A, Rich RG, et al. Comparison of Sanger sequencing, pyrosequencing, and melting curve analysis for the detection of KRAS mutations: diagnostic and clinical implications. J Mol Diagn. 2010; 12(4):425-432. [PubMed: 20431034]

161. Paez JG, Janne PA, Lee JC, et al. EGFR mutations in lung cancer: correlation with clinical response to gefitinib therapy. Science. 2004; 304(5676):1497-1500. [PubMed: 15118125]

162. Lynch TJ, Bell DW, Sordella R, et al. Activating mutations in the epidermal growth factor receptor underlying responsiveness of non-small-cell lung cancer to gefitinib. N Engl J Med. 2004; 350(21):2129-2139. [PubMed: 15118073]

163. Tsao MS, Sakurada A, Cutz JC, et al. Erlotinib in lung cancer-molecular and clinical predictors of outcome. N Engl J Med. 2005; 353(2):133-144. [PubMed: 16014883]

164. Ward R, Hawkins N, O'Grady R, et al. Restriction endonuclease-mediated selective polymerase chain reaction: a novel assay for the detection of K-ras mutations in clinical samples. Am $\mathrm{J}$ Pathol. 1998; 153(2):373-379. [PubMed: 9708798]

165. Diagnostic Innovations. [Accessed June 7, 2011] Urgent field safety notice 001. http:// www.swissmedic.ch/recalllists_dl/02354/Vk_20090603_14-e1.pdf. Published 2009

166. He M, Capelletti M, Nafa K, et al. EGFR exon 19 insertions: a new family of sensitizing EGFR mutations in lung adenocarcinoma. Clin Cancer Res. 2012; 18(6):1790-1797. [PubMed: 22190593]

167. Yasuda H, Kobayashi S, Costa DB. EGFR exon 20 insertion mutations in non-small-cell lung cancer: preclinical data and clinical implications. Lancet Oncol. 2012; 13(1):e23-e31. [PubMed: 21764376]

168. Kobayashi S, Boggon TJ, Dayaram T, et al. EGFR mutation and resistance of non-small-cell lung cancer to gefitinib. N Engl J Med. 2005; 352(8):786-792. [PubMed: 15728811] 
169. Arcila ME, Nafa K, Chaft JE, et al. EGFR exon 20 insertion mutations in lung adenocarcinomas: prevalence, molecular heterogeneity, and clinicopathologic characteristics. Mol Cancer Ther. 2013; 12(2):220-229. [PubMed: 23371856]

170. Miller VA, Riely GJ, Zakowski MF, et al. Molecular characteristics of bronchioloalveolar carcinoma and adenocarcinoma, bronchioloalveolar carcinoma subtype, predict response to erlotinib. J Clin Oncol. 2008; 26(9):1472-1478. [PubMed: 18349398]

171. Sholl LM, Xiao Y, Joshi V, et al. EGFR mutation is a better predictor of response to tyrosine kinase inhibitors in non-small cell lung carcinoma than FISH, CISH, and immunohistochemistry. Am J Clin Pathol. 2010; 133(6):922-934. [PubMed: 20472851]

172. Khambata-Ford S, Harbison CT, Hart LL, et al. Analysis of potential predictive markers of cetuximab benefit in BMS099, a phase III study of cetuximab and first-line taxane/carboplatin in advanced non-small-cell lung cancer. J Clin Oncol. 2010; 28(6):918-927. [PubMed: 20100958]

173. Yu J, Kane S, Wu J, et al. Mutation-specific antibodies for the detection of EGFR mutations in non-small-cell lung cancer. Clin Cancer Res. 2009; 15(9):3023-3028. [PubMed: 19366827]

174. Kato Y, Peled N, Wynes MW, et al. Novel epidermal growth factor receptor mutation-specific antibodies for non-small cell lung cancer: immunohistochemistry as a possible screening method for epidermal growth factor receptor mutations. J Thorac Oncol. 2010; 5(10):1551-1558. [PubMed: 20697298]

175. Kawahara A, Yamamoto C, Nakashima K, et al. Molecular diagnosis of activating EGFR mutations in non-small cell lung cancer using mutation-specific antibodies for immunohistochemical analysis. Clin Cancer Res. 2010; 16(12):3163-3170. [PubMed: 20423982]

176. Brevet M, Arcila M, Ladanyi M. Assessment of EGFR mutation status in lung adenocarcinoma by immunohistochemistry using antibodies specific to the two major forms of mutant EGFR. J Mol Diagn. 2010; 12(2):169-176. [PubMed: 20093391]

177. Kozu Y, Tsuta K, Kohno T, et al. The usefulness of mutation-specific antibodies in detecting epidermal growth factor receptor mutations and in predicting response to tyrosine kinase inhibitor therapy in lung adenocarcinoma. Lung Cancer. 2011; 73(1):45-50. [PubMed: 21129809]

178. Kawahara A, Azuma K, Sumi A, et al. Identification of non-small-cell lung cancer with activating EGFR mutations in malignant effusion and cerebrospinal fluid: rapid and sensitive detection of exon 19 deletion E746-A750 and exon 21 L858R mutation by immunocytochemistry. Lung Cancer. 2011; 74(1):35-40. [PubMed: 21444121]

179. Hasanovic A, Ang D, Moreira AL, Zakowski MF. Use of mutation specific antibodies to detect EGFR status in small biopsy and cytology specimens of lung adenocarcinoma. Lung Cancer. 2012; 77(2):299-305. [PubMed: 22542171]

180. Zhu CQ, da Cunha Santos G, Ding K, et al. Role of KRAS and EGFR as biomarkers of response to erlotinib in National Cancer Institute of Canada Clinical Trials Group Study BR.21. J Clin Oncol. 2008; 26(26):4268-4275. [PubMed: 18626007]

181. Testa JR, Siegfried JM. Chromosome abnormalities in human non-small cell lung cancer. Cancer Res. 1992; 52(9 suppl):2702s-2706s. [PubMed: 1314134]

182. Hirsch FR, Varella-Garcia M, McCoy J, et al. Increased epidermal growth factor receptor gene copy number detected by fluorescence in situ hybridization associates with increased sensitivity to gefitinib in patients with bronchioloal-veolar carcinoma subtypes: a Southwest Oncology Group Study. J Clin Oncol. 2005; 23(28):6838-6845. [PubMed: 15998906]

183. Inoue A, Kobayashi K, Usui K, et al. First-line gefitinib for patients with advanced non-small-cell lung cancer harboring epidermal growth factor receptor mutations without indication for chemotherapy. J Clin Oncol. 2009; 27(9):1394-1400. [PubMed: 19224850]

184. Lee YJ, Park IK, Park MS, et al. Activating mutations within the EGFR kinase domain: a molecular predictor of disease-free survival in resected pulmonary adenocarcinoma. J Cancer Res Clin Oncol. 2009; 135(12):1647-1654. [PubMed: 19517135]

185. Soh J, Toyooka S, Ichihara S, et al. Impact of HER2 and EGFR gene status on gefitinib-treated patients with nonsmall-cell lung cancer. Int J Cancer. 2007; 121(5):1162-1167. [PubMed: 17487844] 
186. Broet P, Dalmasso C, Tan EH, et al. Genomic profiles specific to patient ethnicity in lung adenocarcinoma. Clin Cancer Res. 2011; 17(11):3542-3550. [PubMed: 21521776]

187. Leidner RS, Fu P, Clifford B, et al. Genetic abnormalities of the EGFR pathway in African American patients with non-small-cell lung cancer. J Clin Oncol. 2009; 27(33):5620-5626. [PubMed: 19786660]

188. Reinersman JM, Johnson ML, Riely GJ, et al. Frequency of EGFR and KRAS mutations in lung adenocarcinomas in African Americans. J Thorac Oncol. 2011; 6(1):28-31. [PubMed: 21107288]

189. Riely GJ, Kris MG, Rosenbaum D, et al. Frequency and distinctive spectrum of KRAS mutations in never smokers with lung adenocarcinoma. Clin Cancer Res. 2008; 14(18):5731-5734. [PubMed: 18794081]

190. Thu KL, Vucic EA, Chari R, et al. Lung adenocarcinoma of never smokers and smokers harbor differential regions of genetic alteration and exhibit different levels of genomic instability. PLoS ONE. 2012; 7(3):e33003. [PubMed: 22412972]

191. Massarelli E, Varella-Garcia M, Tang X, et al. KRAS mutation is an important predictor of resistance to therapy with epidermal growth factor receptor tyrosine kinase inhibitors in nonsmall-cell lung cancer. Clin Cancer Res. 2007; 13(10):2890-2896. [PubMed: 17504988]

192. Ludovini V, Bianconi F, Pistola L, et al. Phosphoinositide-3-kinase catalytic alpha and KRAS mutations are important predictors of resistance to therapy with epidermal growth factor receptor tyrosine kinase inhibitors in patients with advanced non-small cell lung cancer. J Thorac Oncol. 2011; 6(4):707-715. [PubMed: 21258250]

193. Hirsch FR, Varella-Garcia M, Cappuzzo F, et al. Combination of EGFR gene copy number and protein expression predicts outcome for advanced non-small-cell lung cancer patients treated with gefitinib. Ann Oncol. 2007; 18(4):752-760. [PubMed: 17317677]

194. Endoh H, Yatabe Y, Kosaka T, Kuwano H, Mitsudomi T. PTEN and PIK3CA expression is associated with prolonged survival after gefitinib treatment in EGFR-mutated lung cancer patients. J Thorac Oncol. 2006; 1(7):629-634. [PubMed: 17409929]

195. Hirsch FR, Kabbinavar F, Eisen T, et al. A randomized, phase II, biomarker-selected study comparing erlotinib to erlotinib intercalated with chemotherapy in first-line therapy for advanced non-small-cell lung cancer. J Clin Oncol. 2011; 29(26):3567-3573. [PubMed: 21825259]

196. Inukai M, Toyooka S, Ito S, et al. Presence of epidermal growth factor receptor gene T790M mutation as a minor clone in non-small cell lung cancer. Cancer Res. 2006; 66(16):7854-7858. [PubMed: 16912157]

197. Tiseo M, Rossi G, Capelletti M, et al. Predictors of gefitinib outcomes in advanced non-small cell lung cancer (NSCLC): study of a comprehensive panel of molecular markers. Lung Cancer. 2010; 67(3):355-360. [PubMed: 19473722]

198. Lara-Guerra H, Waddell TK, Salvarrey MA, et al. Phase II study of preoperative gefitinib in clinical stage I non-small-cell lung cancer. J Clin Oncol. 2009; 27(36):6229-6236. [PubMed: 19884551]

199. Jackman DM, Miller VA, Cioffredi LA, et al. Impact of epidermal growth factor receptor and KRAS mutations on clinical outcomes in previously untreated non-small cell lung cancer patients: results of an online tumor registry of clinical trials. Clin Cancer Res. 2009; 15(16): 5267-5273. [PubMed: 19671843]

200. van Zandwijk N, Mathy A, Boerrigter L, et al. EGFR and KRAS mutations as criteria for treatment with tyrosine kinase inhibitors: retro- and prospective observations in non-small-cell lung cancer. Ann Oncol. 2007; 18(1):99-103. [PubMed: 17060486]

201. Brugger W, Triller N, Blasinska-Morawiec M, et al. Prospective molecular marker analyses of EGFR and KRAS from a randomized, placebo-controlled study of erlotinib maintenance therapy in advanced non-small-cell lung cancer. J Clin Oncol. 2011; 29(31):4113-4120. [PubMed: 21969500]

202. Endo K, Sasaki H, Yano M, et al. Evaluation of the epidermal growth factor receptor gene mutation and copy number in non-small cell lung cancer with gefitinib therapy. Oncol Rep. 2006; 16(3):533-541. [PubMed: 16865253] 
203. O’Byrne KJ, Gatzemeier U, Bondarenko I, et al. Molecular biomarkers in non-small-cell lung cancer: a retrospective analysis of data from the phase 3 FLEX study. Lancet Oncol. 2011; 12(8): 795-805. [PubMed: 21782507]

204. Bean J, Brennan C, Shih JY, et al. MET amplification occurs with or without T790M mutations in EGFR mutant lung tumors with acquired resistance to gefitinib or erlotinib. Proc Natl Acad Sci U S A. 2007; 104(52):20932-20937. [PubMed: 18093943]

205. Engelman JA, Janne PA. Mechanisms of acquired resistance to epidermal growth factor receptor tyrosine kinase inhibitors in non-small cell lung cancer. Clin Cancer Res. 2008; 14(10):28952899. [PubMed: 18483355]

206. Jackman D, Pao W, Riely GJ, et al. Clinical definition of acquired resistance to epidermal growth factor receptor tyrosine kinase inhibitors in non-small-cell lung cancer. J Clin Oncol. 2010; 28(2):357-360. [PubMed: 19949011]

207. Engelman JA, Mukohara T, Zejnullahu K, et al. Allelic dilution obscures detection of a biologically significant resistance mutation in EGFR-amplified lung cancer. J Clin Invest. 2006; 116(10):2695-2706. [PubMed: 16906227]

208. Onitsuka T, Uramoto H, Nose N, et al. Acquired resistance to gefitinib: the contribution of mechanisms other than the T790M, MET, and HGF status. Lung Cancer. 2010; 68(2):198-203. [PubMed: 19589612]

209. Chmielecki J, Foo J, Oxnard GR, et al. Optimization of dosing for EGFR-mutant non-small cell lung cancer with evolutionary cancer modeling. Sci Transl Med. 2011; 3(90):90ra59.

210. Oxnard GR, Miller VA, Robson ME, et al. Screening for germline EGFR T790M mutations through lung cancer genotyping. J Thorac Oncol. 2012; 7(6):1049-1052. [PubMed: 22588155]

211. Bell DW, Lynch TJ, Haserlat SM, et al. Epidermal growth factor receptor mutations and gene amplification in non-small-cell lung cancer: molecular analysis of the IDEAL/INTACT gefitinib trials. J Clin Oncol. 2005; 23(31):8081-8092. [PubMed: 16204011]

212. Nguyen KS, Kobayashi S, Costa DB. Acquired resistance to epidermal growth factor receptor tyrosine kinase inhibitors in non-small-cell lung cancers dependent on the epidermal growth factor receptor pathway. Clin Lung Cancer. 2009; 10(4):281-289. [PubMed: 19632948]

213. Sequist LV, Waltman BA, Dias-Santagata D, et al. Genotypic and histological evolution of lung cancers acquiring resistance to EGFR inhibitors. Sci Transl Med. 2011; 3(75):75ra26.

214. Engelman JA, Zejnullahu K, Mitsudomi T, et al. MET amplification leads to gefitinib resistance in lung cancer by activating ERBB3 signaling. Science. 2007; 316(5827):1039-1043. [PubMed: 17463250]

215. Rikova K, Guo A, Zeng Q, et al. Global survey of phosphotyrosine signaling identifies oncogenic kinases in lung cancer. Cell. 2007; 131(6):1190-1203. [PubMed: 18083107]

216. Takeuchi K, Choi YL, Togashi Y, et al. KIF5B-ALK, a novel fusion oncokinase identified by an immunohistochemistry-based diagnostic system for ALK-positive lung cancer. Clin Cancer Res. 2009; 15(9):3143-3149. [PubMed: 19383809]

217. Camidge DR, Kono SA, Flacco A, et al. Optimizing the detection of lung cancer patients harboring anaplastic lymphoma kinase (ALK) gene rearrangements potentially suitable for ALK inhibitor treatment. Clin Cancer Res. 2010; 16(22):5581-5590. [PubMed: 21062932]

218. Perner S, Wagner PL, Demichelis F, et al. EML4-ALK fusion lung cancer: a rare acquired event. Neoplasia. 2008; 10(3):298-302. [PubMed: 18320074]

219. Wiktor AE, Van Dyke DL, Stupca PJ, et al. Preclinical validation of fluorescence in situ hybridization assays for clinical practice. Genet Med. 2006; 8(1):16-23. [PubMed: 16418595]

220. Mascarello JT, Hirsch B, Kearney HM, et al. Section E9 of the American College of Medical Genetics technical standards and guidelines: fluorescence in situ hybridization. Genet Med. 2011; 13(7):667-675. [PubMed: 21738013]

221. Mino-Kenudson M, Chirieac LR, Law K, et al. A novel, highly sensitive antibody allows for the routine detection of ALK-rearranged lung adenocarcinomas by standard immunohistochemistry. Clin Cancer Res. 2010; 16(5):1561-1571. [PubMed: 20179225]

222. Horn L, Pao W. EML4-ALK: honing in on a new target in non-small-cell lung cancer. J Clin Oncol. 2009; 27(26):4232-4235. [PubMed: 19667260] 
223. Yi ES, Boland JM, Maleszewski JJ, et al. Correlation of IHC and FISH for ALK gene rearrangement in non-small cell lung carcinoma: IHC score algorithm for FISH. J Thorac Oncol. 2011; 6(3):459-465. [PubMed: 21278610]

224. Togashi Y, Soda M, Sakata S, et al. KLC1-ALK: a novel fusion in lung cancer identified using a formalin-fixed paraffin-embedded tissue only. PLoS ONE. 2012; 7(2):e31323. [PubMed: 22347464]

225. Heuckmann JM, Holzel M, Sos ML, et al. ALK mutations conferring differential resistance to structurally diverse ALK inhibitors. Clin Cancer Res. 2011; 17(23):7394-7401. [PubMed: 21948233]

226. Sasaki T, Okuda K, Zheng W, et al. The neuroblastoma-associated F1174L ALK mutation causes resistance to an ALK kinase inhibitor in ALK-translocated cancers. Cancer Res. 2010; 70(24): 10038-10043. [PubMed: 21030459]

227. Sasaki T, Koivunen J, Ogino A, et al. A novel ALK secondary mutation and EGFR signaling cause resistance to ALK kinase inhibitors. Cancer Res. 2011; 71(18):6051-6060. [PubMed: 21791641]

228. Choi YL, Soda M, Yamashita Y, et al. EML4-ALK mutations in lung cancer that confer resistance to ALK inhibitors. N Engl J Med. 2010; 363(18):1734-1739. [PubMed: 20979473]

229. Doebele RC, Pilling AB, Aisner DL, et al. Mechanisms of resistance to crizotinib in patients with ALK gene rearranged non-small cell lung cancer. Clin Cancer Res. 2012; 18(5):1472-1482. [PubMed: 22235099]

230. Katayama R, Shaw AT, Khan TM, et al. Mechanisms of acquired crizotinib resistance in ALKrearranged lung cancers. Sci Transl Med. 2012; 4(120):120ra17.

231. Tiseo M, Gelsomino F, Boggiani D, et al. EGFR and EML4-ALK gene mutations in NSCLC: a case report of erlotinib-resistant patient with both concomitant mutations. Lung Cancer. 2011; 71(2):241-243. [PubMed: 21168933]

232. Kuo YW, Wu SG, Ho CC, Shih JY. Good response to gefitinib in lung adenocarcinoma harboring coexisting EML4-ALK fusion gene and EGFR mutation. J Thorac Oncol. 2010; 5(12):2039_ 2040. [PubMed: 21102267]

233. Department of Health and Human Services. . Clinical laboratory improvement amendments of 1988: final rule. Fed Regist. 1992; 57(40):7001-7186. Codified at 42 CFR 1405-494.

234. Jennings LJ, Smith FA, Halling KC, Persons DL, Kamel-Reid S. Design and analytic validation of BCR-ABL1 quantitative reverse transcription polymerase chain reaction assay for monitoring minimal residual disease. Arch Pathol Lab Med. 2012; 136(1):33-40. [PubMed: 22208485]

235. Pont-Kingdon G, Gedge F, Wooderchak-Donahue W, et al. Design and analytical validation of clinical DNA sequencing assays. Arch Pathol Lab Med. 2012; 136(1):41-46. [PubMed: 22208486]

236. Saxe DF, Persons DL, Wolff DJ, Theil KS. Validation of fluorescence in situ hybridization using an analyte-specific reagent for detection of abnormalities involving the mixed lineage leukemia gene. Arch Pathol Lab Med. 2012; 136(1):47-52. [PubMed: 22208487]

237. Kamel-Reid S, Zhang T, Persons DL, Nikiforova MN, Halling KC. Validation of KRAS testing for anti-EGFR therapeutic decisions for patients with metastatic colorectal carcinoma. Arch Pathol Lab Med. 2012; 136(1):26-32. [PubMed: 22208484]

238. Halling KC, Schrijver I, Persons DL. Test verification and validation for molecular diagnostic assays. Arch Pathol Lab Med. 2012; 136(1):11-13. [PubMed: 22208481]

239. Fitzgibbons PL, Murphy DA, Hammond ME, Allred DC, Valenstein PN. Recommendations for validating estrogen and progesterone receptor immunohistochemistry assays. Arch Pathol Lab Med. 2010; 134(6):930-935. [PubMed: 20524870]

240. Penzel R, Sers C, Chen Y, et al. EGFR mutation detection in NSCLC - assessment of diagnostic application and recommendations of the German Panel for Mutation Testing in NSCLC. Virchows Arch. 2011; 458(1):95-98. [PubMed: 21057810]

241. [Accessed April 28, 2012] Spanish Division of the International Academy of Pathology. http:// www.seap.es/

242. European Molecular Genetics Quality Network. [Accessed April 28, 2012] http://www.emqn.org/ emqn/Home 
243. European Society of Pathology. [Accessed April 28, 2012] http://www.esp-pathology.org/

244. Feng Y, Thiagarajan PS, Ma PC. MET signaling: novel targeted inhibition and its clinical development in lung cancer. J Thorac Oncol. 2012; 7(2):459-467. [PubMed: 22237263]

245. Dziadziuszko R, Wynes MW, Singh S, et al. Correlation between MET gene copy number by silver in situ hybridization and protein expression by immunohistochemistry in non-small cell lung cancer. J Thorac Oncol. 2012; 7(2):340-347. [PubMed: 22237262]

246. De Greve J, Teugels E, Geers C, et al. Clinical activity of afatinib (BIBW 2992) in patients with lung adenocarcinoma with mutations in the kinase domain of HER2/neu. Lung Cancer. 2012; 76(1):123-127. [PubMed: 22325357]

247. Arcila ME, Chaft JE, Nafa K, et al. Prevalence, clinicopathologic associations, and molecular spectrum of ERBB2 (HER2) tyrosine kinase mutations in lung adenocarcinomas. Clin Cancer Res. 2012; 18(18):4910-4918. [PubMed: 22761469]

248. Lipson D, Capelletti M, Yelensky R, et al. Identification of new ALK and RET gene fusions from colorectal and lung cancer biopsies. Nat Med. 2012; 18(3):382-384. [PubMed: 22327622]

249. Roychowdhury S, Iyer MK, Robinson DR, et al. Personalized oncology through integrative highthroughput sequencing: a pilot study. Sci Transl Med. 2011; 3(111):111ra121.

250. Ahn MJ, Park BB, Ahn JS, et al. Are there any ethnic differences in molecular predictors of erlotinib efficacy in advanced non-small cell lung cancer? Clin Cancer Res. 2008; 14(12):38603866. [PubMed: 18559606]

251. Cappuzzo F, Ligorio C, Janne PA, et al. Prospective study of gefitinib in epidermal growth factor receptor fluorescence in situ hybridization-positive/ phospho-Akt-positive or never smoker patients with advanced non-small-cell lung cancer: the ONCOBELL trial. J Clin Oncol. 2007; 25(16):2248-2255. [PubMed: 17538169]

252. Choi DR, Lee DH, Choi C-M, Kim S-W, Suh C, Lee J-S. Erlotinib in first-line therapy for nonsmall cell lung cancer: a prospective phase II study. Anticancer Res. 2011; 31(10):3457-3462. [PubMed: 21965761]

253. Cohen V, Agulnik JS, Ang C, et al. Epidermal growth factor receptor mutations detected by denaturing high-performance liquid chromatography in nonsmall cell lung cancer: impact on response to therapy with epidermal growth factor receptor-tyrosine kinase inhibitors. Cancer. 2010; 116(18):4309-4317. [PubMed: 20549828]

254. Cortes-Funes H, Gomez C, Rosell R, et al. Epidermal growth factor receptor activating mutations in Spanish gefitinib-treated non-small-cell lung cancer patients. Ann Oncol. 2005; 16(7):10811086. [PubMed: 15851406]

255. Han J-Y, Park K, Kim S-W, et al. First-SIGNAL: first-line single-agent iressa versus gemcitabine and cisplatin trial in never-smokers with adenocarcinoma of the lung. J Clin Oncol. 2012; 30(10): 1122-1128. [PubMed: 22370314]

256. Harada T, Lopez-Chavez A, Xi L, Raffeld M, Wang Y, Giaccone G. Characterization of epidermal growth factor receptor mutations in non-small-cell lung cancer patients of AfricanAmerican ancestry. Oncogene. 2011; 30(15):1744-1752. [PubMed: 21132006]

257. Hotta K, Kiura K, Toyooka S, et al. Clinical significance of epidermal growth factor receptor gene mutations on treatment outcome after first-line cytotoxic chemotherapy in Japanese patients with non-small cell lung cancer. J Thorac Oncol. 2007; 2(7):632-637. [PubMed: 17607119]

258. Hsieh MH, Fang YF, Chang WC, et al. Complex mutation patterns of epidermal growth factor receptor gene associated with variable responses to gefitinib treatment in patients with non-small cell lung cancer. Lung Cancer. 2006; 53(3):311-322. [PubMed: 16870303]

259. Jackman DM, Yeap BY, Lindeman NI, et al. Phase II clinical trial of chemotherapy-naive patients $>$ or $1 / 270$ years of age treated with erlotinib for advanced non-small-cell lung cancer. J Clin Oncol. 2007; 25(7):760-766. [PubMed: 17228019]

260. Janne PA, Meyerson M. ROS1 rearrangements in lung cancer: a new genomic subset of lung adenocarcinoma. J Clin Oncol. 2012; 30(8):878-879. [PubMed: 22215755]

261. Jian G, Songwen Z, Ling Z, et al. Prediction of epidermal growth factor receptor mutations in the plasma/pleural effusion to efficacy of gefitinib treatment in advanced non-small cell lung cancer. J Cancer Res Clin Oncol. 2010; 136(9):1341-1347. [PubMed: 20155428] 
262. Kim KS, Jeong JY, Kim YC, et al. Predictors of the response to gefitinib in refractory non-small cell lung cancer. Clin Cancer Res. 2005; 11(6):2244-2251. [PubMed: 15788673]

263. Kim ST, Uhm JE, Lee J, et al. Randomized phase II study of gefitinib versus erlotinib in patients with advanced non-small cell lung cancer who failed previous chemotherapy. Lung Cancer. 2012; 75(1):82-88. [PubMed: 21684626]

264. Kondo M, Yokoyama T, Fukui T, et al. Mutations of epidermal growth factor receptor of nonsmall cell lung cancer were associated with sensitivity to gefitinib in recurrence after surgery. Lung Cancer. 2005; 50(3):385-391. [PubMed: 16140420]

265. Lee DH, Kim SW, Suh C, Han YH, Lee JS. Phase II study of erlotinib for chemotherapy-naive patients with advanced or metastatic non-small cell lung cancer who are ineligible for platinum doublets. Cancer Chemother Pharmacol. 2011; 67(1):35-39. [PubMed: 20182725]

266. Oshita F, Matsukuma S, Yoshihara M, et al. Novel heteroduplex method using small cytology specimens with a remarkably high success rate for analysing EGFR gene mutations with a significant correlation to gefitinib efficacy in non-small-cell lung cancer. Br J Cancer. 2006; 95(8):1070-1075. [PubMed: 17047654]

267. Porta R, Sanchez-Torres JM, Paz-Ares L, et al. Brain metastases from lung cancer responding to erlotinib: the importance of EGFR mutation. Eur Respir J. 2011; 37(3):624-631. [PubMed: 20595147]

268. Rizvi NA, Rusch V, Pao W, et al. Molecular characteristics predict clinical outcomes: prospective trial correlating response to the EGFR tyrosine kinase inhibitor gefitinib with the presence of sensitizing mutations in the tyrosine binding domain of the EGFR gene. Clin Cancer Res. 2011; 17(10):3500-3506. [PubMed: 21558399]

269. Sasaki H, Endo K, Okuda K, et al. Epidermal growth factor receptor gene amplification and gefitinib sensitivity in patients with recurrent lung cancer. J Cancer Res Clin Oncol. 2008; 134(5):569-577. [PubMed: 17932690]

270. Satouchi M, Negoro S, Funada Y, et al. Predictive factors associated with prolonged survival in patients with advanced non-small-cell lung cancer (NSCLC) treated with gefitinib. Br J Cancer. 2007; 96(8):1191-1196. [PubMed: 17387341]

271. Sequist LV, Joshi VA, Janne PA, et al. Response to treatment and survival of patients with nonsmall cell lung cancer undergoing somatic EGFR mutation testing. Oncologist. 2007; 12(1):9098. [PubMed: 17285735]

272. Sutani A, Nagai Y, Udagawa K, et al. Gefitinib for non-small-cell lung cancer patients with epidermal growth factor receptor gene mutations screened by peptide nucleic acid-locked nucleic acid PCR clamp. Br J Cancer. 2006; 95(11):1483-1489. [PubMed: 17106442]

273. Taron M, Ichinose Y, Rosell R, et al. Activating mutations in the tyrosine kinase domain of the epidermal growth factor receptor are associated with improved survival in gefitinib-treated chemorefractory lung adenocarcinomas. Clin Cancer Res. 2005; 11(16):5878-5885. [PubMed: 16115929]

274. Uramoto H, Sugio K, Oyama T, et al. Epidermal growth factor receptor mutations are associated with gefitinib sensitivity in non-small cell lung cancer in Japanese. Lung Cancer. 2006; 51(1): 71-77. [PubMed: 16198442]

275. Wang Z, Wu YL, Zhang GC, Zhou Q, Xu CR, Guo AL. EGFR/KRAS mutations and gefitinib therapy in Chinese NSCLC patients. Onkologie. 2008; 31(4):174-178. [PubMed: 18418018]

276. Xu JM, Han Y, Duan HQ, et al. EGFR mutations and HER2/3 protein expression and clinical outcome in Chinese advanced non-small cell lung cancer patients treated with gefitinib. J Cancer Res Clin Oncol. 2009; 135(6):771-782. [PubMed: 19020901]

277. Yang CH, Yu CJ, Shih JY, et al. Specific EGFR mutations predict treatment outcome of stage IIIB/IV patients with chemotherapy-naive non-small-cell lung cancer receiving first-line gefitinib monotherapy. J Clin Oncol. 2008; 26(16):2745-2753. [PubMed: 18509184]

278. Wu J-Y, Shih J-Y, Chen K-Y, Yang C-H, Yu C-J, Yang P-C. Gefitinib therapy in patients with advanced non-small cell lung cancer with or without testing for epidermal growth factor receptor (EGFR) mutations. Medicine (Baltimore). 2011; 90(3):159-167. [PubMed: 21512416] 
279. Argiris A, Hensing T, Yeldandi A, et al. Combined analysis of molecular and clinical predictors of gefitinib activity in advanced non-small cell lung cancer: epidermal growth factor receptor mutations do not tell the whole story. J Thorac Oncol. 2006; 1(1):52-60. [PubMed: 17409827]

280. Rosell R, Carcereny E, Gervais R. Erlotinib versus standard chemotherapy as first-line treatment for European patients with advanced EGFR mutation-positive non-small-cell lung cancer (EURTAC): a multicentre, open-label, randomised phase 3 trial. Lancet Oncol. 2012; 13(3):239_ 246. [PubMed: 22285168]

281. Zhou C, Wu Y-L, Chen G, et al. Erlotinib versus chemotherapy as first-line treatment for patients with advanced EGFR mutation-positive non-small-cell lung cancer (OPTIMAL, CTONG-0802): a multicentre, open-label, randomised, phase 3 study. Lancet Oncol. 2011; 12(8):735-742. [PubMed: 21783417]

282. Yang JC-H, Schuler MH, Yamamoto N, et al. LUX-Lung 3: a randomized, open-label, phase III study of afatinib versus pemetrexed and cisplatin as first-line treatment for patients with advanced adenocarcinoma of the lung harboring EGFR-activating mutations. J Clin Oncol. 2012; 30(18 suppl):LBA7500.

283. Asahina H, Yamazaki K, Kinoshita I, et al. A phase II trial of gefitinib as first-line therapy for advanced non-small cell lung cancer with epidermal growth factor receptor mutations. Br J Cancer. 2006; 95(8):998-1004. [PubMed: 17047648]

284. Bae NC, Chae MH, Lee MH, et al. EGFR, ERBB2, and KRAS mutations in Korean non-small cell lung cancer patients. Cancer Genet Cytogenet. 2007; 173(2):107-113. [PubMed: 17321325]

285. Haneda H, Sasaki H, Lindeman N, et al. A correlation between EGFR gene mutation status and bronchioloalveolar carcinoma features in Japanese patients with adenocarcinoma. Jpn J Clin Oncol. 2006; 36(2):69-75. [PubMed: 16449241]

286. Inoue A, Suzuki T, Fukuhara T, et al. Prospective phase II study of gefitinib for chemotherapynaive patients with advanced non-small-cell lung cancer with epidermal growth factor receptor gene mutations. J Clin Oncol. 2006; 24(21):3340-3346. [PubMed: 16785471]

287. Kang SM, Kang HJ, Shin JH, et al. Identical epidermal growth factor receptor mutations in adenocarcinomatous and squamous cell carcinomatous components of adenosquamous carcinoma of the lung. Cancer. 2007; 109(3):581-587. [PubMed: 17186532]

288. Riely GJ, Pao W, Pham D, et al. Clinical course of patients with non-small cell lung cancer and epidermal growth factor receptor exon 19 and exon 21 mutations treated with gefitinib or erlotinib. Clin Cancer Res. 2006; 12(3 pt 1):839-844. [PubMed: 16467097]

289. Soung YH, Lee JW, Kim SY, et al. Mutational analysis of EGFR and K-RAS genes in lung adenocarcinomas. Virchows Arch. 2005; 446(5):483-488. [PubMed: 15815931]

290. Sugio K, Uramoto H, Onitsuka T, et al. Prospective phase II study of gefitinib in non-small cell lung cancer with epidermal growth factor receptor gene mutations. Lung Cancer. 2009; 64(3): 314-318. [PubMed: 18992959]

291. Sunaga N, Tomizawa Y, Yanagitani N, et al. Phase II prospective study of the efficacy of gefitinib for the treatment of stage III/IV non-small cell lung cancer with EGFR mutations, irrespective of previous chemotherapy. Lung Cancer. 2007; 56(3):383-389. [PubMed: 17368623]

292. Tang X, Varella-Garcia M, Xavier AC, et al. Epidermal growth factor receptor abnormalities in the pathogenesis and progression of lung adenocarcinomas. Cancer Prev Res (Phila). 2008; 1(3): 192-200. [PubMed: 19138956]

293. Cote ML, Haddad R, Edwards DJ, et al. Frequency and type of epidermal growth factor receptor mutations in African Americans with non-small cell lung cancer. J Thorac Oncol. 2011; 6(3): 627-630. [PubMed: 21317742]

294. Moiseyenko VM, Procenko SA, Levchenko EV, et al. High efficacy of first-line gefitinib in nonAsian patients with EGFR-mutated lung adenocarcinoma. Onkologie. 2010; 33(5):231-238. [PubMed: 20502057]

295. Sahoo R, Harini VV, Babu VC, et al. Screening for EGFR mutations in lung cancer, a report from India. Lung Cancer. 2011; 73(3):316-319. [PubMed: 21315473]

296. Otani H, Toyooka S, Soh J, et al. Detection of EGFR gene mutations using the wash fluid of CTguided biopsy needle in NSCLC patients. J Thorac Oncol. 2008; 3(5):472-476. [PubMed: 18448998] 
297. Dacic S, Shuai Y, Yousem S, Ohori P, Nikiforova M. Clinicopathological predictors of EGFR/ KRAS mutational status in primary lung adenocarcinomas. Mod Pathol. 2010; 23(2):159-168. [PubMed: 19855375]

298. Blons H, Cote JF, Le Corre D, et al. Epidermal growth factor receptor mutation in lung cancer are linked to bronchioloalveolar differentiation. Am J Surg Pathol. 2006; 30(10):1309-1315. [PubMed: 17001163]

299. Takeuchi K, Choi YL, Soda M, et al. Multiplex reverse transcription-PCR screening for EML4ALK fusion transcripts. Clin Cancer Res. 2008; 14(20):6618-6624. [PubMed: 18927303]

300. Lee SY, Kim MJ, Jin G, et al. Somatic mutations in epidermal growth factor receptor signaling pathway genes in non-small cell lung cancers. J Thorac Oncol. 2010; 5(11):1734-1740. [PubMed: 20881644]

301. Miyamae Y, Shimizu K, Hirato J, et al. Significance of epidermal growth factor receptor gene mutations in squamous cell lung carcinoma. Oncol Rep. 2011; 25(4):921-928. [PubMed: 21318227]

302. Cancer Genome Atlas Research Network. Comprehensive genomic characterization of squamous cell lung cancers. Nature. 2012; 489(7417):519-525. [PubMed: 22960745]

303. Sun L, Zhang Q, Luan H, Zhan Z, Wang C, Sun B. Comparison of KRAS and EGFR gene status between primary non-small cell lung cancer and local lymph node metastases: implications for clinical practice. J Exp Clin Cancer Res. 2011; 30:30. [PubMed: 21414214]

304. Gombos Z, Danihel L, Puttaswamy K, Brose M. A comparative study of EGFR mutation screening methods in non-small cell carcinoma of lung. Bratisl Lek Listy. 2010; 111(7):365-368. [PubMed: 20806539]

305. Naoki K, Soejima K, Okamoto H, et al. The PCR-invader method (structure-specific 5' nucleasebased method), a sensitive method for detecting EGFR gene mutations in lung cancer specimens; comparison with direct sequencing. Int J Clin Oncol. 2011; 16(4):335-344. [PubMed: 21311943]

306. Dufort S, Richard MJ, Lantuejoul S, de Fraipont F. Pyrosequencing, a method approved to detect the two major EGFR mutations for anti EGFR therapy in NSCLC. J Exp Clin Cancer Res. 2011; 30:57. [PubMed: 21575212]

307. Cohen V, Agulnik JS, Jarry J, et al. Evaluation of denaturing high-performance liquid chromatography as a rapid detection method for identification of epidermal growth factor receptor mutations in nonsmall-cell lung cancer. Cancer. 2006; 107(12):2858-2865. [PubMed: 17096434]

308. Hlinkova K, Babal P, Berzinec P, Majer I, Ilencikova D. Rapid and efficient detection of EGFR mutations in problematic cytologic specimens by high-resolution melting analysis. Mol Diagn Ther. 2011; 15(1):21-29. [PubMed: 21469767]

309. Nakajima T, Yasufuku K, Suzuki M, et al. Assessment of epidermal growth factor receptor mutation by endobronchial ultrasound-guided transbronchial needle aspiration. Chest. 2007; 132(2):597-602. [PubMed: 17573511]

310. Soh J, Toyooka S, Aoe K, et al. Usefulness of EGFR mutation screening in pleural fluid to predict the clinical outcome of gefitinib treated patients with lung cancer. Int J Cancer. 2006; 119(10): 2353-2358. [PubMed: 16921488]

311. Bamford S, Dawson E, Forbes S, et al. The COSMIC (Catalogue of Somatic Mutations in Cancer) database and website. Br J Cancer. 2004; 91(2):355-358. [PubMed: 15188009]

312. De Pas T, de Braud F, Mandala M, et al. Cisplatin and vinorelbine as second-line chemotherapy in patients with advanced non-small cell lung cancer (NSCLC) resistant to taxol plus gemcitabine. Lung Cancer. 2001; 31(2-3):267-270. [PubMed: 11165406]

313. Murray S, Dahabreh IJ, Linardou H, Manoloukos M, Bafaloukos D, Kosmidis P. Somatic mutations of the tyrosine kinase domain of epidermal growth factor receptor and tyrosine kinase inhibitor response to TKIs in non-small cell lung cancer: an analytical database. J Thorac Oncol. 2008; 3(8):832-839. [PubMed: 18670300]

314. Pinter F, Papay J, Almasi A, et al. Epidermal growth factor receptor (EGFR) high gene copy number and activating mutations in lung adenocarcinomas are not consistently accompanied by positivity for EGFR protein by standard immunohistochemistry. J Mol Diagn. 2008; 10(2):160168. [PubMed: 18258923] 
315. Sequist LV, Martins RG, Spigel D, et al. First-line gefitinib in patients with advanced non-smallcell lung cancer harboring somatic EGFR mutations. J Clin Oncol. 2008; 26(15):2442-2449. [PubMed: 18458038]

316. Sone T, Kasahara K, Kimura H, et al. Comparative analysis of epidermal growth factor receptor mutations and gene amplification as predictors of gefitinib efficacy in Japanese patients with nonsmall cell lung cancer. Cancer. 2007; 109(9):1836-1844. [PubMed: 17387741]

317. Ichihara S, Toyooka S, Fujiwara Y, et al. The impact of epidermal growth factor receptor gene status on gefitinib-treated Japanese patients with non-small-cell lung cancer. Int J Cancer. 2007; 120(6):1239-1247. [PubMed: 17192902]

318. Takezawa K, Pirazzoli V, Arcila ME, et al. HER2 amplification: a potential mechanism of acquired resistance to EGFR inhibition in EGFR-mutant lung cancers that lack the second-site EGFRT790M mutation. Cancer Discov. 2012; 2(10):922-933. [PubMed: 22956644]

319. Ju YS, Lee WC, Shin JY, et al. A transforming KIF5B and RET gene fusion in lung adenocarcinoma revealed from whole-genome and transcriptome sequencing. Genome Res. 2012; 22(3):436-445. [PubMed: 22194472]

320. Kohno T, Ichikawa H, Totoki Y, et al. KIF5B-RET fusions in lung adenocarcinoma. Nature Med. 2012; 18(3):375-377. [PubMed: 22327624]

321. Takeuchi K, Soda M, Togashi Y, et al. RET, ROS1 and ALK fusions in lung cancer. Nature Med. 2012; 18(3):378-381. [PubMed: 22327623]

322. Suehara Y, Arcila M, Wang L, et al. Identification of KIF5B-RET and GOPC-ROS1 fusions in lung adenocarcinomas through a comprehensive mRNA-based screen for tyrosine kinase fusions. Clin Cancer Res. 2012; 18(24):6599-6608. [PubMed: 23052255]

\section{APPENDIX: Disclosed Interests and Activities}

\begin{tabular}{|c|c|c|}
\hline Name & Interest/Activity Type & Entity \\
\hline \multirow[t]{5}{*}{ Mary Beth Beasley, MD } & Board or advisory board & Pulmonary Pathology Society Board of Trustees \\
\hline & Lecture fees paid by entity & $\begin{array}{l}\text { International Association for the Study of Lung } \\
\text { Cancer }\end{array}$ \\
\hline & Expert witness & $\begin{array}{l}\text { Willcox and Savage, Asbestos Litigation } \\
\text { McGuire Woods, Cooch and Taylor, Asbestos } \\
\text { Litigation } \\
\text { Cetrulo and Capone, Asbestos Litigation } \\
\text { Rassmussen, Dickey, Willis and Moore, Asbestos } \\
\text { Litigation } \\
\text { Informa Health Care }\end{array}$ \\
\hline & Royalties & Lippincott, Williams \& Wilkins \\
\hline & Leadership in associations & $\begin{array}{l}\text { Pulmonary Pathology Society, Secretary } \\
\text { College of American Pathologists, Chair, Surgical } \\
\text { Pathology Resource Committee }\end{array}$ \\
\hline \multirow[t]{3}{*}{ Philip T. Cagle, MD } & Lecture fees paid by entity & $\begin{array}{l}\text { Emory University } \\
\text { New York University } \\
\text { Oklahoma State Association of Pathologists } \\
\text { University of Michigan } \\
\text { Massachusetts General Hospital }\end{array}$ \\
\hline & Royalties & $\begin{array}{l}\text { Springer Publishing } \\
\text { Lippincott, Williams \& Wilkins }\end{array}$ \\
\hline & Leadership in associations & $\begin{array}{l}\text { Archives of Pathology \& Laboratory Medicine, } \\
\text { Editor-in-Chief }{ }^{\circ} \\
\text { Texas Society of Pathologists, Chair of Education } \\
\text { Council } \\
\text { Pulmonary Pathology Society, Past President } \\
\text { Pulmonary Pathology Society, Chair of Nominating } \\
\text { Committee }\end{array}$ \\
\hline
\end{tabular}




\begin{tabular}{|c|c|c|}
\hline Name & Interest/Activity Type & Entity \\
\hline Dhananjay A. Chitale, MD & Grants & $\begin{array}{l}\text { Pennsylvania Breast Cancer Coalition } \\
\text { Department of Defense } \\
\text { Susan G. Komen for the Cure } \\
\text { National Institutes of Health }\end{array}$ \\
\hline \multirow{2}{*}{$\begin{array}{l}\text { David J. Kwiatkowski, MD, } \\
\mathrm{PhD}\end{array}$} & Consultancy & Novartis \\
\hline & Lecture fees paid by entity & Millenium \\
\hline \multirow[t]{5}{*}{ Marc Ladanyi, MD } & Consultancy & $\begin{array}{l}\text { Arqule/Daiichi Sankyo (April 2010) } \\
\text { NanoString (September 2012) }\end{array}$ \\
\hline & Lecture fees paid by entity & $\begin{array}{l}\text { Genzyme (March 2010) } \\
\text { Infinity (July 2010) } \\
\text { Sequenom (November 2009) } \\
\text { Remedica Medical Education (June 2012) }\end{array}$ \\
\hline & Family and business partners & $\begin{array}{l}\text { Wife: Continuing medical education activities for } \\
\text { Abbott }\end{array}$ \\
\hline & Institutional financial interest & $\begin{array}{l}\text { Memorial Sloan-Kettering Cancer Center licensed } \\
\text { patent for EGFR T790M testing to MolecularMD. } \\
\text { M.L. is not a patent holder. }\end{array}$ \\
\hline & Leadership in associations & $\begin{array}{l}\text { Association for Molecular Pathology, Strategic } \\
\text { Opportunities Committee } \\
\text { United States and Canadian Academy of Pathology, } \\
\text { Translational Genomics in Anatomic Pathology Task } \\
\text { Force } \\
\text { American Association for Cancer Research, } 2012 \\
\text { Annual Meeting Program Committee }\end{array}$ \\
\hline \multirow[t]{2}{*}{ Neal I. Lindeman, MD } & Institutional financial interest & $\begin{array}{l}\text { Partners Health Care has a patent on EGFR Mutation } \\
\text { Testing. N.I.L. is not a patent holder. }\end{array}$ \\
\hline & Leadership in associations & $\begin{array}{l}\text { Academy of Clinical Laboratory Physicians and } \\
\text { Scientists, Paul E. Strandjord Young Investigator } \\
\text { Award Coordinator } \\
\text { Association for Molecular Pathology, Solid Tumor } \\
\text { Representative, Clinical Practices Committee } \\
\text { Association for Molecular Pathology, Nominating } \\
\text { Committee, Solid Tumors Subdivision } \\
\text { Representative } \\
\text { AACC, Nominating Committee, Molecular Division } \\
\text { AACC, Short Course/Interactive Workshops Director } \\
\text { for AACC Annual Meeting Organizing Committee } \\
\text { College of American Pathologists, Molecular } \\
\text { Oncology Resource Committee }\end{array}$ \\
\hline \multirow[t]{2}{*}{ Juan-Sebastian Saldivar, MD } & Additional employment & $\begin{array}{l}\text { Sequenom Center for Molecular Medicine } \\
\text { Existence Genetics }\end{array}$ \\
\hline & Institutional financial interest & $\begin{array}{l}\text { City of Hope functions as a reference laboratory, } \\
\text { providing somatic testing for NSCLC }\end{array}$ \\
\hline \multirow[t]{5}{*}{ Jeremy A. Squire, $\mathrm{PhD}$} & Consultancy & CymoGen Dx, LLC \\
\hline & Board or advisory board & Applied Spectral Imaging \\
\hline & Patents received or pending & $\begin{array}{l}\text { Development of PTEN FISH Probe through Queens' } \\
\text { University Commercialization Office (Parteq) }\end{array}$ \\
\hline & Royalties & Parteq-Queen's Commercialization Office \\
\hline & Leadership in associations & $\begin{array}{l}\text { NCIC (National Cancer Institute of Canada) Clinical } \\
\text { Trials Group, Director of Laboratory Translational } \\
\text { Research }\end{array}$ \\
\hline \multirow[t]{2}{*}{ Erik Thunnissen, MD, PhD } & Board or advisory board & $\begin{array}{l}\text { Merck } \\
\text { Eli Lilly } \\
\text { Pfizer }\end{array}$ \\
\hline & Lecture fees paid by entity & $\begin{array}{l}\text { Merck } \\
\text { Pfizer } \\
\text { Eli Lilly }\end{array}$ \\
\hline
\end{tabular}




\begin{tabular}{|c|c|c|}
\hline Name & Interest/Activity Type & Entity \\
\hline \multirow{4}{*}{$\begin{array}{l}\text { Paul A. Bunn Jr, MD, } \\
\text { Steering Committee }\end{array}$} & Leadership in associations & $\begin{array}{l}\text { European Society of Pathology lung external quality } \\
\text { assessment }\end{array}$ \\
\hline & Consultancy & $\begin{array}{l}\text { Eli Lilly } \\
\text { OSI/Genentech/Roche } \\
\text { Astra Zeneca } \\
\text { Boehringer Ingelheim } \\
\text { Pfizer } \\
\text { Amgen } \\
\text { GlaxoSmithKline } \\
\text { Bristol-Myers-Squibb } \\
\text { Sanofi-Aventis }\end{array}$ \\
\hline & Board or advisory board & $\begin{array}{l}\text { OSI/Genentech/Roche } \\
\text { Astra Zeneca } \\
\text { Boehringer Ingelheim } \\
\text { Amgen } \\
\text { Bristol-Myers-Squibb } \\
\text { Sanofi-Aventis } \\
\text { Eli Lilly }\end{array}$ \\
\hline & Patents received or pending & $\begin{array}{l}\text { Patent relating to use of EGFR FISH results as } \\
\text { predictive biomarkers for EGFR therapy }\end{array}$ \\
\hline \multirow{5}{*}{$\begin{array}{l}\text { Jan A. Nowak, MD, Steering } \\
\text { Committee }\end{array}$} & Employment & $\begin{array}{l}\text { University of Colorado Denver } \\
\text { International Association for the Study of Lung } \\
\text { Cancer }\end{array}$ \\
\hline & Leadership in associations & $\begin{array}{l}\text { International Association for the Study of Lung } \\
\text { Cancer, Executive Director }\end{array}$ \\
\hline & Lecture fees paid by entity & William Beaumont Symposium \\
\hline & Employment & North Shore University Health System \\
\hline & Leadership in associations & $\begin{array}{l}\text { AMP, Past President } 2010 \\
\text { AMP, Professional Relations Committee Member } \\
\text { AMP, Economic Affairs Committee Member }\end{array}$ \\
\hline
\end{tabular}

Abbreviations: AACC, American Association for Clinical Chemistry; AMP, Association for Molecular Pathology; EGFR, epidermal growth factor receptor; FISH, fluorescence in situ hybridization; NSCLC, non-small cell lung cancer; PTEN, phosphatase and tensin homolog.

${ }^{a}$ Dr. Cagle recused himself from the 3 journals' peer review process for this guideline, a process completed subsequent to the approval of the guideline by the 3 societies. 

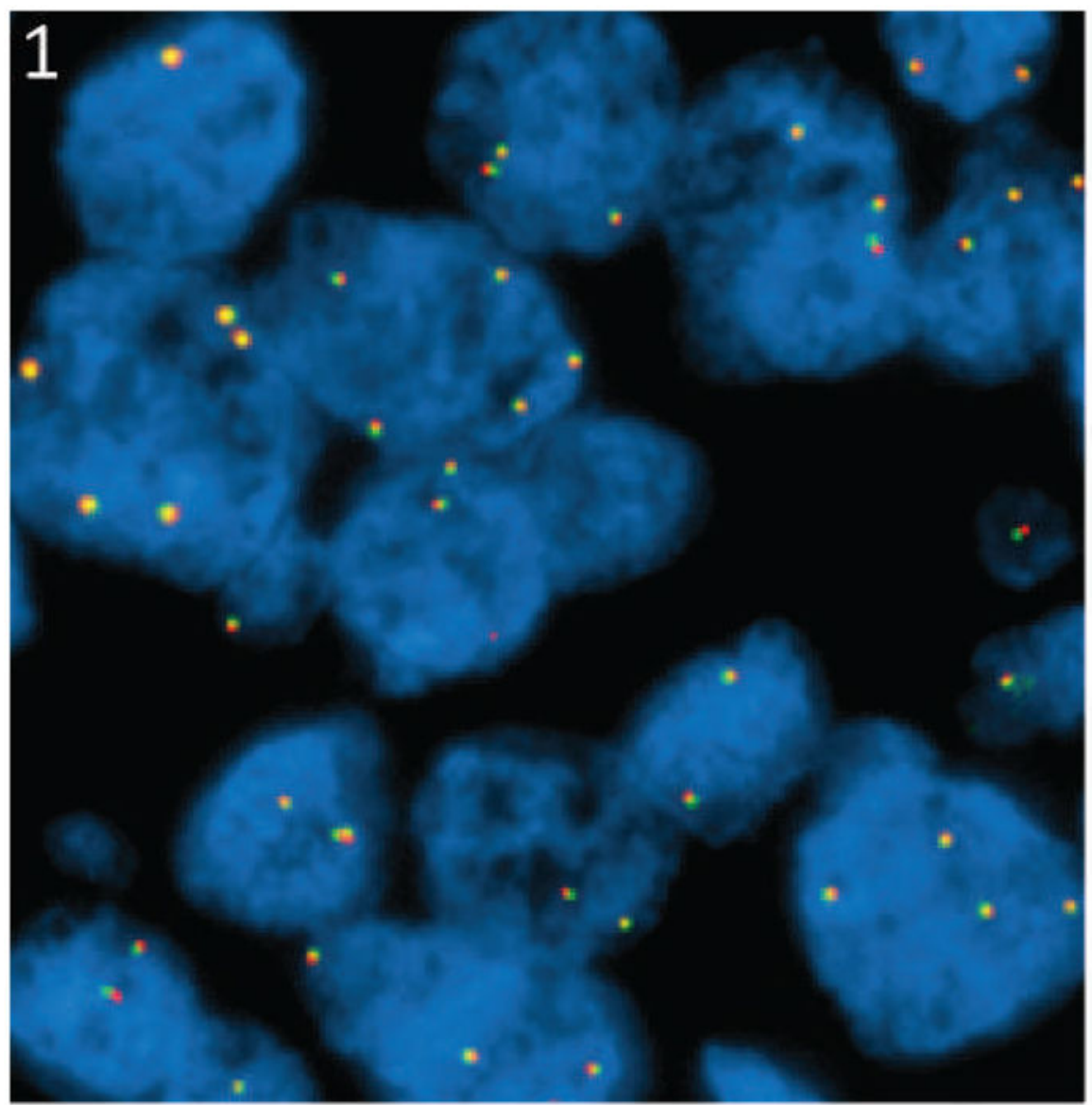

Figure 1.

Negative for $A L K$ rearrangement (original magnification $\times 1000$ ). 


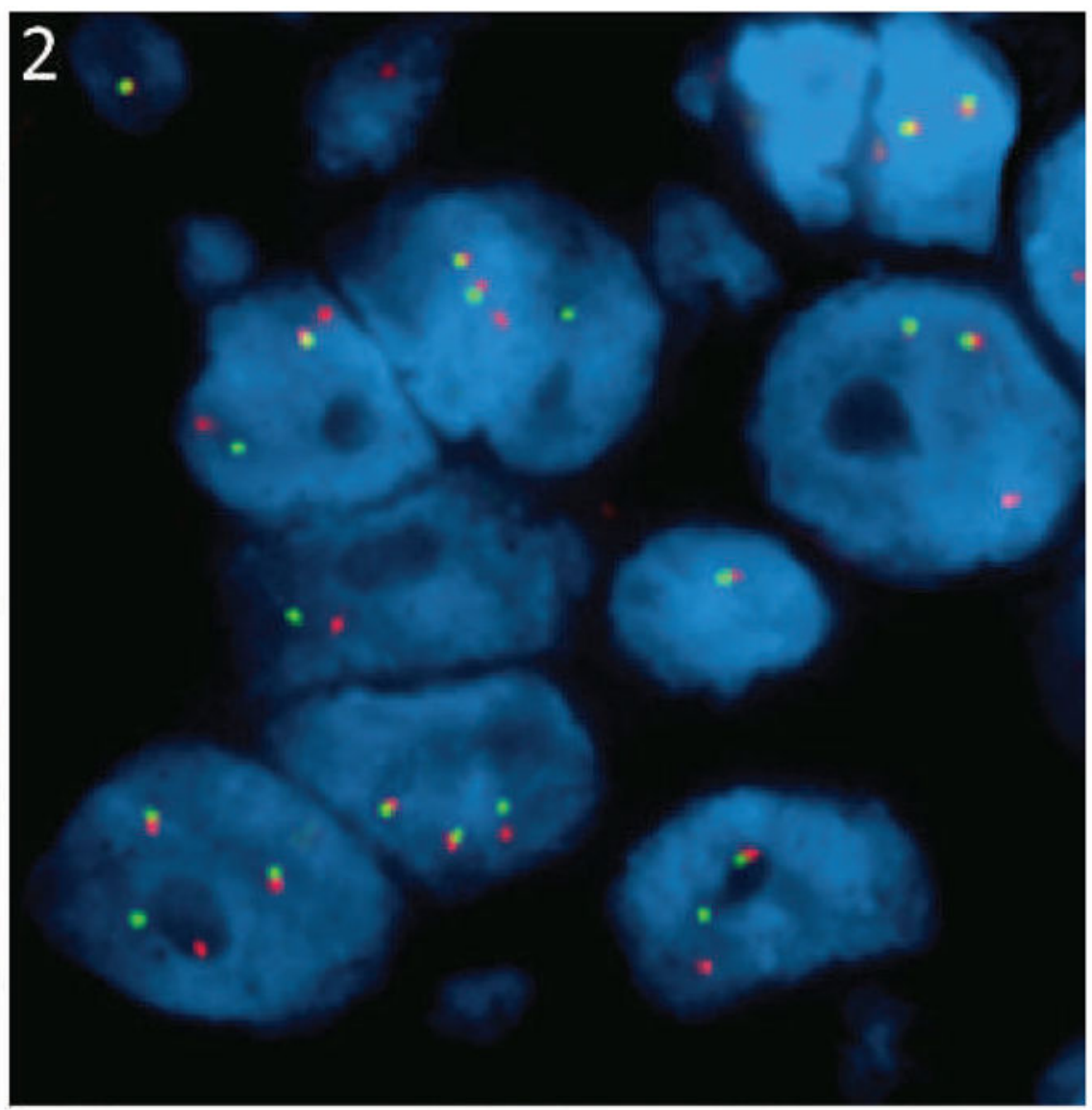

Figure 2.

Positive for $A L K$ rearrangement (split $3^{\prime} A L K-5^{\prime}$ ALK) (original magnification $\times 1000$ ). 


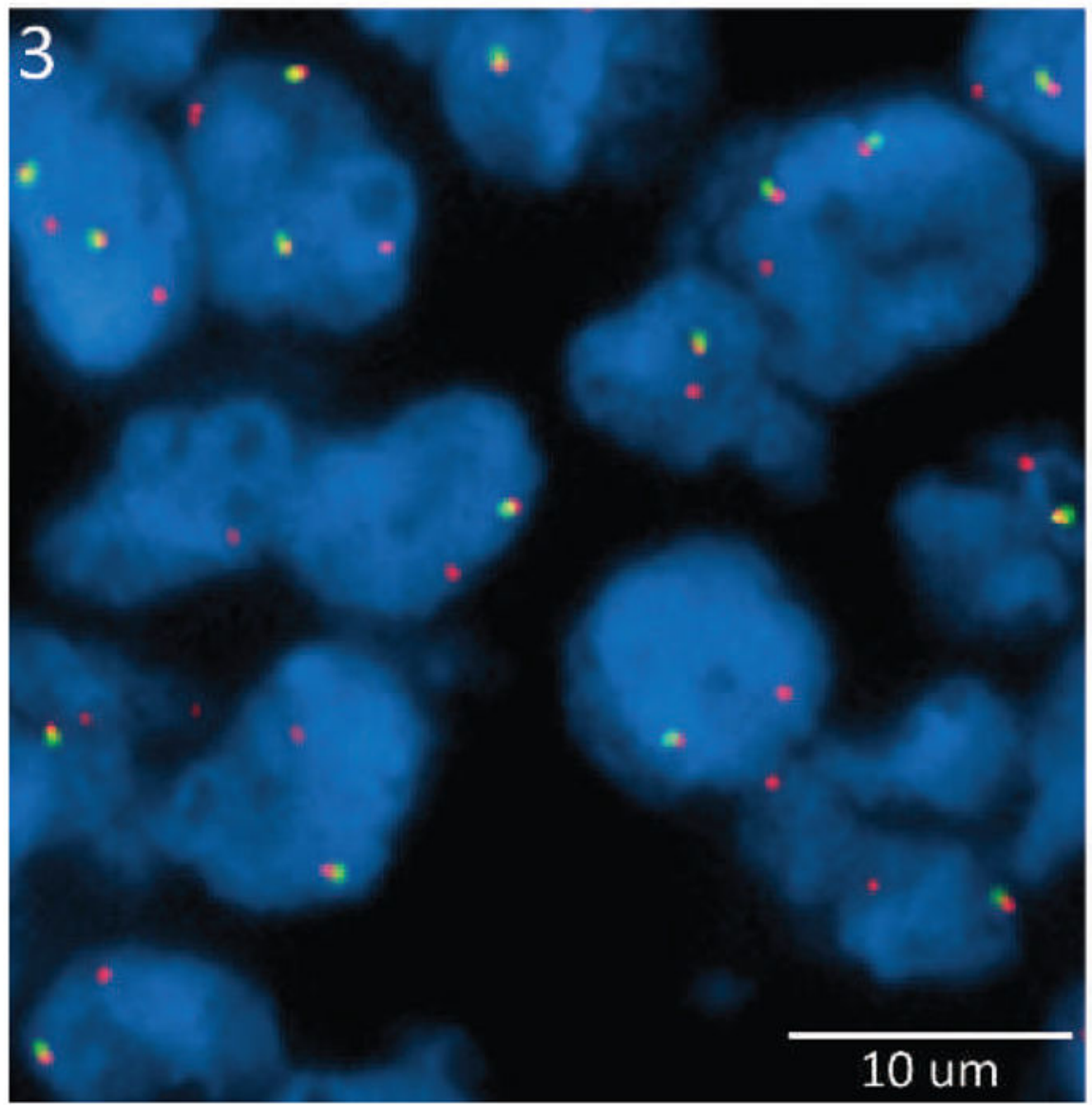

Figure 3.

Positive for $A L K$ rearrangement (single $3^{\prime} A L K$ ) (original magnification $\times 1000$ ). 


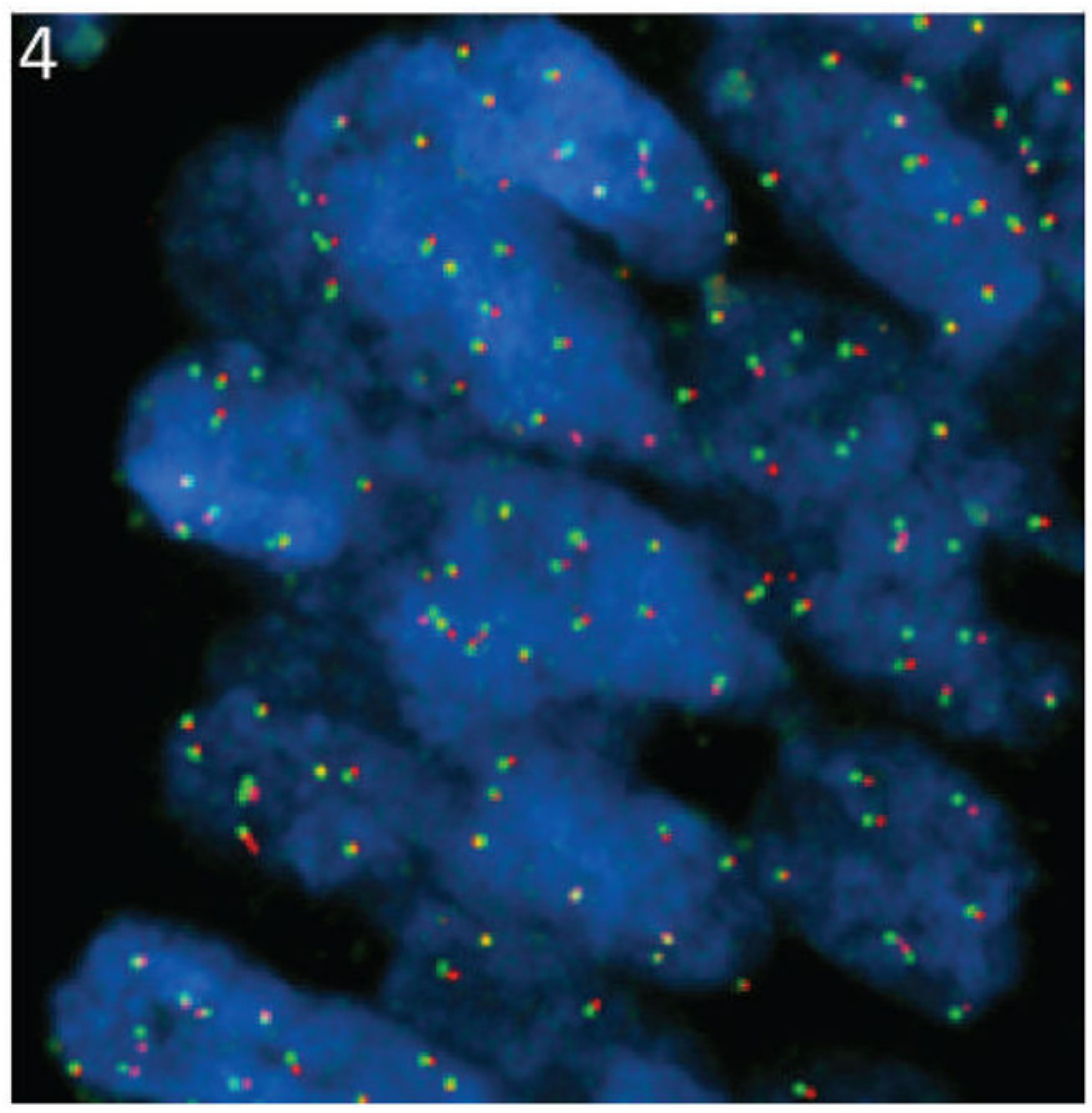

Figure 4.

Negative for $A L K$ rearrangement with $A L K$ high copy number (original magnification $\times$ 1000). 


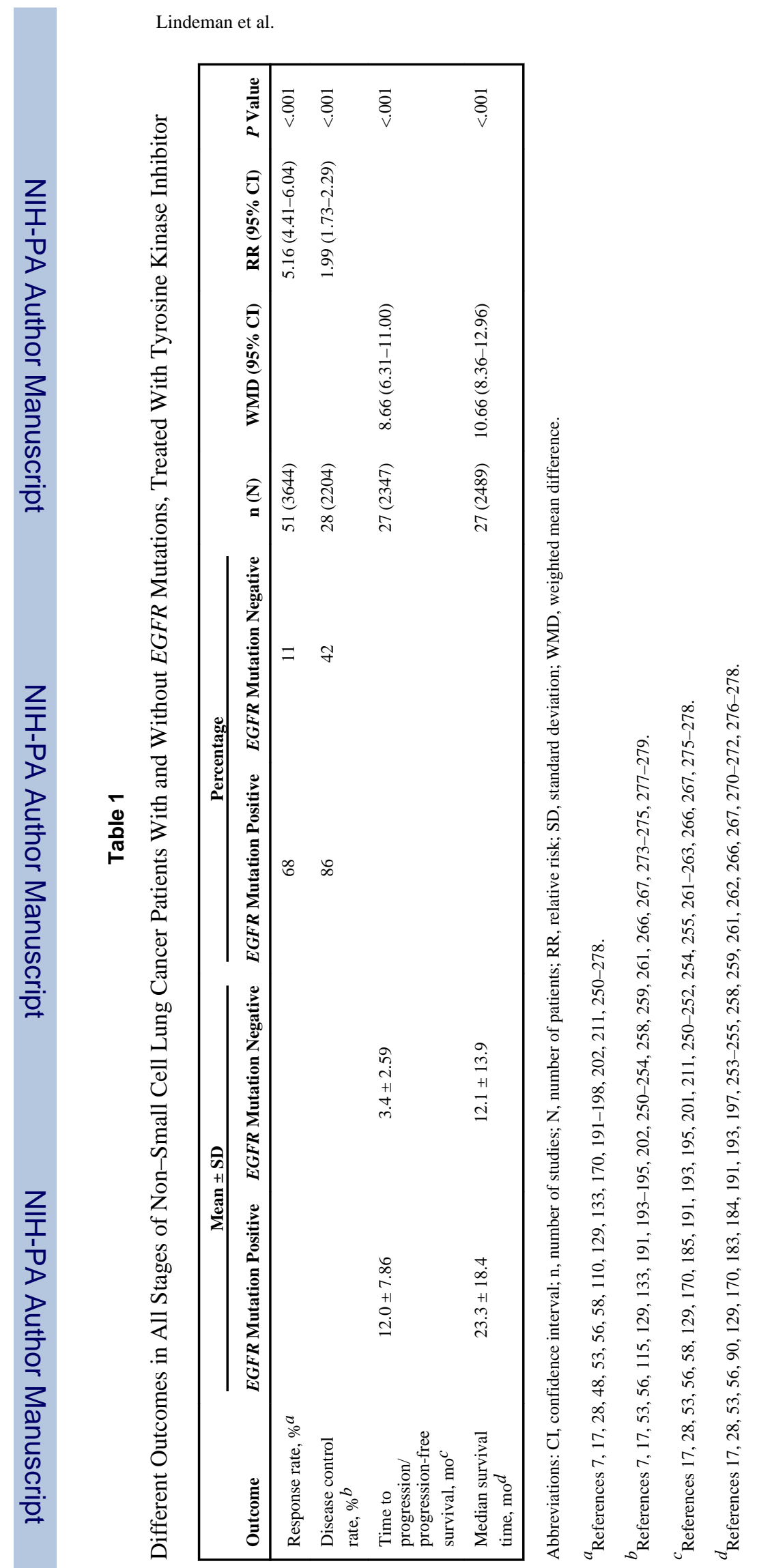

Arch Pathol Lab Med. Author manuscript; available in PMC 2014 September 12. 


\section{Table 2}

Randomized Clinical Trial Data on Epidermal Growth Factor Receptor (EGFR) Tyrosine Kinase Inhibitor (TKI) Therapy Versus Chemotherapy as First-Line Therapy for Patients With EGFR-Mutated Lung Cancers

\begin{tabular}{|c|c|c|c|}
\hline Study & $\begin{array}{l}\text { No. of Patients With EGFR-Mutated } \\
\text { Lung Cancers }\end{array}$ & $\begin{array}{c}\text { Response Rate (EGFR } \\
\text { TKI Versus } \\
\text { Chemotherapy), \% }\end{array}$ & $\begin{array}{r}\text { Progression-Free Survival (EGFR TKI } \\
\text { Versus Chemotherapy), mo }\end{array}$ \\
\hline EURTAC ${ }^{280}$ & 173 (86 erlotinib and 87 chemo) & 58 versus 15 & 9.7 versus 5.2 (HR 0.37 ) \\
\hline OPTIMAL $^{281}$ & 154 (82 erlotinib and 72 chemo) & 83 versus 36 & 13.1 versus 4.6 (HR 0.16$)$ \\
\hline NEJ $002^{91}$ & 228 (114 gefitinib and 114 chemo) & 74 versus 31 & 10.8 versus 5.4 (HR 0.30$)$ \\
\hline WJTOG $3405^{26}$ & 117 (58 gefitinib and 59 chemo) & 62 versus 32 & 9.2 versus 6.3 (HR 0.49$)$ \\
\hline IPASS $^{7,90}$ & 261 (132 gefitinib and 129 chemo) & 71 versus 47 & 9.5 versus 6.3 (HR 0.48 ) \\
\hline LUX LUNG3 $^{282}$ & 345 (230 afatinib and 115 chemo) & 56 versus 23 & 11.1 versus 6.9 (HR 0.58$)$ \\
\hline
\end{tabular}

Abbreviations: Chemo, chemotherapy; HR, hazard ratio. 


\section{Table 3}

\section{Summary of Guideline Recommendations}

Section I: When Should Molecular Testing of Lung Cancers Be Performed?

Question 1: Which Patients Should Be Tested for EGFR Mutations and ALK Rearrangements?

1.1a Recommendation: EGFR molecular testing should be used to select patients for EGFR-targeted TKI therapy, and patients with lung adenocarcinoma should not be excluded from testing on the basis of clinical characteristics.

1.1b Recommendation: $A L K$ molecular testing should be used to select patients for ALK-targeted TKI therapy, and patients with lung adenocarcinoma should not be excluded from testing on the basis of clinical characteristics.

1.2 Recommendation: In the setting of lung cancer resection specimens, EGFR and $A L K$ testing is recommended for adenocarcinomas and mixed lung cancers with an adenocarcinoma component, regardless of histologic grade. In the setting of fully excised lung cancer specimens, EGFR and $A L K$ testing is not recommended in lung cancers that lack any adenocarcinoma component, such as pure squamous cell carcinomas, pure small cell carcinomas, or large cell carcinomas lacking any immunohistochemistry (IHC) evidence of adenocarcinoma differentiation.

1.3 Recommendation: In the setting of more limited lung cancer specimens (biopsies, cytology) where an adenocarcinoma component cannot be completely excluded, EGFR and $A L K$ testing may be performed in cases showing squamous or small cell histology but clinical criteria (eg, young age, lack of smoking history) may be useful in selecting a subset of these samples for testing.

1.4 Recommendation: To determine EGFR and $A L K$ status for initial treatment selection, primary tumors or metastatic lesions are equally suitable for testing.

1.5 Expert consensus opinion: For patients with multiple, apparently separate, primary lung adenocarcinomas, each tumor may be tested but testing of multiple different areas within a single tumor is not necessary.

Question 2: When Should a Patient Specimen Be Tested for EGFR Mutation or ALK Rearrangement?

2.1a Recommendation: EGFR mutation testing should be ordered at the time of diagnosis for patients presenting with advancedstage disease (stage IV according to the 7th edition TNM staging system) who are suitable for therapy or at time of recurrence or progression in patients who originally presented with lower-stage disease but were not previously tested.

2.1b Suggestion: $A L K$ rearrangement testing should be ordered at the time of diagnosis for patients presenting with advancedstage disease (stage IV according to the 7th edition TNM staging system) who are suitable for therapy or at time of recurrence or progression in patients who originally presented with lower-stage disease but were not previously tested.

2.2a Expert consensus opinion: EGFR testing of tumors at diagnosis from patients presenting with stage I, II, or III disease is encouraged but the decision to do so should be made locally by each laboratory, in collaboration with its oncology team.

2.2b Expert consensus opinion: $A L K$ testing of tumors at diagnosis from patients presenting with stage I, II, or III disease is encouraged, but the decision to do so should be made locally by each laboratory, in collaboration with its oncology team.

2.3 Recommendation: Tissue should be prioritized for EGFR and $A L K$ testing.

Question 3: How Rapidly Should Test Results Be Available?

3.1 Expert consensus opinion: $E G F R$ and $A L K$ results should be available within 2 weeks (10 working days) of receiving the specimen in the testing laboratory.

3.2 Expert consensus opinion: Laboratories with average turnaround times beyond 2 weeks need to make available a more rapid test—either in-house or through a reference laboratory—in instances of clinical urgency.

3.3 Expert consensus opinion: Laboratory departments should establish processes to ensure that specimens that have a final histopathologic diagnosis are sent to outside molecular pathology laboratories within 3 working days of receiving requests and to intramural molecular pathology laboratories within 24 hours.

Section II: How Should EGFR Testing Be Performed?

Question 4: How Should Specimens Be Processed for EGFR Mutation Testing?

4.1 Expert consensus opinion: Pathologists should use formalin-fixed, paraffin-embedded (FFPE) specimens or fresh, frozen, or alcohol-fixed specimens for PCR-based EGFR mutation tests. Other tissue treatments (eg, acidic or heavy metal fixatives, or decalcifying solutions) should be avoided in specimens destined for EGFR testing.

4.2 Expert consensus opinion: Cytologic samples are also suitable for $E G F R$ and $A L K$ testing, with cell blocks being preferred over smear preparations.

Question 5: What Are the Specimen Requirements for EGFR Testing?

5.1 Expert consensus opinion: Pathologists should determine the adequacy of specimens for EGFR testing by assessing cancer cell content and DNA quantity and quality.

5.2 Expert consensus opinion: Each laboratory should establish the minimum proportion and number of cancer cells needed for mutation detection during validation. 
5.3 Expert consensus opinion: A pathologist should assess the tumor content of each specimen and either perform, or guide a trained technologist to perform, microdissection for tumor cell enrichment as needed.

Question 6: How Should EGFR Testing Be Performed?

6.1 Recommendation: Laboratories may use any validated EGFR testing method with sufficient performance characteristics.

6.2 Expert consensus opinion: Laboratories should use EGFR test methods that are able to detect mutations in specimens with at least $50 \%$ cancer cell content, although laboratories are strongly encouraged to use (or have available at an external reference laboratory) more sensitive tests that are able to detect mutations in specimens with as little as $10 \%$ cancer cells.

6.3 Expert consensus opinion: Clinical EGFR mutation testing should be able to detect all individual mutations that have been reported with a frequency of at least $1 \%$ of $E G F R$-mutated lung adenocarcinomas.

6.4 Recommendation: Immunohistochemistry for total EGFR is not recommended for selection of EGFR TKI therapy.

6.5 Recommendation: EGFR copy number analysis (ie, FISH or CISH) is not recommended for selection of EGFR TKI therapy.

Question 7: What Is the Role of KRAS Analysis in Selecting Patients for Targeted Therapy With EGFR TKIs?

7.1 Recommendation: KRAS mutation testing is not recommended as a sole determinant of EGFR TKI therapy.

Question 8: What Additional Testing Considerations Are Important in the Setting of Secondary or Acquired EGFR TKI Resistance?

8.1 Recommendation: If a laboratory performs testing on specimens from patients with acquired resistance to EGFR kinase inhibitors, such tests should be able to detect the secondary EGFR T790M mutation in as few as $5 \%$ of cells.

Section III: How Should $A L K$ Testing Be Performed?

Question 9: What methods should be used for ALK testing?

9.1 Recommendation: Laboratories should use an $A L K$ FISH assay using dual-labeled break-apart probes for selecting patients for ALK TKI therapy; ALK immunohistochemistry, if carefully validated, may be considered as a screening methodology to select specimens for $A L K$ FISH testing.

9.2 Recommendation: RT-PCR is not recommended as an alternative to FISH for selecting patients for ALK inhibitor therapy.

9.3 Expert consensus opinion: A pathologist should be involved in the selection of sections for ALK FISH testing, by assessing tumor architecture, cytology, and specimen quality.

9.4 Expert consensus opinion: A pathologist should participate in the interpretation of $A L K$ FISH slides, either by performing the analysis directly or by reviewing the interpretations of cytogeneticists or technologists with specialized training in solid tumor FISH analysis.

9.5 Expert consensus opinion: Testing for secondary mutations in ALK associated with acquired resistance to ALK inhibitors is not currently required for clinical management.

Section IV: Should Other Genes Be Routinely Tested in Lung Adenocarcinoma?

Question 10: Are Other Molecular Markers Suitable for Testing in Lung Cancer?

10.1a Recommendation: Testing for EGFR should be prioritized over other molecular markers in lung adenocarcinoma.

10.1b Suggestion: After $E G F R$ testing, testing for $A L K$ should be prioritized over other proposed molecular markers in lung adenocarcinoma, for which published evidence is insufficient to support testing guideline development at the present time.

Section V: How Should Molecular Testing of Lung Adenocarcinomas Be Implemented and Operationalized?

Question 11: Must All Adenocarcinomas Be Tested for Both EGFR and ALK?

11.1 Expert consensus opinion: Laboratories may implement testing algorithms to enhance the efficiency of molecular testing of lung adenocarcinomas, provided the overall turnaround time requirements are met.

Question 12: How Should EGFR and ALK Results Be Reported?

12.1 Expert consensus opinion: EGFR mutation testing reports and $A L K$ FISH reports should include a results and interpretation section readily understandable by oncologists and by nonspecialist pathologists.

Question 13: How Should EGFR and ALK Testing Be Validated?

13.1 Expert consensus opinion: $E G F R$ and $A L K$ testing validation should follow the same guidelines as for other molecular diagnostics and FISH tests.

Question 14: How Should Quality Assurance Be Maintained?

14.1 Expert consensus opinion: Laboratories should follow similar quality control and quality assurance policies and procedures for $E G F R$ and $A L K$ testing in lung cancers as for other clinical laboratory assays. In particular, laboratories performing $E G F R$ and $A L K$ testing for TKI therapy should enroll in proficiency testing, if available.

Abbreviations: CISH, chromogenic in situ hybridization; EGFR, epidermal growth factor receptor; FISH, fluorescence in situ hybridization; PCR, polymerase chain reaction; RT-PCR, reverse transcription-polymerase chain reaction; TKI, tyrosine kinase inhibitor; TNM, tumor, node, metastasis. 
Table 4

EGFR Mutation Prevalence in Different Lung Adenocarcinoma Patient Populations ${ }^{a}$

\begin{tabular}{|c|c|c|c|c|}
\hline & EGFR Mutation Prevalence, \% & EGFR Mutation Positive & EGFR Mutation Negative & $\mathbf{n}(\mathbf{N})$ \\
\hline Asian/Pacific ${ }^{b}$ & 45 & 1547 & 1905 & $31(3452)$ \\
\hline White ${ }^{c}$ & 24 & 853 & 2681 & $10(3534)$ \\
\hline African American $d$ & 20 & 19 & 78 & $3(97)$ \\
\hline Hispanic $^{e}$ & 17 & 65 & 307 & $4(372)$ \\
\hline Asian/Indian $f$ & 52 & 114 & 106 & $1(220)$ \\
\hline
\end{tabular}

Abbreviations: $n$, number of studies; $\mathrm{N}$, number of patients.

${ }^{a}$ Data for other populations were absent or too limited for analysis.

${ }^{b}$ References 7, 17, 32, 35, 48, 49, 55, 133, 184, 185, 191, 257, 264, 269, 270, 272-276, 278, 283-292.

${ }^{c}$ References 17, 32, 191, 192, 253, 273, 288, 292-294.

$d_{\text {References 256, 288, } 293 .}$

$e_{\text {References 128, 254, 267, } 288 .}$

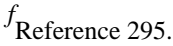


Table 5

Clinicopathologic Characteristics in Relation to EGFR Mutation Status in Studies Containing Primarily Asian Patients $^{a}$

\begin{tabular}{|c|c|c|c|c|}
\hline & EGFR Mutation Prevalence, \% & EGFR Mutation Positive & EGFR Mutation Negative & $\mathbf{n}(\mathbf{N})$ \\
\hline \multicolumn{5}{|l|}{ Age with cutoff, $y$} \\
\hline$<65^{b}$ & 46 & 370 & 433 & $6(803)$ \\
\hline $265^{c}$ & 38 & 432 & 709 & $5(1141)$ \\
\hline \multicolumn{5}{|l|}{ Sex } \\
\hline Female $^{d}$ & 58 & 1027 & 733 & $27(1760)$ \\
\hline Male $^{e}$ & 32 & 456 & 962 & $26(1418)$ \\
\hline \multicolumn{5}{|l|}{ Smoking } \\
\hline Never $f$ & 58 & 843 & 599 & $22(1442)$ \\
\hline Ever $f$ & 26 & 265 & 767 & $22(1032)$ \\
\hline \multicolumn{5}{|c|}{ History of smoking, pack-years } \\
\hline $0-10^{g}$ & 67 & 10 & 5 & $1(15)$ \\
\hline $11-40^{g}$ & 45 & 5 & 6 & $1(11)$ \\
\hline$>40 g$ & 23 & 5 & 17 & $1(22)$ \\
\hline$>20^{h}$ & 25 & 13 & 40 & $1(53)$ \\
\hline \multicolumn{5}{|l|}{ Histology } \\
\hline Adenocarcinoma $^{i}$ & 50 & 1278 & 1256 & $25(2534)$ \\
\hline Squamous $^{j}$ & 5 & 8 & 160 & $8(168)$ \\
\hline Adenosquamous $k$ & 67 & 4 & 2 & $2(6)$ \\
\hline Large cell $l$ & 7 & 1 & 14 & $4(15)$ \\
\hline \multicolumn{5}{|l|}{ Differentiation } \\
\hline \multicolumn{5}{|l|}{ Two grades } \\
\hline Well $^{m}$ & 37 & 62 & 107 & $3(169)$ \\
\hline Moderate to poor ${ }^{m}$ & 14 & 27 & 162 & $3(189)$ \\
\hline \multicolumn{5}{|l|}{ Three grades } \\
\hline Well $^{n}$ & 65 & 28 & 15 & $2(43)$ \\
\hline Moderate $^{n}$ & 48 & 59 & 63 & $2(122)$ \\
\hline Poor $^{n}$ & 34 & 17 & 33 & $2(50)$ \\
\hline
\end{tabular}

Abbreviations: $n$, number of studies; $\mathrm{N}$, number of patients.

${ }^{a}$ Most studies contained primarily patients with adenocarcinoma.

${ }^{b}$ References 7, 55, 184, 272, 276, 290.

$c_{\text {References 55, 184, 272, 276, } 290 .}$

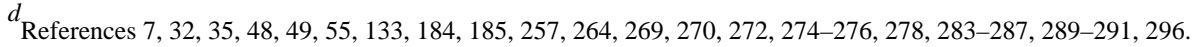

$e^{e}$ References 32, 35, 48, 49, 55, 133, 184, 185, 257, 264, 269, 270, 272, 274-276, 278, 283-287, 289-291, 296. 


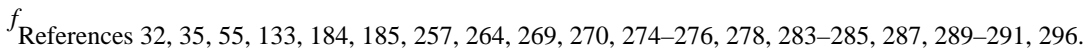

${ }^{g}$ Reference 290.

$h_{\text {Reference } 272 .}$

${ }^{i}$ References 32, 35, 48, 49, 55, 133, 184, 185, 257, 264, 269, 270, 272, 274-276, 278, 283-286, 289-291, 296.

$j_{\text {References 55, 257, 264, 272, 274, 275, 289, } 296 .}$

$k_{\text {References 272, } 289 .}$

$l_{\text {References 48, 272, 275, } 289 .}$

$m_{\text {References 119, 184, } 202 .}$

${ }^{n}$ References 49, 184. 
Table 6

Clinicopathologic Characteristics in Relation to EGFR Mutation Status in Studies Containing Primarily NonAsian Patients ${ }^{a}$

\begin{tabular}{|c|c|c|c|c|}
\hline & EGFR Mutation Prevalence, \% & EGFR Mutation Positive & EGFR Mutation Negative & $\mathbf{n}(\mathbf{N})$ \\
\hline \multicolumn{5}{|l|}{ Sex } \\
\hline Female $b$ & 28 & 859 & 2239 & $19(3098)$ \\
\hline $\operatorname{Male}^{b}$ & 18 & 397 & 1768 & $19(2165)$ \\
\hline \multicolumn{5}{|l|}{ Smoking } \\
\hline Never $^{c}$ & 45 & 666 & 805 & $18(1471)$ \\
\hline Ever $^{c}$ & 15 & 569 & 3154 & $18(3723)$ \\
\hline \multicolumn{5}{|c|}{ History of smoking, pack-years } \\
\hline $0-10^{d}$ & 39 & 18 & 28 & $1(46)$ \\
\hline $11-50^{d}$ & 8 & 7 & 86 & $1(93)$ \\
\hline$>50^{d}$ & 5 & 3 & 56 & $1(59)$ \\
\hline \multicolumn{5}{|l|}{ Histology } \\
\hline Adenocarcinoma $^{e}$ & 24 & 1266 & 3918 & $19(5184)$ \\
\hline Squamous $f$ & 5 & 6 & 104 & $9(110)$ \\
\hline Adenosquamous $g$ & 13 & 1 & 7 & $2(8)$ \\
\hline Large cell ${ }^{h}$ & 5 & 2 & 37 & $6(39)$ \\
\hline
\end{tabular}

Abbreviations: $n$, number of studies; $\mathrm{N}$, number of patients.

${ }^{a}$ Most studies contained primarily patients with adenocarcinoma.

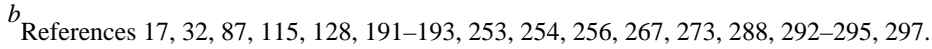

${ }^{c}$ References 17, 32, 87, 128, 191-193, 253, 254, 256, 267, 273, 288, 292-295, 297.

$d_{\text {Reference } 288 .}$

${ }^{e}$ References 17, 32, 87, 115, 128, 191-193, 253, 254, 256, 267, 273, 288, 292-294, 297, 298.

$f_{\text {References 17, 191, 193, 254, 256, 267, 273, 288, } 298 .}$

$g_{\text {References 17, } 288 .}$

$h_{\text {References 17, 193, 254, 267, 273, } 298 .}$ 
Table 7

Clinicopathologic Characteristics in Relation to $A L K$ Rearrangement Status ${ }^{a}$

\begin{tabular}{|c|c|c|c|c|}
\hline & $\begin{array}{l}A L K \text { Rearrangement } \\
\text { Prevalence, } \%\end{array}$ & $A L K$ Rearrangement Positive & $A L K$ Rearrangement Negative & $\mathbf{n}(\mathbf{N})$ \\
\hline \multicolumn{5}{|l|}{ Age with cutoff, y } \\
\hline $565^{20}$ & 6 & 13 & 210 & $1(223)$ \\
\hline$>65^{20}$ & 3 & 6 & 224 & $1(230)$ \\
\hline \multicolumn{5}{|l|}{ Sex } \\
\hline Females $11,12,15,20$ & 5 & 28 & 579 & $4(607)$ \\
\hline Males ${ }^{11,12,15,20}$ & 4 & 30 & 738 & $4(768)$ \\
\hline \multicolumn{5}{|l|}{ Smoking } \\
\hline Never ${ }^{11,15,20}$ & 8 & 30 & 331 & $3(361)$ \\
\hline Ever $^{11,15,20}$ & 3 & 20 & 652 & $3(672)$ \\
\hline \multicolumn{5}{|l|}{ Ethnicity } \\
\hline Asian/Pacific ${ }^{11,12,14}$ & 5 & 35 & 654 & $3(689)$ \\
\hline White (Caucasian) $)^{12,15}$ & 4 & 22 & 474 & $2(496)$ \\
\hline \multicolumn{5}{|l|}{ Histology } \\
\hline Adenocarcinoma $9,11,12,15,16,19,20$ & 5 & 67 & 1319 & $7(1386)$ \\
\hline Squamous $9,11,12,16,19,20$ & 0.2 & 1 & 522 & $6(523)$ \\
\hline Adenosquamous ${ }^{11,12,19}$ & 0 & 0 & 19 & $3(19)$ \\
\hline \multicolumn{5}{|l|}{ Differentiation } \\
\hline Well $^{11}$ & 1 & 1 & 97 & $1(98)$ \\
\hline Not well ${ }^{11}$ & 6 & 10 & 145 & $1(155)$ \\
\hline
\end{tabular}

Abbreviations: $\mathrm{n}$, number of studies; $\mathrm{N}$, number of patients.

${ }^{a}$ Most studies contained primarily patients with adenocarcinoma. 
Table 8

Studies Specifically Reporting Outcome of $A L K$ Rearrangement Studies in Squamous Cell Carcinomas

\begin{tabular}{|lcc|}
\hline Source, $\mathbf{y}$ & $\mathbf{n}$ & ALK Rearrangement Positive, \% \\
\hline Takeuchi et al, ${ }^{299} 2008$ & 71 & 0 \\
Takahashi et al ${ }^{39} 2010$ & 75 & 0 \\
Inamura et al, ${ }^{10} 2008$ & 48 & 0 \\
\hline
\end{tabular}

Abbreviation: $\mathrm{n}$, number of squamous cell carcinoma samples tested. 
Table 9

Major Studies Specifically Reporting EGFR Mutation Analysis in Surgically Resected Squamous Cell Carcinomas as Compared to Adenocarcinomas

\begin{tabular}{|llcl|}
\hline Source, $\mathbf{y}$ & $\begin{array}{l}\text { Predominant Ethnic Origin of } \\
\text { Study Population }\end{array}$ & $\begin{array}{c}\text { EGFR Mutations in Resected } \\
\text { Adenocarcinomas, No. (\%) }\end{array}$ & $\begin{array}{l}\text { EGFR Mutations in Resected } \\
\text { Squamous Cell Carcinomas, No. } \\
(\%)\end{array}$ \\
\hline Marchetti et al, ${ }^{45} 2005$ & European & $39 / 375(10.4)$ & $0 / 454$ \\
Sugio et al, ${ }^{43} 2006$ & Asian & $136 / 322(42.2)$ & $0 / 102$ \\
Tsao et al, ${ }^{44} 2006$ & North American & $14 / 96(14.6)$ & $0 / 63$ \\
Tsao et al, ${ }^{60} 2011$ & North American & $32 / 231(13.9)$ & $8 / 162(4.9)$ \\
Bae et al, ${ }^{284} 2007$ & Asian & $20 / 55(36.4)$ & $0 / 60$ \\
Lee et al, ${ }^{300} 2010$ & Asian & $36 / 117(30.8)$ & $0 / 56$ \\
Miyamae et al, ${ }^{301} 2011$ & Asian & $\ldots$ & $3 / 87^{a}(3.4)$ \\
Rekhtman et al, ${ }^{36} 2012$ & North American & $\ldots$ & $0 / 95$ \\
TCGA,${ }^{302, b} 2012$ & North American & $\ldots$ & $2 / 178^{c}(1.1)$ \\
\hline
\end{tabular}

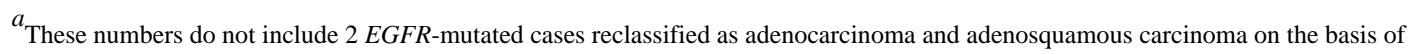
immunohistochemistry (IHC) for thyroid transcription factor 1 (TTF-1)/p63; the remaining $3 E G F R$-mutated cases were reported as IHC-confirmed squamous cell carcinoma.

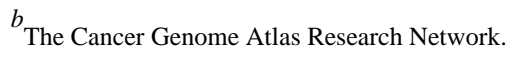

${ }^{c}$ Both EGFR mutations were L861R. 


\section{Table 10}

Summary of Studies of the Concordance of EGFR Mutations in Primary Versus Metastatic Tumors in the Same Patient ${ }^{a}$

\begin{tabular}{|lrr|}
\hline & \multicolumn{2}{c|}{ Primary Tumor } \\
\cline { 2 - 3 } Metastatic Lesions & EGFR+ & EGFR- \\
\hline EGFR+ & 108 & 6 \\
EGFR- & 11 & 183 \\
\hline
\end{tabular}

${ }^{a}$ Data derived from Park et al ${ }^{57}$; Yatabe et al ${ }^{80}$; and Sun et al. ${ }^{303}$ 


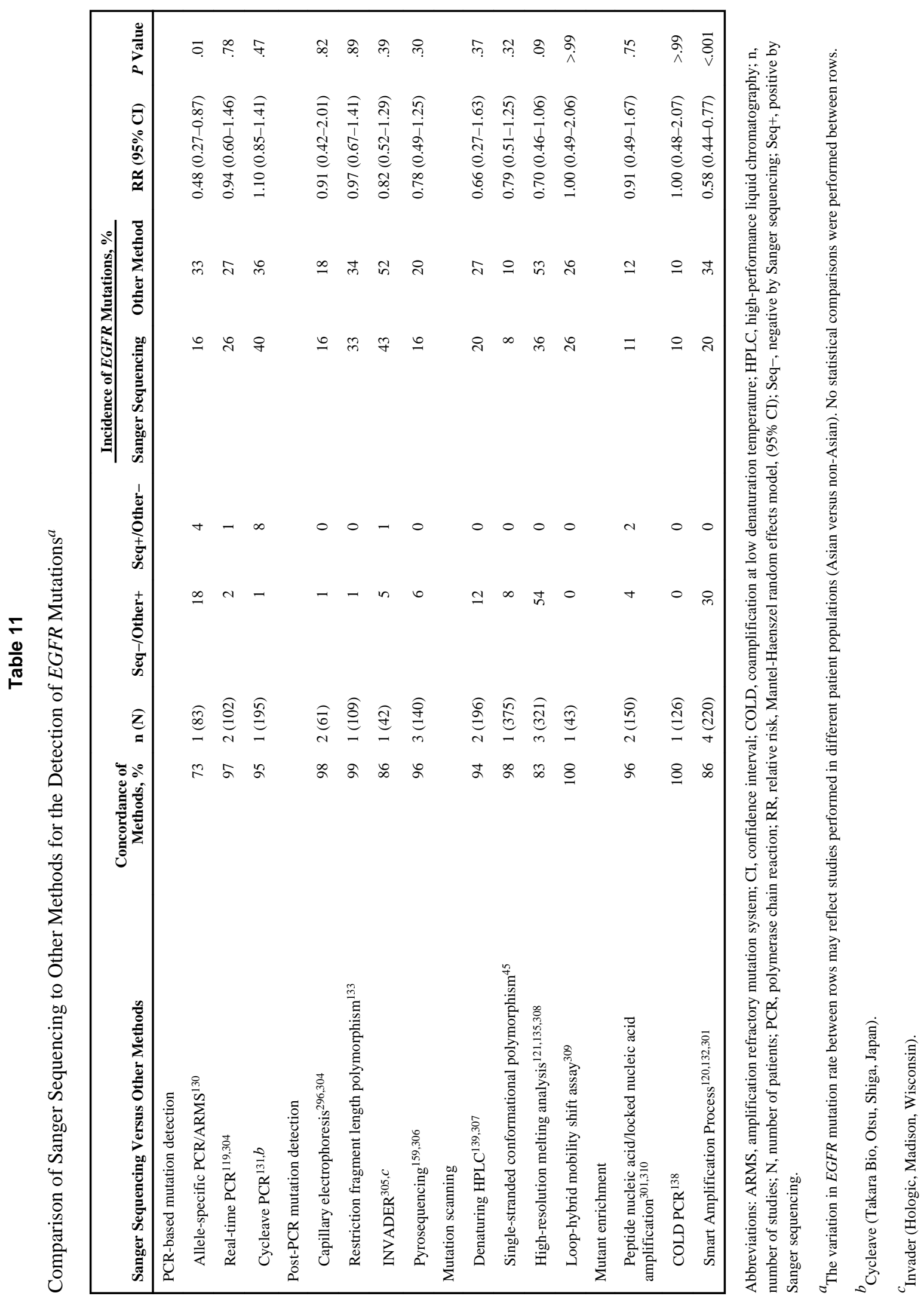

Arch Pathol Lab Med. Author manuscript; available in PMC 2014 September 12. 
Table 12

EGFR mutations accounting individually for at least $1 \%$ of all EGFR mutations

\begin{tabular}{|c|c|c|c|c|}
\hline$E G F R$ exon & $E G F R$ codon & Mutations $^{a}$ (amino acid) & Nucleotide substitutions & $\begin{array}{l}\text { Approximate \% of all } \\
\text { EGFR mutations }\end{array}$ \\
\hline \multirow[t]{10}{*}{18} & E709 & E709K & c. $2125 \mathrm{G}>\mathrm{A}$ & $1 \%$ \\
\hline & & E709A & c. $2126 \mathrm{~A}>\mathrm{C}$ & \\
\hline & & E709G & c. $2126 \mathrm{~A}>\mathrm{G}$ & \\
\hline & & E709V & c. $2126 \mathrm{~A}>\mathrm{T}$ & \\
\hline & & E709D & c. $2127 \mathrm{~A}>\mathrm{C}, \mathrm{c} .2127 \mathrm{~A}>\mathrm{T}$ & \\
\hline & & E709Q & c. $2125 \mathrm{G}>\mathrm{C}$ & \\
\hline & G719 & G719S & c. $2155 \mathrm{G}>\mathrm{A}$ & $2-5 \%$ \\
\hline & & G719A & c. $2156 \mathrm{G}>\mathrm{C}$ & \\
\hline & & G719C & c. $2155 \mathrm{G}>\mathrm{T}$ & \\
\hline & & G719D & c. $2156 \mathrm{G}>\mathrm{A}$ & \\
\hline \multirow[t]{8}{*}{19} & K739, I740, P741, V742, A743, I744 & Insertions & & $1 \%$ \\
\hline & & 18 bp ins & & \\
\hline & $\begin{array}{l}\text { E746, L747, R748, E749, A750, T751, } \\
\text { S752, P753 }\end{array}$ & Deletions & & $45 \%$ \\
\hline & & $15 \mathrm{bp}$ del & & \\
\hline & & $18 \mathrm{bp}$ del & & \\
\hline & & 9 bp del & & \\
\hline & & $24 \mathrm{bp}$ del & & \\
\hline & & $12 \mathrm{bp}$ del & & \\
\hline \multirow[t]{7}{*}{20} & $\begin{array}{l}\text { A763, A767, S768, V769, D770, } \\
\text { N771, P772, H773, V774 }\end{array}$ & Insertions & & $5-10 \%$ \\
\hline & & 3 bp ins & & \\
\hline & & 6 bp ins & & \\
\hline & & 9 bp ins & & \\
\hline & & 12 bp ins & & \\
\hline & S768 & S768I & c. $2303 \mathrm{G}>\mathrm{T}$ & $1-2 \%$ \\
\hline & T790 & $\mathrm{T} 790 \mathrm{M}$ & c. $2369 \mathrm{C}>\mathrm{T}$ & $2 \%^{b}$ \\
\hline \multirow[t]{4}{*}{21} & L858 & L858R & c. $2573 \mathrm{~T}>\mathrm{G}$ & $40 \%$ \\
\hline & & L858M & c. $2572 \mathrm{C}>\mathrm{A}($ rare $)$ & \\
\hline & L861 & L861Q & c. $2582 \mathrm{~T}>\mathrm{A}$ & $2-5 \%$ \\
\hline & & L861R & c. $2582 \mathrm{~T}>\mathrm{G}$ & \\
\hline
\end{tabular}

Abbreviations: del, deletion; ins, insertion.

$a_{\text {For each codon or region, missense mutations are listed in decreasing order of frequency; for less common missense mutations, this order is }}$ approximate. For insertions or deletions, the codons most commonly involved are simply listed by cDNA order only.

${ }^{b} \mathrm{Up}$ to $50 \%$ of T790M mutations detected in pre-treatment tumor samples may be germline mutations.

Notes: All mutations listed are generally associated with sensitivity to EGFR TKIs except T790M and some exon 20 insertions. G719 and L861 mutations are considered sensitive but somewhat less so than the major exon 19 and 21 mutations. Exon 20 insertions are variable in exact position and structure and EGFR TKI response data remain very limited for some types of insertions. Mutations at E709 and S768 often occur in 
combination with another of the listed mutations. Data derived from Chen et al ${ }^{110}$; He et al ${ }^{166}$; Oxnard et al ${ }^{210}$; Wu et al 278 ; Bamford et al $^{311}$; De Pas et al ${ }^{312}$; and Murray et al. 313 


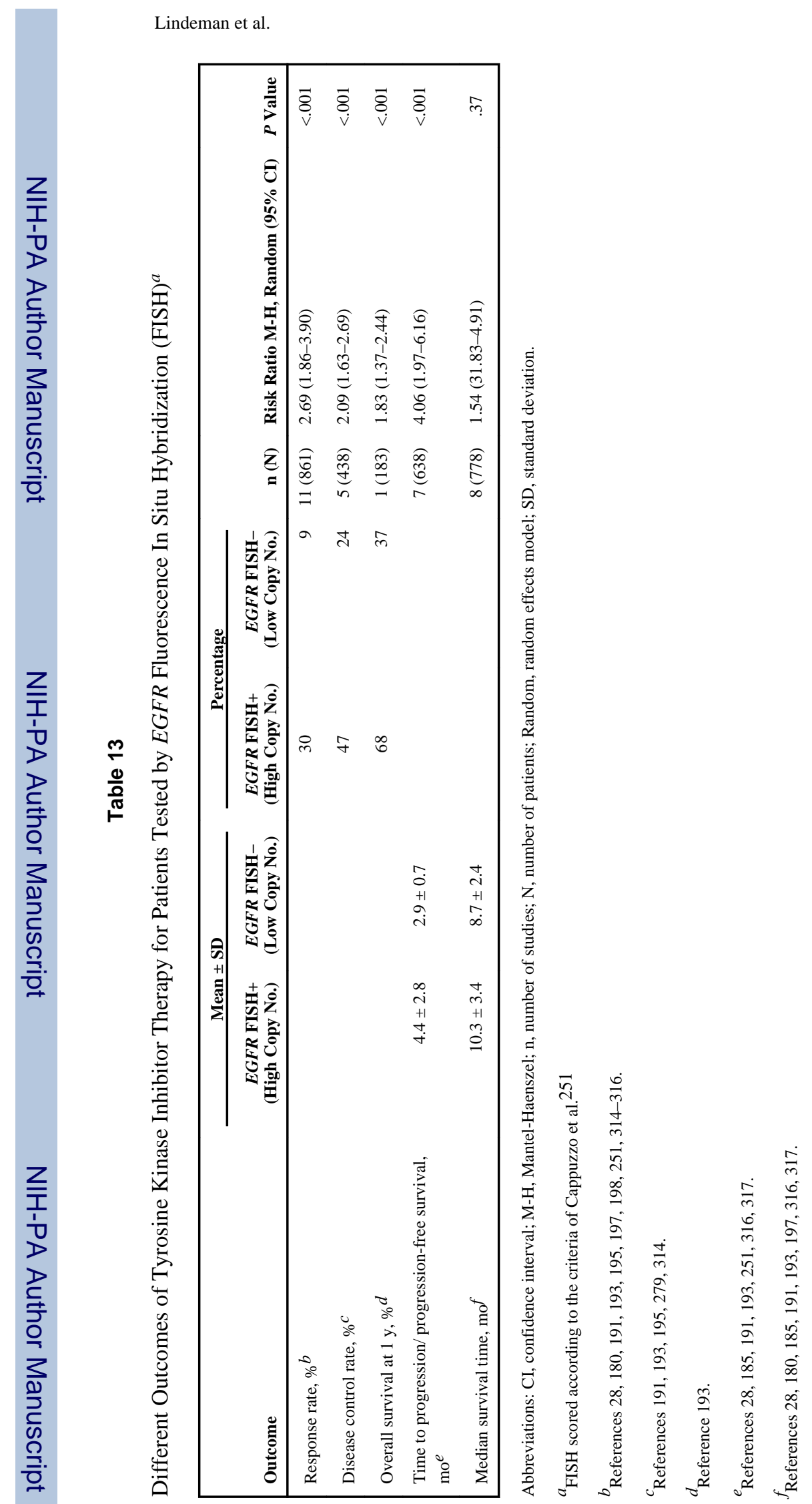

Arch Pathol Lab Med. Author manuscript; available in PMC 2014 September 12. 